GIOVANE MARINANGELO

\title{
ESTUDO DA COPOLIMERIZAÇÃO EM EMULSÃO DE ESTIRENO E ACRILATO DE BUTILA COM ALTO TEOR DE SÓLIDOS EM REATOR SEMICONTÍNUO
}

\author{
Dissertação apresentada à Escola \\ Politécnica da Universidade de São Paulo \\ para a obtenção do título de Mestre em \\ Engenharia.
}

SÃo PAULO 
GIOVANE MARINANGELO

\title{
ESTUDO DA COPOLIMERIZAÇÃO EM EMULSÃO DE ESTIRENO E ACRILATO DE BUTILA COM ALTO TEOR DE SÓLIDOS EM REATOR SEMICONTÍNUO
}

\author{
Dissertação apresentada à Escola \\ Politécnica da Universidade de São Paulo \\ para a obtenção do título de Mestre em \\ Engenharia.
}

Àrea de concentração:

Engenharia Química

Orientador:

Prof. Dr. Reinaldo Giudici

SÃo PAULO 


\section{FICHA CATALOGRÁFICA}

\section{Marinangelo, Giovane}

Estudo da copolimerização em emulsão de estireno e acrilato

de butila com alto teor de sólidos em reator semicontínuo / G. Marinangelo. -- São Paulo, 2005.

$98 \mathrm{p}$.

Dissertação (Mestrado) - Escola Politécnica da Universidade de São Paulo. Departamento de Engenharia Química.

1.Polimerização em emulsão 2.Reator semi-contínuo I.Universidade de São Paulo. Escola Politécnica. Departamento de Engenharia Química Il.t. 


\section{AGRADECIMENTOS}

Ao Prof. Dr. Reinaldo Giudici, pela orientação e pela paciência;

Ao Prof. Dr. Mauri Sergio Alves Palma, pela co-orientação e auxílio na realização dos ensaios;

Aos colegas do LSCP pelo apoio durante a realização deste trabalho;

Ao Prof. Dr. José Luis de Paiva, por disponibilizar o laboratório para as análises de viscosidade;

À Rhodia/Paulínia, Raiso/Latexia, e Ciba, na pessoa do Dr. Odair Araujo, pela doação dos monômeros utilizados neste trabalho e pelas análises de Tg e TMFF;

À Cognis e à Oxiteno, pela doação dos emulsificantes utilizados neste trabalho;

À Escola Politécnica, pela oportunidade de realização do curso de mestrado e desenvolvimento deste trabalho;

À Fundação de Amparo à Pesquisa do Estado de São Paulo - FAPESP, pelo apoio financeiro concedido para a realização deste trabalho;

E a todos os outros que também contribuíram e prestaram auxílio durante a execução deste trabalho. 


\section{RESUMO}

MARINANGELO, G. Estudo da copolimerização em emulsão de estireno e acrilato de butila com alto teor de sólidos em reator semicontínuo. 2005. 98f. Dissertação (Mestrado) - Escola Politécnica, Universidade de São Paulo, São Paulo, 2005.

Neste trabalho estudou-se o processo de copolimerização em emulsão de estireno e acrilato de butila em processo semicontínuo onde o produto final é um látice com alto teor de sólidos. Foi realizada uma série de experimentos de copolimerização em emulsão em um reator de vidro, empregando receitas com teores de sólidos na faixa de 50 a 64\% em massa. Foram estudados os seguintes fatores: teor de sólidos, teor de ácido acrílico, teor de emulsificantes e tempo de adição dos monômeros. Os efeitos estudados são avaliados principalmente em termos de conversão, diâmetro médio das partículas, concentração de partículas, número médio de radicais por partícula, taxa de polimerização, viscosidade e fração de coágulos. Também se avaliou a distribuição de tamanhos de partículas para o processo. Utilizando informações experimentais e da literatura, foi aplicado um modelo matemático para o processo, com razoável adequação aos dados experimentais. 


\begin{abstract}
MARINANGELO, G. Study of the emulsion copolymerization of styrene and butyl acrylate with high solid contents in a semi-batch reactor. 2005. 98f. Dissertation (Mastering) - Escola Politécnica, Universidade de São Paulo, São Paulo, 2005.

The aim of this work was the study of the high solid contents emulsion copolymerization of styrene and butyl acrylate in semi-batch process. Copolymerization reactions were undertaken in a glass reactor, and recipes with solid contents up to $64 \mathrm{wt} \%$ were used. Were evaluated the effects of: solid contents on recipe, amounts of acrylic acid and surfactants on recipe and monomer feeding time. The effects were evaluated in terms of conversion, particle mean diameter, and particle concentration, average number of radicals per particle, polymerization rate, viscosity and coagulum content. It was performed a characterization of the particle size distribution for this process. Using experimental observations and literature information, it was applied a mathematical model for this process, with satisfactory agreement with experimental data.
\end{abstract}




\section{LISTA DE TABELAS}

Tabela 5.1.1 Composição empregada nos ensaios de reprodutibilidade

Tabela 5.1.2 Propriedades finais do látices obtidos para os ensaios de reprodutibilidade.

Tabela 5.2.1 Receita empregada na polimerização $A V / A B$

Tabela 5.2.2 Receita empregada na polimerização $A B / S$

Tabela 5.3.1 Receita de polimerização de $A B / S(\%$ em relação à massa total de monômero da receita)

Tabela 5.3.2 Quantidades de emulsificante não-iônico, E1, emulsificante iônico, $E 2$, ácido acrílico, $A A 1$, empregadas na carga inicial das receitas AS07 a AS-13 (\% em relação à massa total de monômero da receita), e as propriedades finais de teor de polímeros, TP, teor de sólidos, TS, diâmetro médio das partículas, $D_{P}$, conversão global, $X_{\text {global }}$ e viscosidade, $\eta$, dos látices obtidos.

Tabela 5.3.3 Teor de coágulos após ensaio e após 1 ano de armazenamento para os ensaios AS-07 a $A S-13$.

Tabela 5.4.1 Receitas de Polimerização de $A B / S(\%$ em relação à massa total da receita)

Tabela 5.5.1 Composição dos ensaios

Tabela 5.5.2 Propriedades finais dos látices $A B / S$

Tabela 6.1 Composições empregadas na simulação dos ensaios AS-05, AS-08 e AS-21 $\left(\mathrm{TP}_{\text {RECEITA }}=50 \%, 54 \%\right.$ e $\left.58 \%\right)$

Tabela 6.2 Parâmetros utilizados na simulação do modelo ( $A=$ acrilato de butila; $B=$ estireno)

Tabela A1.1 Quantidade (em g) dos reagentes utilizados nos ensaios de polimerização

Tabela A1.2 Valores de temperatura $\left(T\right.$, em $\left.{ }^{\circ} \mathrm{C}\right)$, quantidade de pré-emulsão alimentada ( $P E$, em g), quantidade de iniciador alimentado (Ini, em g), fração de sólidos por gravimetria $(F S)$, diâmetro médio das partículas $\left(D_{p}\right.$, em nm)

Tabela A1.3 Ensaios exploratórios cujos resultados não foram tratados neste trabalho 


\section{LISTA DE FIGURAS}

Figura 2.2.1 Fração máxima em volume e teor máximo de sólidos em função da composição de partículas (CHU e GUYOT, 2001)

Figura 2.5.1 Mecanismo de nucleação homogênea (PRIEST, 1952)

Figura 4.2.1 Esquema da aparelhagem utilizada

Figura 4.2.2 Foto do equipamento experimental utilizado

Figura 5.1.1 Conversão, $X_{\text {Global, }}$ como função do tempo para os ensaios de reprodutibilidade

Figura 5.1.2 Diâmetro médio das partículas, $D_{p}$, como função do tempo para os ensaios de reprodutibilidade

Figura 5.2.1 Taxa de polimerização, $R p(\Delta)$ e de adição de monômeros (......) dos sistemas: a) $A V / A B(T S=69 \%)$ e b) $A B / S(T S=52 \%)$

Figura 5.2.2 Resultados de a) fração de sólidos, $f s$, b) tamanho médio de partículas, $D_{p}$, e de c) viscosidade, $\eta$, a $20^{\circ} \mathrm{C}$ do copolímero $A V / A B$ para os teores de sólidos, $T S_{\text {RECEITA }}=69 \%(\mathrm{O}), T S_{\text {RECEITA }}=71 \%(+) \mathrm{e}$ $T S_{\text {RECEITA }}=73 \%(\mathbf{\Delta})$

Figura 5.2.3 Resultados de a) fração de sólidos, $f s$, b) tamanho médio de partículas, $D_{p}$, e de c) viscosidade, $\eta$, a $20^{\circ} \mathrm{C}$ do copolímero $A B / S$ para os teores de sólidos, $T S_{\text {RECEITA }}=52 \%(\Delta), T S_{\text {RECEITA }}=54 \%(\square)$ e $T S_{R E C E I T A}=57 \%(\mathrm{x})$

Figura 5.3.1 a) Diâmetro médio das partículas; e b) Concentração de partículas para diferentes concentrações de emulsificante na receita $(4,3 \%(\Delta)$, $5,3 \%$ (口) e 6,4\% (x) em massa do total de emulsificante em relação aos monômeros, respectivamente AS-07, AS-10 e AS-11)

Figura 5.3.2 Viscosidade, $\eta$, do látice em função da taxa de cisalhamento para diferentes concentrações de ácido acrílico na receita $(1,5 \%(+), 2,5 \%$ $(\bullet), 3,5 \%(*)$ e $5,0 \%$ (•) em massa do total de ácido acrílico na receita em relação aos monômeros, respectivamente $A S-07, A S-08$, AS-09 e AS-17)

Figura 5.4.1 Evolução durante o período de reação de: a) Conversão global, $X_{\text {Global }}$; b) Diâmetro médio das partículas, $D_{p}$; c) Concentração de partículas, $N_{p}$; d)Número médio de radicais por partícula, $\tilde{n}$; e e) Taxa de polimerização*, $R p$, para: $T P_{\text {RECEITA }}=54 \% \quad(\mathrm{o})$; $T P_{\text {RECEITA }}=56 \%(\Delta) ; T P_{\text {RECEITA }}=58 \%(\square)$; e TP RECEITA $=60 \%(\times){ }^{*}(---)$ Taxa de adição de monômeros 
Figura 5.4.2 Propriedades finais do látex em função do teor de sólidos final obtido: a) Diâmetro médio das partículas, $D_{p}$; b) Concentração de partículas, $N_{p}$; c) Conversão global, $X$; d) Viscosidade, $\eta\left(\mathrm{T}=20^{\circ} \mathrm{C}\right.$, taxa de cisalhamento $=46,5 \mathrm{~s}^{-1}$ ); e e)Teor de Coágulos

Figura 5.5.1 Taxas de polimerização, $R_{p}$, para a) $t_{A}=180 \mathrm{~min}$, b) $t_{A}=240 \mathrm{~min}$, c) $t_{A}=300 \mathrm{~min}$ e taxa de alimentação de monômeros (..............). $\left(t_{N}=\right.$ tempo normalizado $\left.=t_{\text {reação }} / t_{A}\right)$

Figura 5.5.2 Número médio de radicais por partícula, $\tilde{n}$, durante a reação $\left(t_{N}=\right.$ $\left.t_{\text {reação }} / t_{A}\right)$ para $t_{A}=180 \mathrm{~min}(\Delta), t_{A}=240 \mathrm{~min}(\square)$ e $t_{A}=300 \mathrm{~min}(\mathrm{x})$

Figura 5.6.1 Fotografias obtidas por TEM para o ensaio AS-23 para os tempos de reação a) $110 \mathrm{~min}$, b) $180 \mathrm{~min}$, c) $270 \mathrm{~min}$ e d) $360 \mathrm{~min}$. (A barra de referência indica uma medida de: a) $500 \mathrm{~nm}$, b) $2000 \mathrm{~nm}$, c) $2000 \mathrm{~nm}$ e d) $2000 \mathrm{~nm}$ )

Figura 5.6.2 Distribuições de tamanhos de partículas a) numérica e b) mássica para $t=110 \mathrm{~min}(\square), t=180 \mathrm{~min}(\Delta), t=270 \mathrm{~min}(\mathrm{x})$ e $t=360 \mathrm{~min}(\mathrm{o})$, para o ensaio AS-23

Figura 6.1 Evolução durante o período de reação de: a) diâmetro médio das partículas, $D_{p}$; b) número total de partículas, $N_{T}$; c) concentração de partículas, $N_{P}$; d) conversão global, $X_{\text {global }}$; e) número médio de radicais por partícula, $\tilde{n}$, para o modelo (-) e para o experimento AS-05 ( $\boldsymbol{\Delta})$; e f) fração molar de acrilato de butila, $f_{a}$, e estireno, $f_{b}$, na quantidade total de monômero no reator $\left(f_{\text {aexp }}=\mathbf{\Lambda}, f_{\text {bexp }}=\Delta\right.$, $f_{\text {amodel }}=(---)$ e,$\left.f_{\text {bmodel }}=(\cdots \cdots \cdots \cdots)\right)$

Figura 6.2 Evolução durante o período de reação de: a) Número total de partículas, $N_{T}$; b) concentração de partículas, $N_{P}$; c)diâmetro médio das partículas, $D_{P}$; d)conversão global, $X_{\text {global }}$; e e) número médio de radicais por partícula, $\tilde{n}$, para os experimentos $A S-08$ e $A S-21$ (AS$\left.08_{\text {exp }}=\mathbf{m}, A S-21_{\text {exp }}=\square, A S-08_{\text {model }}=(-) \mathrm{e}, A S-21_{\text {model }}=(\cdots \cdots \cdots)\right)$ 


\section{LISTA DE ABREVIATURAS E NOTAÇÕES}

Notação Significado

$\left[I_{2}\right] \quad$ Concentração de iniciador na fase aquosa $\left(\mathrm{kmol} / \mathrm{m}^{3}\right)$

[I $\left.I_{2 e}\right] \quad$ Concentração de iniciador na alimentação $\left(\mathrm{kmol} / \mathrm{m}^{3}\right)$

$\left[M_{e i}\right]$ Concentração do monômero $i$ na alimentação $\left(\mathrm{kmol} / \mathrm{m}^{3}\right)$

$\left[M_{i}\right] \quad$ Concentração do monômero $i$ no reator $\left(\mathrm{kmol} / \mathrm{m}^{3}\right)$

$\left[M_{i 0}\right] \quad$ Concentração do monômero $i$ introduzido no reator $\left(\mathrm{kmol} / \mathrm{m}^{3}\right)$

$\left[M_{p}\right] \quad$ Concentração de monômero nas partículas $\left(\mathrm{kmol} / \mathrm{m}^{3}\right)$

$\left[M_{p i}\right] \quad$ Concentração do monômero $i$ nas partículas $\left(\mathrm{kmol} / \mathrm{m}^{3}\right)$

$\left[R_{a q}{ }^{*}\right] \quad$ Concentração de radicais na fase aquosa $\left(\mathrm{kmol} / \mathrm{m}^{3}\right)$

[S] Concentração de emulsificante livre na fase aquosa $\left(\mathrm{kmol} / \mathrm{m}^{3}\right)$

$\left[S_{0}\right] \quad$ Concentração de emulsificante total na fase aquosa $\left(\mathrm{kmol} / \mathrm{m}^{3}\right)$

$\left[S_{e}\right] \quad$ Concentração de emulsificante na alimentação $\left(\mathrm{kmol} / \mathrm{m}^{3}\right)$

$A, B \quad$ Monômeros $A$ (Acrilado de Butila) e $B$ (Estireno)

AA Ácido acrílico

AA1 Quantidade de ácido acrílico na carga inicial do reator (\% mássica em relação aos monômeros)

$A B \quad$ Acrilato de butila

AV Acetato de vinila

$a_{e} \quad$ Área de cobrimento de partícula de uma molécula de emulsificante $\left(\mathrm{m}^{2} /\right.$ molécula $)$

CMC Concentração micelar crítica $\left(\mathrm{kmol} / \mathrm{m}^{3}\right)$

$D_{P} \quad$ Diâmetro médio das partículas (nm)

DTP Distribuição de tamanhos de partículas 
EE1, EE2 Quantidade, na carga inicial do reator, de emulsificantes não iônico e iônico, respectivamente (\% mássica em relação aos monômeros).

Fração de monômero na receita

FP

Fração de polímeros no látice do instante considerado

FS

Fração de sólidos no látice do instante considerado

FT

Fração de sólidos não polimerizáveis adicionados ao reator até o instante considerado.

Fator de eficiência da decomposição do iniciador (adimensional)

Fração molar do monômero $i$ no reator (adimensional)

$f m v$

Fração volumétrica máxima de sólidos

Ini Iniciador

$K_{m}^{p} \quad$ Coeficiente de partição do monômero entre as partículas e fase aquosa

$k_{c p} \quad$ Coeficiente de captura global pelas partículas $\left(\mathrm{m}^{3} / \mathrm{s}\right)$

$k_{d} \quad$ Coeficiente de decomposição do iniciador $\left(\mathrm{s}^{-1}\right)$

$k_{\text {mic }} \quad$ Coeficiente de captura global pelas micelas $\left(\mathrm{m}^{3} / \mathrm{s}\right)$

$k_{p i}$

Coeficiente da taxa de propagação do monômero $i \quad\left(\mathrm{~m}^{3} / \mathrm{kmol} . \mathrm{s}\right)$

$k_{p i j}$

Coeficiente da taxa de propagação entre um radical terminado em $i$ e um monômero $j\left(\mathrm{~m}^{3} / \mathrm{kmol} . \mathrm{s}\right)$

$k_{t i j}$

Coeficiente da taxa de terminação entre dois radicais terminados em $i$ e $j$ $\left(\mathrm{m}^{3} / \mathrm{kmol} . \mathrm{s}\right)$

$k_{t p}$

Coeficiente de terminação global $\left(\mathrm{m}^{3} / \mathrm{kmol} . \mathrm{s}\right)$

MAS Massa da placa com amostra úmida para análise gravimétrica $(\mathrm{g})$.

MDS Massa da placa com amostra seca para análise gravimétrica $(\mathrm{g})$.

MPHI Massa da placa com hidroquinona para análise gravimétrica $(\mathrm{g})$.

MPV Massa da placa vazia para análise gravimétrica (g).

$M_{\text {total }} \quad$ Massa total adicionada ao reator até o instante total (g).

ñ Número médio de radicais por partícula (radicais/partícula) 


\begin{tabular}{|c|c|}
\hline$N(j)$ & Número de partículas contendo $j$ radicais (partículas) \\
\hline$N_{A}$ & Número de Avogadro (moléculas/kmol) \\
\hline$N_{\text {mic }}$ & Número de micelas (micelas) \\
\hline$N_{P}$ & Concentração de partículas (partículas $/ \mathrm{m}^{3}$ ) \\
\hline$N_{T}$ & Número total de partículas no látice (partículas) \\
\hline$n_{s}$ & $\begin{array}{l}\text { Número de moléculas de emulsificante necessárias para formar uma micela } \\
\text { (moléculas) }\end{array}$ \\
\hline$P E$ & Pré-emulsão \\
\hline$P_{j}$ & $\begin{array}{l}\text { Fração de radicais terminados por uma unidade monomérica } j \text { nas partículas } \\
\text { (adimensional) }\end{array}$ \\
\hline$P M_{\text {mon }}$ & Peso molecular médio de uma unidade monomérica $(\mathrm{kg} / \mathrm{kmol})$ \\
\hline$P M_{\text {moni }}$ & Peso molecular do monômero i $(\mathrm{kg} / \mathrm{kmol})$ \\
\hline$Q_{e}$ & Vazão total de alimentação $\left(\mathrm{m}^{3} / \mathrm{s}\right)$ \\
\hline$R_{c p}$ & Taxa de captura de radicais pelas partículas $(\mathrm{kmol} / \mathrm{s})$ \\
\hline$R_{d}$ & Taxa de decomposição térmica do iniciador $(\mathrm{kmol} / \mathrm{s})$ \\
\hline$R_{\text {mic }}$ & Taxa de captura de radicais pelas micelas $(\mathrm{kmol} / \mathrm{s})$ \\
\hline$R_{p i}$ & Taxa de polimerização do monômero i $(\mathrm{kmol} / \mathrm{s})$ \\
\hline$R_{t p}$ & Taxa de terminação global $(\mathrm{kmol} / \mathrm{s})$ \\
\hline$r_{i j}$ & Razão de reatividade (adimensional) \\
\hline$r_{\text {mic }}$ & Raio de uma micela (m) \\
\hline$r_{p}$ & Raio médio das partículas (m) \\
\hline$r_{s}$ & Raio médio das partículas inchadas com monômero (m) \\
\hline$S$ & Estireno \\
\hline Sm & Conteúdo máximo em sólidos (adimensional) \\
\hline$T$ & Temperatura $(\mathrm{K})$ \\
\hline TEM & Microscopia eletrônica de transmissão \\
\hline
\end{tabular}


TMFF Temperatura mínima de formação de filme $\left({ }^{\circ} \mathrm{C}\right)$

$T P_{\text {RECEITA }}$ Teor de polímeros na receita (adimensional)

TP Teor de polímeros no látice no instante considerado (adimensional)

$T_{\text {RECEITA }} \quad$ Teor de sólidos na receita (adimensional)

TS Teor de sólidos no látice no instante considerado (adimensional)

$t_{A} \quad$ Tempo total de alimentação

$t_{N} \quad$ Tempo normalizado (tempo de reação/ $t_{A}$ )

V Volume médio de uma partícula $\left(\mathrm{m}^{3}\right)$

$V_{m} \quad$ Volume de monômero livre no reator $\left(\mathrm{m}^{3}\right)$

$V_{m}{ }^{P} \quad$ Volume de monômero nas partículas $\left(\mathrm{m}^{3}\right)$

$V_{P}{ }^{P} \quad$ Volume de polímero na fase polimérica $\left(\mathrm{m}^{3}\right)$

$V_{r} \quad$ Volume de meio reacional $\left(\mathrm{m}^{3}\right)$

$V_{w} \quad$ Volume de água no reator $\left(\mathrm{m}^{3}\right)$

X Conversão instantânea (adimensional)

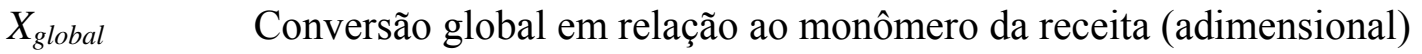

$X_{c r} \quad$ Conversão crítica (adimensional)

$\alpha$

Fator de eficiência da terminação (adimensional)

$\delta \quad$ Razão entre o coeficiente de captura global pelas micelas e partículas (adimensional)

$\eta \quad$ Viscosidade (mPa.s)

$\varphi \quad$ Fração volumétrica de água no reator $\left(\mathrm{m}^{3}{ }_{\mathrm{H} 2 \mathrm{O}} / \mathrm{m}^{3}\right.$ Látice $)$

$\varphi_{e} \quad$ Fração volumétrica de água na alimentação $\left(\mathrm{m}^{3}{ }_{\mathrm{H} 2 \mathrm{O}} / \mathrm{m}^{3}\right.$ alimentação $)$

$\phi \quad$ Fração volumétrica de partículas $\left(\mathrm{m}^{3}{ }_{\text {pol }} / \mathrm{m}^{3}{ }_{\text {látice }}\right)$

$\phi \quad$ Fração volumétrica máxima de partículas $\left(\mathrm{m}^{3}{ }_{\text {pol }} / \mathrm{m}^{3}\right.$ látice $)$

$\rho_{i} \quad$ Densidade do monômero $i\left(\mathrm{~kg} / \mathrm{m}^{3}\right)$ 
$\rho_{\text {mon }} \quad$ Densidade média do monômero $\left(\mathrm{kg} / \mathrm{m}^{3}\right)$

$\rho_{\text {pol }} \quad$ Densidade média do polímero $\left(\mathrm{kg} / \mathrm{m}^{3}\right)$ 


\section{SUMÁRIO}

1 Introdução

1.1 Justificativa 1

1.2 Organização da dissertação 2

2 Revisão bibliográfica 4

2.1 Introdução 4

2.2 Polimerização em emulsão com alto teor de sólidos 4

2.3 Medidas de caracterização do produto (látice) e do processo 6

$\begin{array}{ll}2.4 \text { Formulação básica do sistema } & 10\end{array}$

$\begin{array}{ll}2.5 \text { Mecanismos cinéticos } & 14\end{array}$

$\begin{array}{lr}3 \text { Objetivos } & 18\end{array}$

4 Materiais e métodos $\quad 19$

4.1.Ingredientes 19

$\begin{array}{ll}\text { 4.2 Equipamento } & 20\end{array}$

4.3 Procedimento experimental 22

$\begin{array}{ll}\text { 4.4 Procedimento analítico } & 24\end{array}$

$\begin{array}{ll}4.5 \text { Tratamento de dados } & 26\end{array}$

4.6 Planejamento dos experimentos $\quad 29$

5 Resultados e discussão 31

$\begin{array}{ll}5.1 \text { Reprodutibilidade } & 31\end{array}$

5.2 Ensaios Exploratórios $\quad 34$

5.2.1 Introdução 34

5.2.2 Resultados e discussão 35

5.2.3 Conclusões 40

5.3 Influência do emulsificante e do ácido acrílico sobre a copolimerização de acrilato de butila/estireno com alto teor de sólidos em processo semibatelada. $\quad 42$

5.3.1 Introdução 42

5.3.2 Resultados e discussão 43

5.3.3 Conclusões $\quad 47$

5.4 Influência do teor de sólidos sobre a copolimerização de acrilato de butila/estireno com alto teor de sólidos em processo semibatelada 48

5.4.1 Introdução 48

5.4.2 Resultados e Discussão 49 
5.5 Influência do taxa de adição de monômeros sobre a copolimerização de acrilato de butila/estireno com alto teor de sólidos em processo semibatelada

5.5.1 Introducão $\quad 57$

5.5.2 Resultados e discussão

$\begin{array}{ll}5.5 .3 \text { Conclusões } & 60\end{array}$

$\begin{array}{ll}\text { 5.6 Distribuição de tamanhos de partícula } & 61\end{array}$

$\begin{array}{ll}\text { 5.6.1 Introdução } & 61\end{array}$

5.6.2 Resultados e discussão $\quad 61$

5.6.3 Conclusões 63

6 Modelagem do processo de copolimerização em emulsão de estireno e acrilato de butila em reator semi-batelada 64

6.1 Introdução 64

6.2 Mecanismo cinético $\quad 65$

$\begin{array}{ll}6.3 \text { Balanços das espécies } & 68\end{array}$

$\begin{array}{ll}6.4 \text { Taxas de reação } & 70\end{array}$

6.5 Simulação do modelo $\quad 73$

6.6 Resultados e discussão 76

$\begin{array}{lr}6.7 \text { Conclusões } & 80\end{array}$

7 Conclusões $\quad 82$

8 Sugestões futuras $\quad 84$

$\begin{array}{lr}\text { Referências bibliográficas } & 85\end{array}$

$\begin{array}{ll}\text { Apêndice } & 89\end{array}$ 


\section{Introdução}

\subsection{Justificativa}

A polimerização em emulsão é um processo que envolve a dispersão em água, com a ajuda de emulsificantes, de um monômero relativamente insolúvel na água, seguida pela adição de um iniciador que desencadeia reações químicas paralelas e consecutivas. O produto deste processo, uma dispersão aquosa de polímero, é chamado látice ou látex.

A polimerização em emulsão, devido à sua aplicação industrial, revela-se de grande importância, tanto mais quando avaliamos a produção mundial de polímeros baseada neste processo, estimada em $10^{7}$ ton/ano (GILBERT, 1995).

Em relação a outros processos de polimerização com radicais livres existentes (em massa; em solução; em suspensão), a polimerização em emulsão apresenta a vantagem de possuir uma taxa de reação relativamente elevada, além de permitir um bom controle da temperatura do processo influenciada pelo calor de reação. Por outro lado, é possível obter um produto de elevado teor de sólidos com um aumento de viscosidade moderado (KEMMERE, 1999).

Como principal desvantagem, o sistema pode conter um grande número de aditivos que, por sua vez, podem afetar a qualidade do produto final.

Em adição, as legislações ambientais caminham na substituição de polímeros com base em solventes orgânicos pelos látices em base aquosa, elevando a importância da polimerização em emulsão (ZUBITUR e ASUA, 2001).

Dentre os polímeros obtidos através deste processo, podemos citar os empregados na produção de tintas, resinas, filmes, plásticos e elastômeros (GUYOT et al., 2002). O copolímero de acrilato de butila $(A B)$ e estireno $(S)$ com $50 \%$ em massa de cada monômero 
tem muitas aplicações em produtos têxteis, na pintura e recobrimento arquitetônicos, “coating" de papel, calafetadores e como adesivos (ARBINA et al., 1997; LESKO e SPERRY, 1997).

Industrialmente, a polimerização em emulsão é realizada usualmente em reatores em batelada e semibatelada. Contudo, existem também processos contínuos em CSTR e pesquisas de processos em reatores contínuos tubulares. Mas há limitações quanto ao uso de reatores contínuos em reações de polimerização, como as necessidades de paradas para limpeza do reator devido à incrustação de polímeros; e a elevada viscosidade em sistemas com alto teor de sólidos que dificultam a homogeneização e o escoamento.

O objetivo geral do presente trabalho foi estudar experimentalmente o processo de copolimerização em emulsão de estireno e acrilato de butila em processo semicontínuo visando um produto com alto teor de sólidos. Em particular estudou-se a influência dos componentes da receita (ácido acrílico e emulsificantes) e do teor de sólidos da receita, no processo de polimerização e no produto formado. Adicionalmente, foi estudado e testado um modelo matemático para representar a relação entre as principais variáveis do processo.

\subsection{Organização da dissertação}

A dissertação está assim organizada. No Capítulo 2 apresentam-se as principais informações obtidas na literatura sobre os processos de polimerização em emulsão com alto teor de sólidos, abordando tanto aos aspectos de ordem prática como aqueles de caráter mais fundamental. No Capítulo 3 são enunciados formalmente os objetivos específicos do trabalho, e no Capítulo 4 são apresentados a metodologia experimental e os equipamentos utilizados. No Capítulo 5 os resultados obtidos são apresentados e discutidos. O modelo matemático do processo é apresentado e aplicado no Capítulo 6, mostrando-se a comparação das previsões do modelo com os resultados experimentais. Finalmente, no Capítulo 7 são resumidas as 
principais conclusões e contribuições do trabalho, e no Capítulo 8 apresentadas algumas sugestões e recomendações para possíveis estudos adicionais no tema. 


\section{Revisão bibliográfica}

\subsection{Introdução}

Para embasar adequadamente a metodologia empregada no trabalho e a interpretação dos resultados obtidos, neste Capítulo apresentam-se as informações obtidas na literatura que foram consideradas relevantes para o trabalho.

\subsection{Polimerização em emulsão com alto teor de sólidos}

A produção de polímeros de elevado teor de sólidos é interessante devido a vários fatores: elevação da produtividade do reator, redução dos custos de transporte de produto, aumento da eficiência do produto, entre outros. Contudo, a qualidade do polímero obtido, assim como sua estabilidade, limita o teor de sólidos.

Processos de polimerização com alto teor de sólidos exigem controles mais rígidos, visto que estão no limite da estabilidade da dispersão. Nesta faixa de operação, pequenos acréscimos na concentração de sólidos podem ocasionar grandes aumentos na viscosidade do meio, podendo, em alguns casos, chegar à necessidade de parada do sistema e limpeza do reator.

Neste aspecto, resultados positivos e repetitivos podem ser obtidos através de um controle rígido da distribuição do tamanho de partículas $(D T P)$. Embora os produtos obtidos atualmente na indústria usualmente apresentam uma DTP monomodal, estudos revelam que produtos com maiores teores de sólidos podem ser obtidos através de uma distribuição de tamanho de partículas larga ou bimodal (GUYOT et al., 2002). Estes resultados ocorrem devido à possibilidade de partículas menores poderem se acomodar nos interstícios deixados 
por partículas maiores, havendo um maior empacotamento com relativamente baixo aumento na interação entre as partículas.

Trabalhos publicados mostram que em distribuições bi ou trimodais com $80 \%$ de partículas maiores (e os $20 \%$ restantes distribuídos entre partículas médias e menores), e relação entre diâmetros das partículas maiores e menores de cerca de 6 a 11 vezes, são obtidos as menores viscosidades (GUYOT et al., 2002; CHU e GUYOT, 2001).

$\mathrm{Na}$ figura que se segue, observa-se como a quantidade de partículas grandes e pequenas afeta a fração volumétrica máxima $(F m v)$ e o conteúdo máximo em sólidos $(S m)$ alcançável em um sistema.

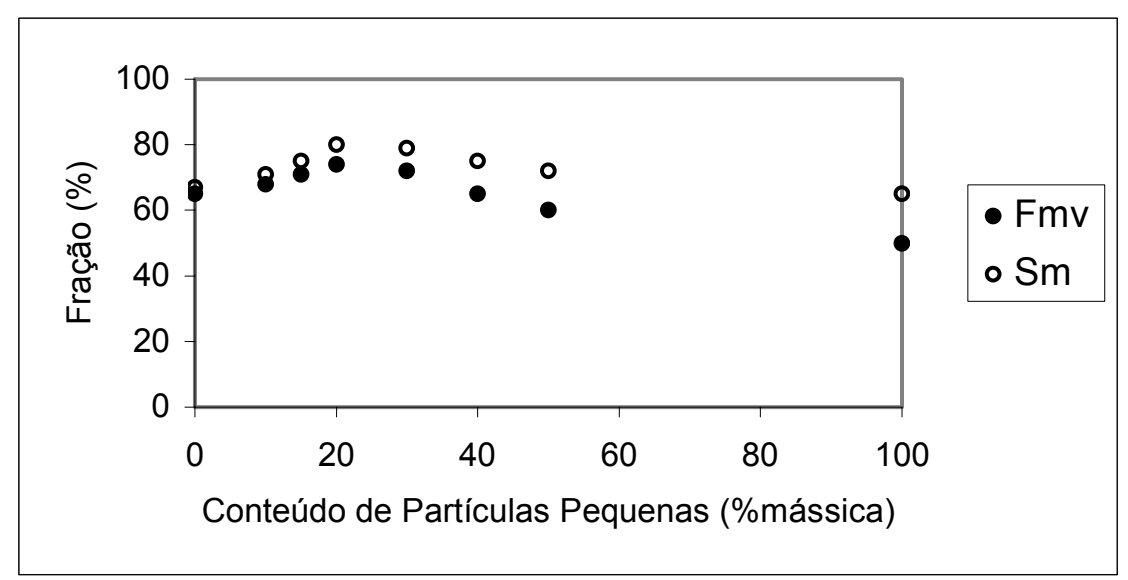

Figura 2.2.1 - Fração máxima em volume e teor máximo de sólidos em função da composição de partículas (CHU e GUYOT, 2001).

Atualmente, o uso de estratégias semi-empíricas relacionando a distribuição do tamanho de partículas com a viscosidade tem obtido sucesso na polimerização de látices com teores de sólidos superiores a 65\% (GUYOT et al., 2002). 


\subsection{Medidas de caracterização do produto (látice) e do processo}

\section{Distribuição de Tamanhos de Partículas (DTP)}

A Distribuição de Tamanhos de Partículas de uma emulsão também influencia nas características do filme produzido com esta emulsão. Contudo, a DTP também tem importante influência na viscosidade e estabilidade coloidal da emulsão. De fato, o controle da DTP é essencial ao trabalhar com polimerização em emulsão com alto teor de sólidos. Por outro lado, muitos fatores afetam a DTP.

A concentração de iniciador afeta o tamanho médio e a concentração das partículas. Um aumento na concentração de persulfato de potássio (iniciador térmico) pode ocasionar um aumento na taxa de formação de novas partículas (BLACKLEY, 1975). Contudo, o tipo de iniciador empregado também pode influenciar o tamanho médio das partículas e sua polidispersidade (BADRAN et al., 1997).

A temperatura do processo também pode influenciar a DTP. Partículas menores podem ser obtidas com o aumento da temperatura do processo. Tal fato pode ser mais ou menos evidente, dependendo do iniciador empregado (CAPEK e POTISK, 1995).

A agitação dentro do reator é determinante para o processo. Baixas velocidades de agitação podem ocasionar a formação de uma camada sobrenadante de monômero e a formação de muitos coágulos. Aumentos na velocidade de agitação podem reduzir o número de coágulos, até o ponto onde a agitação perde sua influência sobre a formação de coágulos (ZUBITUR e ASUA, 2001).

O tipo e a concentração de emulsificante empregado podem influenciar tanto o processo como o produto formado. Maiores quantidades de emulsificante acarretam uma larga distribuição de partículas, assim como uma menor viscosidade (GUYOT et al., 2002). Por outro lado, diferentes tipos de emulsificantes podem ser empregados, inclusive aqueles que 
participam na formação da cadeia polimérica, modificando também as características do polímero formado, como sua resistência mecânica, absorção de água, características do filme, etc. (ABELE et al., 2000).

A forma de alimentação do reator (batelada/semibatelada e tempos de alimentação) influencia a taxa de reação, assim como a DTP (MARINANGELO et al., 2001b; ZUBITUR e ASUA, 2001).

\section{Viscosidade}

A viscosidade também é característica importante da emulsão, pois ditará a viabilidade do processo e do produto. Emulsões muito viscosas exigem métodos mais específicos para seu manuseio. Para dispersões de esferas rígidas, a viscosidade é grandemente afetada pela fração volumétrica de sólidos, aumentando exponencialmente para valores próximos da compactação máxima das esferas. Contudo, as partículas de um látice dificilmente podem ser consideradas esferas rígidas e a interação entre as partículas afeta a reologia do látice. A reologia do fluído dispersante também é importante, esta podendo ser manipulada com o uso de espessantes.

\section{Estabilidade Coloidal}

A estabilidade coloidal de um látice refere-se à capacidade de suas partículas permanecerem como entidades únicas por longos períodos de tempo. Em látices instáveis, as partículas se associam para formar agregados ou coágulos. A estabilidade do látice é importante, por exemplo, em processos onde o produto deve ser mantido armazenado por longos períodos. Por outro lado, a instabilidade pode facilitar processos de separação (LOVEL e EL-AASSER, 1997). 
Os procedimentos para a análise da estabilidade de um látice no decorrer do tempo podem incluir a aceleração de seu envelhecimento através da criação de condições adversas. Como procedimentos usuais citam-se o armazenamento sob temperatura moderada em estufa e o ciclo gelo-degelo. Neste último, o látice é submetido por um período a uma temperatura abaixo da de congelamento, seguindo um período em que o látice é submetido a uma temperatura acima à de congelamento, constituindo um ciclo. A estabilidade pode ser medida pelo número de ciclos em que o látice mantém as suas características, ou a quantidade de coágulos formada após determinado número de ciclos.

O uso de emulsificantes iônicos e não-iônicos, assim como o uso de monômeros funcionais, ajuda a conferir estabilidade eletrostática e estérica às partículas (SCHNEIDER et al., 2002; GILBERT, 1995). Entretanto, também a força iônica do meio, assim como a distância entre as partículas e o seu grau de cobrimento por emulsificante, afeta a estabilidade do látice.

Entretanto, fenômenos de coagulação das partículas podem ocorrer mesmo nos primeiros instantes da polimerização. Partículas recém-nucleadas, formadas principalmente através de nucleação homogênea, tendem a ser pouco estáveis e podem sofrer autoestabilização através da coagulação com outras partículas, aumentando assim o seu potencial elétrico de superfície. Desta forma, o diâmetro das partículas, assim como o número de partículas formadas, é afetado. O diâmetro das partículas depende, portanto, da carga superficial das partículas e força iônica do meio (OTTEWILL, 1997).

\section{Temperatura de Transição Vítrea (Tg)}

Quando um polímero fundido é resfriado torna-se mais rígido ao se aproximar de uma certa faixa de temperatura. Este enrijecimento é o resultado de um dos dois possíveis eventos: cristalização ou transição vítrea. Para que ocorra a cristalização as moléculas de polímero 
devem, necessariamente, ser regulares para permitir a formação de retículos cristalinos. A velocidade de resfriamento deve ser suficientemente lenta para que o arranjo molecular cristalino se complete antes que a movimentação molecular torne-se excessivamente baixa. Quando o polímero não é passível de cristalização, a estrutura amorfa e irregular do polímero é mantida no estado sólido e o polímero adquire uma estrutura vítrea. Esta mudança de estado ocorre em um intervalo de temperatura, mas suficientemente abrupta para ser denominada de transição vítrea.

A Tg de um polímero pode ser determinada através da variação do comportamento mecânico, viscoelástico ou da entalpia da amostra. O resultado será, usualmente, um valor médio de todas as cadeias poliméricas com suas distribuições de composição.

Um látice consiste de partículas esféricas, da ordem de 10 a $1000 \mathrm{~nm}$, emulsionadas em água. Se um tal látice é espalhado sobre uma superfície sólida e a água é evaporada, as partículas aproximam-se e podem se tocar quando o teor de sólidos excede cerca de $70 \%$. À medida que a água remanescente é evaporada dos interstícios entre as partículas, dois comportamentos são possíveis dependendo da $\mathrm{Tg}$ do polímero.

Se a temperatura de secagem for muito inferior à $T g$, as partículas serão vítreas e não haverá a formação de filme. Por outro lado, se a temperatura de secagem for muito superior à $\mathrm{Tg}$, as partículas serão macias e fundir-se-ão formando um filme contínuo.

\section{Temperatura Mínima de Formação de Filme (TMFF)}

A temperatura mínima de formação de filme de um látice é determinada por um processo padronizado definido na norma ISO. O princípio de funcionamento dos aparelhos desenvolvidos para esta determinação baseia-se na mudança das características visuais do látice colocado para secagem: a TMFF é a temperatura na qual uma camada delgada de látice muda de aspecto, de branca para transparente e homogênea. 
Enquanto a $T g$ é propriedade do polímero, a TMFF é propriedade do látice. A TMFF do látice é ligeiramente inferior à $\mathrm{Tg}$ do polímero, pois o meio dispersante (água) e o diâmetro médio da partícula influenciam a TMFF. A medida da TMFF é dependente do tempo, porque os polímeros são viscoelásticos, assim, deve-se padronizar também o tempo para leitura da TMFF após o espalhamento do látice na placa.

\subsection{Formulação básica do sistema}

A polimerização em emulsão é um processo heterogêneo complexo. Há muitos componentes presentes na formulação que influenciam tanto o processo como o produto final. A formulação típica de um processo de polimerização em emulsão envolve basicamente monômero, água como meio dispersante, emulsificante, iniciador e aditivos.

\section{Monômero}

O monômero é claramente o mais importante componente do sistema, visto que a polimerização se efetua a partir deste. As características do látice, inclusive as relacionadas com o seu uso final, dependem em grande parte do monômero, principal bloco de construção das cadeias poliméricas.

Contudo, o emprego, ou não, de um monômero na produção de um látice baseia-se, além das características desejadas do polímero final, na compatibilidade do látice com pigmentos e cargas e na processabilidade do látice.

Usualmente, as propriedades desejadas de um látice não podem ser obtidas com o emprego de apenas um monômero, empregando-se, então, dois ou mais co-monômeros na produção do látice. Neste caso, a reatividade relativa entre os co-monômeros passa a ser um fator importante no estabelecimento da estratégia de síntese do látice. 
Geralmente, nos processos de polimerização em emulsão, o monômero é pouco solúvel ou praticamente insolúvel na água. A solubilidade do monômero na água é um fator importante no processo, pois impacta na nucleação das partículas durante a síntese do látice.

Entretanto, é usual o emprego de pequenas quantidades de um monômero relativamente solúvel, como o ácido acrílico, para aumentar a estabilidade coloidal das partículas, uma vez que as cadeias relativamente hidrofílicas posicionadas na superfície das partículas auxiliam na estabilização estérica.

\section{Meio dispersivo}

Apesar de ser basicamente um componente inerte, o meio dispersivo é componente chave do processo, constituindo o meio contínuo do sistema. Neste meio ocorrem os fenômenos de transferência de monômero entre gotas e partículas, decomposição do iniciador, formação de radicais e equilíbrio dinâmico do emulsificante entre as fases. Num processo de polimerização em emulsão, as principais características técnicas de interesse do meio dispersivo são:

-Ser solvente para o gerador de micelas e para ao menos um dos componentes do sistema iniciador;

-Induzir as moléculas dissolvidas do gerador de micelas se agregarem para formar micelas, de preferência com baixa concentração micelar crítica;

-Preferencialmente, os monômeros devem ser relativamente insolúveis neste meio;

-As moléculas do meio dispersivo não devem ser reativas com os radicais livres presentes no processo;

-Deve possuir baixa viscosidade e deve permitir a transferência de calor entre o meio reacional e as paredes do reator; 
-As propriedades físicas deste meio devem permitir a realização de reações de polimerização em uma ampla faixa de temperatura e pressão.

Para a maioria dos monômeros de interesse, a água satisfaz estes requisitos, o que, aliado às vantagens de baixo custo, disponibilidade e ausência de periculosidade, a torna o meio dispersivo normalmente usado nos processos de polimerização em emulsão. Impurezas de caráter inorgânico na água podem apresentar variabilidade sazonal e efeitos indesejáveis, o que torna comum o uso de água deionizada. Por outro lado, a presença de gases dissolvidos, principalmente o oxigênio podem reagir preferencialmente com os radicais livres, retardando a polimerização. Desta maneira, é comum a prática de desoxigenação da água, usualmente empregando nitrogênio.

\section{Emulsificante}

O emulsificante (também chamado surfatante ou estabilizante) atua em uma série de funções num processo de polimerização, como por exemplo:

-Atua como gerador de micelas, local de nucleação de partículas;

-Estabiliza as gotas de monômeros na forma de emulsão;

-Estabiliza as partículas de látice formadas inclusive durante o crescimento das mesmas;

Usualmente, são empregados emulsificantes aniônicos e não-iônicos na produção de látices. Emulsificantes aniônicos compõem-se de uma parte hidrofóbica e outra hidrofílica negativamente carregada. A parte hidrofóbica é responsável pela adsorção do emulsificante na superfície da partícula de látice, enquanto que a parte hidrofílica é responsável pela estabilização eletrostática, evitando a coagulação das partículas através de repulsão de cargas. Emulsificantes não-iônicos são geralmente estabilizantes poliméricos que conferem estabilidade através de repulsão entrópica. 


\section{Iniciador}

Como fonte de radicais livres para o processo de polimerização em emulsão, são empregados basicamente dois tipos de sistemas iniciadores: térmicos e redox.

Um sistema de iniciador térmico consiste de uma substância que, ao fornecermos a energia de ativação necessária, dissocia-se formando radicais livres. Usualmente, empregamse sais de persulfato como iniciador térmico. A energia de ativação é relativamente alta, devendo o processo operar em temperaturas na faixa de $50-90^{\circ} \mathrm{C}$.

No caso de um sistema de iniciador redox, utiliza-se um oxidante e um redutor para a produção de radicais livres a baixas temperaturas, o que pode ser interessante em determinados processos.

Do ataque dos radicais livres do iniciador ao monômero formam-se radicais monoméricos que propagam a reação de polimerização reagindo com outras moléculas de monômeros.

\section{Aditivos}

Aditivos podem ser acrescentados ao sistema com o objetivo de controlar o $\mathrm{pH}$ do meio, controlar o peso molecular das cadeias poliméricas e aumentar a estabilidade coloidal, entre outros.

A regulação do $p H$ com o uso de tampões é comumente utilizada para garantir a estabilidade de certos monômeros ou influenciar a taxa de decomposição do iniciador. No entanto, uma vez que freqüentemente são sais, tais tampões podem influenciar a estabilidade coloidal das partículas de látex.

O peso molecular das cadeias poliméricas é usualmente controlado com o uso de agentes de transferência de cadeia. Uma vez que o tamanho médio das cadeias obtidas por 
polimerização em emulsão é elevado, tais agentes podem ser utilizados para reduzir o tamanho médio das cadeias. Estes atuam por terminar radicais poliméricos em crescimento, formando um novo radical de tamanho reduzido.

Entre os aditivos utilizados para aumentar a estabilidade coloidal do látice podem-se citar os monômeros funcionais. Estes podem ser monômeros de caráter hidrofílico, e que são adicionados em pequena quantidade para ajudar a conferir estabilidade estérica para as partículas.

\subsection{Mecanismos cinéticos}

O conhecimento dos mecanismos cinéticos que descrevem a polimerização em emulsão se faz importante ao estudarmos os fatores que a influenciam.

Harkins (1947) foi o primeiro a descrever qualitativamente a polimerização em emulsão com base em dados experimentais. Sua teoria se aplica a monômeros pouco solúveis em água como o estireno e em casos onde a concentração de emulsificante está acima da CMC.

Com base nesta teoria, a polimerização ocorre preferencialmente nas partículas de polímero. Para processo em batelada, a evolução no tempo da polimerização é descrita em três intervalos:

Intervalo I: O iniciador se decompõe formando radicais livres na fase aquosa. Estes radicais livres crescem, reagindo com o monômero, até adquirir certa propriedade tensoativa que lhes permita entrar nas micelas com monômero, formando partículas de polímero. A entrada do radical na micela contendo monômero propicia uma reação de propagação, e representa a etapa de nucleação de partícula, chamada de nucleação micelar. 
No intervalo I estão presentes gotas de monômero de tamanho entre $10^{3}-10^{4} \mathrm{~nm}$, micelas contendo monômero solubilizado de tamanho aproximado de $10 \mathrm{~nm}$ e partículas de polímero em crescimento de tamanho entre 50-100 nm.

Depois de formada, a partícula cresce devido ao consumo de monômeros pelos radicais poliméricos presentes na partícula. Os radicais podem sair das partículas assim como entrar em outras partículas. Os radicais também podem ser terminados pela reação com outros radicais presentes na partícula.

Com o curso da polimerização, mais emulsificante é requerido para estabilizar as partículas de polímero em crescimento até que todo o emulsificante seja consumido e as micelas desapareçam, marcando o fim do intervalo I. A partir deste ponto o número de partículas permanece constante, uma vez que não são mais geradas partículas por nucleação micelar. A velocidade de polimerização é crescente no intervalo I.

Intervalo II: As partículas continuam crescendo e consumindo o monômero, através de reações de propagação. A concentração de monômero nas partículas é constante e está em equilíbrio termodinâmico com a fase aquosa, a transferência de monômero das gotas para a fase aquosa é feita para manter esta condição de equilíbrio. Como o número de gotas de monômero é muito menor do que o de partículas de polímero na proporção aproximada de 1 para 100, a probabilidade de nucleação nas gotas é muito pequena. O fim deste intervalo é marcado pelo desaparecimento das gotas de monômero. A velocidade de polimerização é constante no intervalo II.

Intervalo III: Nesta etapa o monômero restante na fase aquosa e dentro das partículas é consumido. $\mathrm{O}$ interior das partículas torna-se mais viscoso e, eventualmente, as reações podem vir a ser controladas pela difusão dos radicais poliméricos. A concentração de monômero na fase aquosa e dentro das partículas decresce com o tempo ao invés de permanecer aproximadamente constante como no intervalo II. O tamanho das partículas 
inchadas de monômero pode sofrer redução, pois a densidade do polímero formado é maior do que a do monômero consumido. A velocidade de polimerização no intervalo III pode ser decrescente.

\section{Mecanismos de Nucleação}

Entre os mecanismos de nucleação tradicionalmente aceitos, o de nucleação micelar (HARKINS, 1947), já descrito anteriormente, e o de nucleação homogênea (PRIEST, 1952), são os mais importantes.

A nucleação homogênea aplica-se principalmente a monômeros parcialmente solúveis em água, como o acetato de vinila ou para reações sem emulsificante ou com quantidades de emulsificante abaixo da CMC. Segundo este mecanismo o radical livre formado pode propagar-se na fase aquosa até atingir um comprimento crítico, tornando-se insolúvel em água e precipitando-se para formar uma partícula primária de látice estabilizada por emulsificante. A nucleação homogênea está representada esquematicamente na Figura 2.5.1.

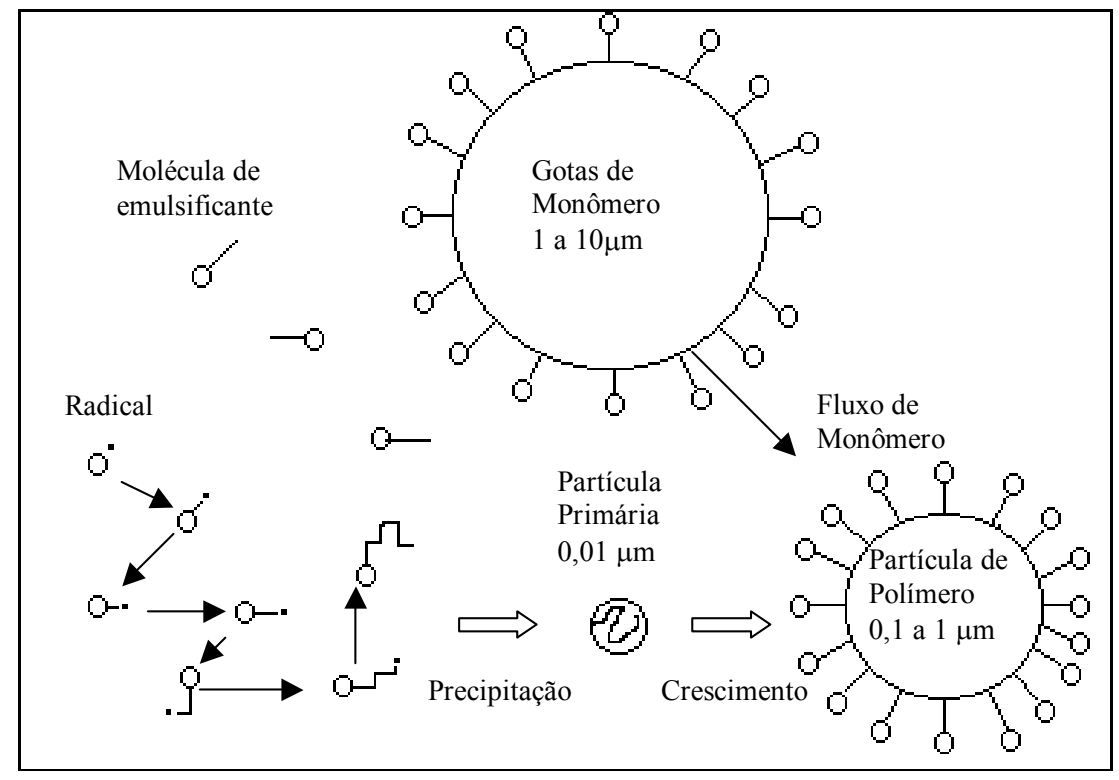

Figura 2.5.1 - Mecanismo de nucleação homogênea (PRIEST, 1952). 
Trabalhos posteriores propuseram alterações aos mecanismos propostos, adequandoos a uma variedade maior de sistemas. Atualmente, considera-se que ambos os mecanismos de nucleação propostos ocorram concomitantemente, podendo, ou não, haver a prevalência de um deles dependendo do sistema e das condições estudados. Entre as alterações propostas para os mecanismos, as mais significativas são (GILBERT, 1995):

-Os radicais oligoméricos na fase aquosa propagam-se até atingir um comprimento de cadeia mínimo para que possam entrar numa micela ou partícula; e

-As partículas recém-formadas por nucleação homogênea ou nucleação micelar, usualmente chamadas partículas precursoras, apresentam baixa estabilidade e podem sofrer certo grau de coagulação até se tornarem estáveis. 


\section{Objetivos}

Os objetivos específicos deste trabalho são os seguintes:

-Estudar experimentalmente, em escala de laboratório, a copolimerização em emulsão de estireno e acrilato de butila em processo semicontínuo visando um produto com alto teor de sólidos;

-Estudar a influência dos componentes da receita, como o ácido acrílico e os emulsificantes, no processo de polimerização e no produto formado;

-Estudar a influência do teor de sólidos da receita no processo de polimerização e no produto formado;

-Aplicar um modelo matemático que possa descrever a relação entre as principais variáveis do processo. 


\section{Materiais e métodos}

\subsection{Ingredientes}

Os produtos químicos utilizados, de grau comercial, são:

- Acrilato de butila ( $A B$ - monômero contendo $50 \mathrm{ppm}$ de inibidor metil-etilhidroquinona);

- Estireno ( $S$ - monômero contendo 50 ppm de inibidor p-t-butilcatecol);

- Ácido acrílico (AA - monômero funcional, protetor coloidal), fornecidos pela Rhodia S.A de Paulínia e utilizados sem purificação;

- Nonil-fenol etoxilado com 23 mols de óxido de etileno (Ultrawet 230, emulsificante não iônico), fornecido pela Oxiteno S.A.;

- Nonil-fenol etoxilado com 25 mols de óxido de etileno sulfato de sódio (Disponil 25 S, emulsificante iônico), fornecido pela Cognis S.A;

- Persulfato de sódio $\left(\mathrm{Na}_{2} \mathrm{~S}_{2} \mathrm{O}_{8}\right.$, Iniciador);

- Bicarbonato de sódio $\left(\mathrm{NaHCO}_{3}\right.$, regulador de $\left.\mathrm{pH}\right)$;

- N-dodecilmercaptano (NDDM - agente de transferência de cadeia);

- Hidroquinona (função de interromper a reação nas amostragens);

- Utilizou-se água deionizada em todos os ensaios e formulações.

Todos os reagentes foram utilizados como adquiridos, isto é, sem qualquer purificação. 


\subsection{Equipamento}

O equipamento experimental utilizado, esquematizado na Figura 4.2.1 foi montado segundo informações contidas na literatura (MARINANGELO et al., 2001a; MARINANGELO et al., 2001b; PALMA et al., 2001; YOKOTE et al., 2001), consistindo de:

-1 Reator de vidro $(\boldsymbol{F})$ encamisado de capacidade de 1 litro com válvula de fundo para retirada de amostras $(\boldsymbol{G})$, e cuja tampa possui entradas para alimentação e agitador (as letras em parênteses referem-se às indicações na Figura 4.2.1);

-1 Agitador com velocidade regulável de 100 a 500 rotações por minuto e constante para o valor ajustado com haste do tipo turbina com quatro lâminas planas verticais de dimensões $25 \times 25 \mathrm{~mm}$

-1 Condensador $(\boldsymbol{C})$;

-Sistema de controle de temperatura consistindo de:

-1Termopar (D);

-1 Controlador de Temperatura (E);

-1 Contator Magnético;

-5 válvulas solenóide $(\boldsymbol{H}, \mathbf{I}, \mathbf{J}, \boldsymbol{K}, \mathbf{L})$;

-2 banhos termostatizados (B1, B2).

-Sistema de alimentação de pré-emulsão consistindo de:

-1 Balança;

-1 Bomba Diafragma (M).

-Sistema de alimentação de iniciador consistindo de:

-1 Bureta $(N)$;

-1 Bomba Peristáltica $(\boldsymbol{O})$. 
-Sistema de purga do reator (não mostrado na Figura 4.2.1) para remoção de $\mathrm{O}_{2}$ dissolvido no meio, consistindo de:

-1 Cilindro de Nitrogênio;

-1 Válvula Redutora de Pressão;

-1 Rotâmetro.

-Equipamentos auxiliares para tratamento de amostras:

-Analisador de tamanho de partículas Coulter N4+;

-Cromatógrafo com head-space;

-Viscosímetro Brookfield RVDV-III;

-Peneiras (Mesh 40, 80 e 100);

-Balanças Analíticas;

-Estufa a $95^{\circ} \mathrm{C}$.

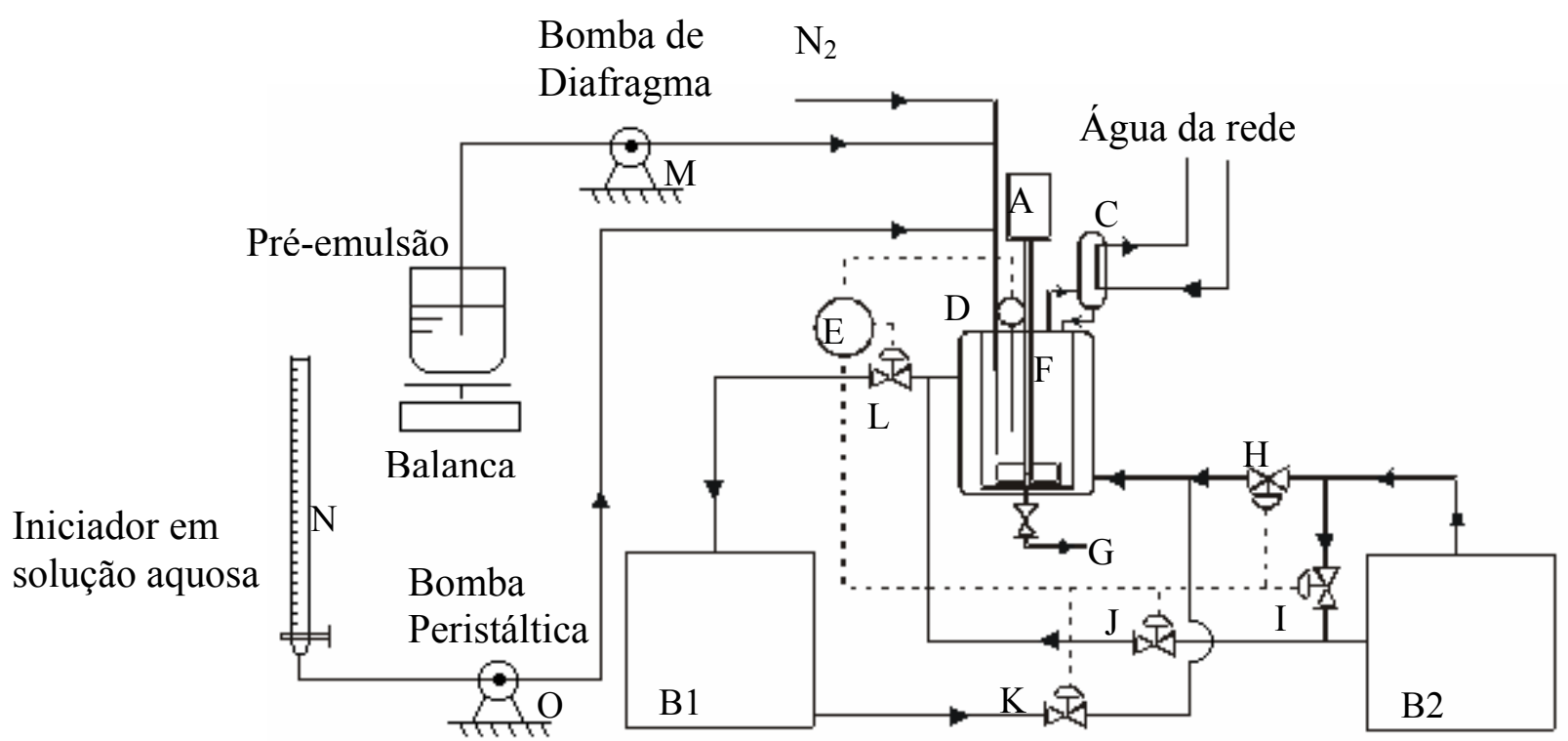

Figura 4.2.1 - Esquema da aparelhagem utilizada

A Figura 4.2.2 é uma foto destacando o reator utilizado nas reações de polimerização. 


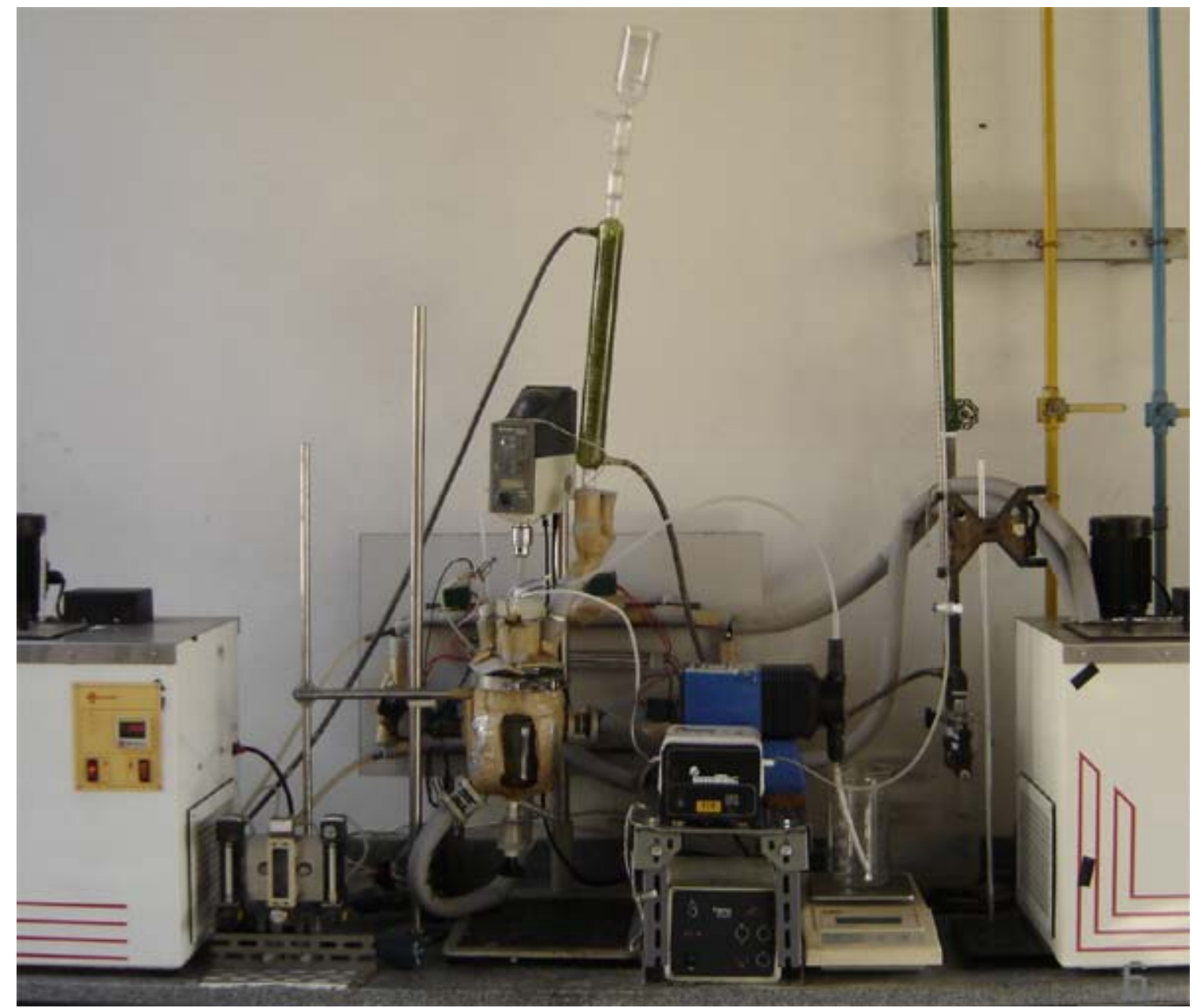

Figura 4.2.2 - Foto do equipamento experimental utilizado.

\subsection{Procedimento experimental}

Preparação do ensaio

-Preparar 50ml de solução de hidroquinona 1\%;

-Pesar os reagentes em balança analítica (carga inicial, pré-emulsão e iniciador);

-Dissolver os reagentes da carga inicial e adicionar ao reator com auxílio de funil;

-Injetar nitrogênio no reator para purga por cerca de 1 hora;

-Misturar os reagentes da pré-emulsão em um becker de 2 litros e agitar com agitador em rotação alta (cerca de 2000 rotações por minuto) até formar uma mistura homogênea (pré-emulsão); 
-Transferir a pré-emulsão para um becker de 1 litro e colocar sobre a balança de adição;

-Dissolver o iniciador e colocar na bureta;

-No final da purga, fechar a válvula do cilindro de nitrogênio, ligar os banhos termostatizados, ajustar os "set-points" dos banhos e do controlador e aguardar até o reator atingir a temperatura do ensaio $\left(85^{\circ} \mathrm{C}\right)$;

-Retirar uma amostra para determinar o teor de sólidos não polimerizáveis.

\section{Reação}

-Ligar o agitador, ajustado para uma velocidade constante de 100 rotações por minuto.

-Quando o reator atingir a temperatura do "set-point", ligar a bomba peristáltica e a de diafragma para iniciar adição de iniciador e pré-emulsão respectivamente;

-Ligar o cronômetro;

-Retirar amostragens para gravimetria, determinação de tamanho de partículas e cromatografia em intervalos pré-definidos, curtos no início do ensaio (5 em $5 \mathrm{~min}$ ) e mais espaçados (30 em 30 min) a partir da primeira hora de ensaio até o final do ensaio (cerca de 5,5 horas de reação);

-Periodicamente, com base nos valores indicados pela balança e pela bureta, corrigir, se necessário, as vazões das bombas de adição da pré-emulsão e do iniciador;

-Repetir o último item até completar a adição de toda a pré-emulsão e iniciador da receita (cerca de 3 horas de adição), após o que são desligadas as bombas de adição;

-Aos 240 minutos de reação, o "set-point" do controle de temperatura do reator é aumentado para $90^{\circ} \mathrm{C}$, para garantir conversão próxima da máxima;

-Aos 330 minutos termina-se o tempo da reação, após o que são desligados os equipamentos e procede-se a limpeza do equipamento e tratamento das amostras; 
-São preparadas amostras do produto final para análise de viscosidade e teor de coágulos.

\subsection{Procedimento analítico}

-Análise gravimétrica: pesar uma placa de alumínio e anotar o valor (MPV), adicionar 5 gotas da solução de hidroquinona a 1\%, pesar novamente e anotar a massa $(M P H I)$. Coletar 3 a $4 \mathrm{~g}$ de amostra na placa, pesar novamente e anotar a massa (MAS). Colocar as placas de alumínio das amostras na estufa a $95^{\circ} \mathrm{C}$. As placas devem ficar cerca de 8 horas na estufa, secando todo o monômero e água (testes preliminares mostraram que este tempo é suficiente para que, nas condições utilizadas, as placas atinjam a condição de "massa constante", ou seja, sem quantidades significativas de componentes voláteis). Após este tempo as placas podem ser pesadas novamente e a massa anotada para análise gravimétrica (MDS);

-Análise de tamanho de partículas: em um frasco de $10 \mathrm{ml}$ colocar $2 \mathrm{ml}$ de água, 5 gotas de solução de hidroquinona $1 \%, 5$ gotas de solução da mistura de emulsificantes (mesma relação usada nos ensaios), e retirar cerca de $0,5 \mathrm{~g}$ de amostra do reator logo após a amostragem para gravimetria. Fechar o frasco e conservar em caixa de isopor com água fria até análise. O tamanho médio das partículas é obtido com o analisador Coulter N4+ pela técnica conhecida por "espalhamento dinâmico de luz" ou “espectroscopia de correlação de fótons". Para o ensaio AS-23, foi avaliada a distribuição de tamanhos de partículas ao longo da reação. Neste caso, as amostras foram analisadas em microscópio eletrônico de transmissão no Laboratório de Microscopia Eletrônica da Faculdade de Medicina da USP. 
-Análise de monômero residual por cromatografia: em frasco específico, colocar $2 \mathrm{ml}$ de água e 2 gotas de solução de hidroquinona e medir tal massa adicionada. Colocar uma gota de amostra do reator e medir a massa. Lacrar o frasco e conservar em água fria até análise no cromatógrafo a gás com Head Space. Através da análise obtém-se a quantidade (e composição) de monômero residual (ainda não reagido). A composição do copolímero já reagido é obtida através de balanço de massa incluindo os resultados da composição do monômero residual.

-Análise de viscosidade: após agitação, retira-se uma amostra do látice. A amostra é passada em peneira mesh 40 para retirada de coágulos maiores. A medida de viscosidade é realizada em reômetro Brookfield RVDV-III com haste SC4-21 a $20^{\circ} \mathrm{C}$.

-Análise de teor de coágulos: após agitação, pesar uma amostra de $50 \mathrm{~g}$ do látice, e anotar a massa. Dissolver a amostra em cerca de 300ml de água. Pesar as peneiras mesh limpas e secas e anotar a massa. Peneirar a amostra nas peneiras mesh 40, 80 e 100, sucessivamente. Secar as peneiras em estufa a $95^{\circ} \mathrm{C}$ por cerca de 8 horas. Pesar novamente as peneiras com o polímero seco e anotar a massa. Tal análise foi realizada nas emulsões logo após o término do experimento. Para algumas emulsões armazenadas à temperatura ambiente, esta análise foi repetida após um período de 1 ano, onde verificou-se a estabilidade do látice no decorrer do tempo.

-Temperatura Mínima de Formação de Filme (TMFF) e Temperatura de Transição Vítrea (Tg): Para os ensaios de reprodutibilidade foram também realizadas análises 
de Tg e de TMFF. As análises de temperatura de transição vítrea foram feitas na Rhodia S.A, unidade Paulínia, pelo aparelho de DSC 2010 (Differential Scanning Calorimeter), utilizando a técnica de calorimetria diferencial de varredura (DSC). O aparelho DSC 2010 utiliza um método de comparação entre uma cápsula contendo a amostra de polímero e uma cápsula vazia de referência. As análises de TMFF foram feitas no equipamento MFFT - Bar 6.0 (Minimum Film Forming Temperature Bar), na Rhodia S.A unidade Paulínia.

\subsection{Tratamento de dados}

$\mathrm{O}$ tratamento dos dados experimentais foi realizado com base nas seguintes equações:

Fração de sólidos na amostra da placa:

$$
F S=(M D S-M P V) /(M A S-M P H I)
$$

Fração de polímeros:

$$
F P=F S-F T
$$

onde:

$F T$ = Massa de sólidos não polimerizáveis adicionados / Massa total adicionada

Conversão Global do monômero em \%:

$$
X_{\text {Global }}=\frac{F P}{F M_{\text {total }}} \cdot 100
$$

onde:

$F M_{\text {total }}=$ Massa de monômero da receita / Massa total da receita 
Concentração de Partículas, Np (partículas/L látice):

$$
N_{p}=\frac{F P}{\frac{\rho_{\text {pol }}}{\rho_{\text {látex }}} \cdot\left(\frac{\pi}{6} D_{p}^{3}\right)}
$$

onde:

$\rho_{\text {pol }}=$ Densidade do polímero em $\mathrm{g} / \mathrm{L}$

$\rho_{\text {látice }}=$ Densidade do látice em $\mathrm{g} / \mathrm{L}$ para a composição no instante considerado

$D_{p}=$ Diâmetro médio das partículas em dm

Taxa de Polimerização (g/min):

$$
R_{p}=\frac{\left[F P \cdot M_{\text {total }}\right]_{(t+\Delta t)}-\left[F P \cdot M_{\text {total }}\right]_{(t)}}{\Delta t}
$$

onde:

$M_{\text {total }}=$ Massa total adicionada ao reator até o instante atual

Número médio de radicais por partícula:

Obteve-se $V_{m}{ }^{P}$ pela seguinte equação (ARAÚJO, 1999):

$\left(K_{m}{ }^{P}-1\right) \cdot\left(V_{m}^{P}\right)^{2}+\left(K_{m}^{P} \cdot\left(V_{P}^{P}-V_{m}\right)+V_{W}+V_{m}\right) \cdot V_{m}^{P}-K_{m}^{P} \cdot V_{m} \cdot V_{P}^{P}=0$

onde:

$V_{m}{ }^{P}=$ volume de monômero nas partículas;

$K_{m}{ }^{P}=$ coeficiente de partição do monômero entre partícula e fase aquosa;

$V_{p}{ }^{P}=$ volume de polímero na fase polimérica;

$V_{m}=$ volume de monômero livre no reator;

$V_{W}=$ volume de água no reator. 
Os valores de $K_{m}{ }^{P}$ utilizados foram obtidos da literatura $\left(K_{m}{ }^{P}=1629 \mathrm{~mol} / \mathrm{mol}\right.$ e $K_{m}{ }^{P}{ }{ }^{A}$ $=471 \mathrm{~mol} / \mathrm{mol}$; ARBINA et al., 1997). Os valores para $V_{p}^{P}, V_{m}$ e $V_{W}$ são obtidos por balanço de massa. A concentração de monômero dentro das partículas é dada por:

$$
[M]_{P}=\left(\frac{V_{m}^{P}}{V_{m}^{P}+V_{p}^{P}}\right) \cdot \frac{\rho_{\text {mon }}}{\overline{P M_{\text {mon }}}}
$$

$\rho_{\text {mon }}=$ densidade média dos monômeros;

$P M_{\text {mon }}=$ peso molecular médio dos monômeros.

Obteve-se a constante de propagação, $k_{p}$, por (KONG et al.,1988):

$$
k_{P}=\frac{\frac{k_{p A A} \cdot k_{p B B}}{r_{A} \cdot r_{B}}}{\frac{k_{p A A}}{r_{A}} \cdot\left(1-f_{A}\right)+\frac{k_{p B B}}{r_{B}} \cdot f_{A}} \cdot\left\{r_{A} \cdot f_{A}^{2}+2 \cdot f_{A} \cdot\left(1-f_{A}\right)+r_{B} \cdot\left(1-f_{A}\right)\right\}
$$

Os valores das razões de reatividade, $r_{A}$ e $r_{B}$, e constantes de homopolimerização $\left(k_{p A A}\right.$ e $k_{p B B}$ ) foram obtidos da literatura (MANDERS et al., 1996; MCKENNA et al., 1995; GINSBURGER et al., 2003). Utilizou-se valor de fração molar do monômero $A$ em relação ao total de monômeros, $f_{A}$, baseado na composição da alimentação. Visto ser um processo semibatelada em que as razões de reatividade dos monômeros são relativamente próximas, este valor de $f_{A}$ utilizado deve representar razoavelmente a composição dos monômeros, podendo-se esperar desvios principalmente após o fim da alimentação. O número médio de radicais por partícula, ñ, é obtido, então, da expressão de taxa de polimerização:

$$
R_{P}=k_{p} \cdot M_{p} \cdot \frac{N_{T}}{N_{A}} \cdot \tilde{n} \cdot P M_{m o n}
$$


onde:

$N_{T}=$ número total de partículas no látex;

$N_{A}=$ número de Avogadro.

\subsection{Planejamento dos experimentos}

A descrição das condições utilizadas em cada ensaio está apresentada no Anexo 1 . O planejamento dos ensaios realizados foi o seguinte:

-Ensaios de reprodutibilidade com teor de sólidos da receita, $T S_{R E C E I T A}$, igual a 53\%; (Ensaios AS-01, AS-02, AS-03 e AS-04)

-Ensaios exploratórios com $T S_{R E C E I T A}$ variando entre 53 e 57\%;

(Ensaios AS-05, AS-06 e AS-07)

-Estudo da influência do teor de emulsificante e protetor coloidal, com $T S_{R E C E I T A} \sim 57 \%$;

(Ensaios AS-07, AS-08, AS-09, AS-10, AS-11, AS-12, AS-13, AS-14, AS-15, AS-16 e AS-17)

-Estudo da influência do teor de sólidos, utilizando a composição do ensaio com as melhores características reológicas e de estabilidade do estudo anterior, e $T S_{R E C E I T A}$ variando entre 57 e $64 \%$;

(Ensaios AS-08, AS-20, AS-21, AS-22)

-Estudo da influência do tempo de adição com $T S_{R E C E I T A} \sim 57 \%$; 
(Ensaios AS-07, AS-18, AS-19)

A caracterização do processo deu-se através de análises de conversão, diâmetro médio das partículas, concentração das partículas, taxa de polimerização e número médio de radicais por partícula.

A caracterização do produto deu-se através de análises de diâmetro médio das partículas, concentração das partículas, viscosidade, teor de coágulos e conversão final. 


\section{Resultados e discussão}

As composições empregadas nos ensaios se encontram no Anexo 1. Também no Anexo 1 se encontram os dados de temperatura, $T$, alimentações de pré-emulsão, $P E$, e iniciador, Ini, fração de sólidos, $F S$, e diâmetro das partículas, $D_{p}$, para os ensaios.

\subsection{Reprodutibilidade}

Foram realizados quatro ensaios de reprodutibilidade em condições idênticas (Ensaios AS-01, AS-02, AS-03, AS-04), assim como as suas análises. A composição empregada nos ensaios de reprodutibilidade é indicada na Tabela 5.1.1. O processo se mostrou reprodutivo, como se pode notar nos gráficos de conversão e tamanho de partículas em função do tempo (Figuras 5.1.1 e 5.1.2).

Tabela 5.1.1 - Composição empregada nos ensaios de reprodutibilidade

\begin{tabular}{|c|c|c|c|}
\hline Reagente & $\%$ mássica* & Reagente & \% mássica* \\
\hline \multicolumn{2}{|c|}{ REATOR } & \multicolumn{2}{|c|}{ PRÉ-EMULSÃO } \\
\hline Água & 60,2 & $S$ & 50,0 \\
\hline Ultrawet 230 & 2,85 & $A B$ & 50,0 \\
\hline Disponil 25S & 0,55 & $A A$ & 1,50 \\
\hline $\mathrm{NaHCO}_{3}$ & 0,50 & Ultrawet 230 & 0,71 \\
\hline \multicolumn{2}{|c|}{ INICIADORES } & Disponil 25S & 0,14 \\
\hline $\mathrm{Na}_{2} \mathrm{~S}_{2} \mathrm{O}_{8}$ & 0,33 & Água & 25,0 \\
\hline Água & 8,10 & $N D D M$ & 0,10 \\
\hline
\end{tabular}

*em rel. aos monômeros

A Figura 5.1.1 mostra pequena diferença na evolução da conversão entre o experimento AS-03 e os demais para um tempo de reação maior do que 200 minutos. Tal diferença pode ser explicada pelo efeito da temperatura nas taxas de reação, visto que, para o 
experimento $A S-03$, a temperatura foi elevada de $75^{\circ} \mathrm{C}$ para $85^{\circ} \mathrm{C}$ após os 250 minutos de reação, enquanto que esta elevação ocorreu por volta dos 200 minutos para os demais experimentos. Para os ensaios de reprodutibilidade, os desvios padrão para as medidas de conversão e diâmetro médio das partículas foram de $1,0 \%$ e $25,7 \mathrm{~nm}$, respectivamente.

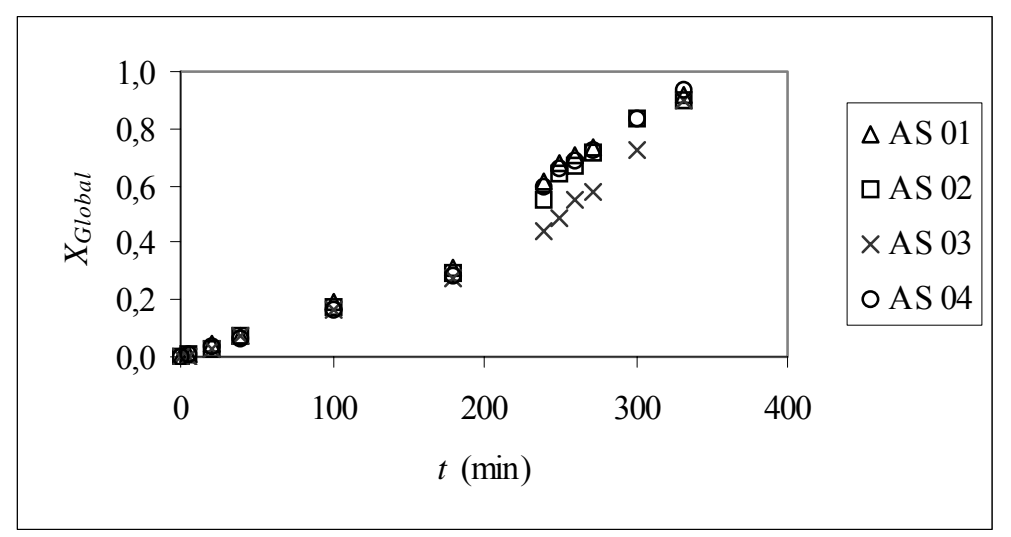

Figura 5.1.1 - Conversão, $X_{\text {Global, }}$, como função do tempo para os ensaios de reprodutibilidade

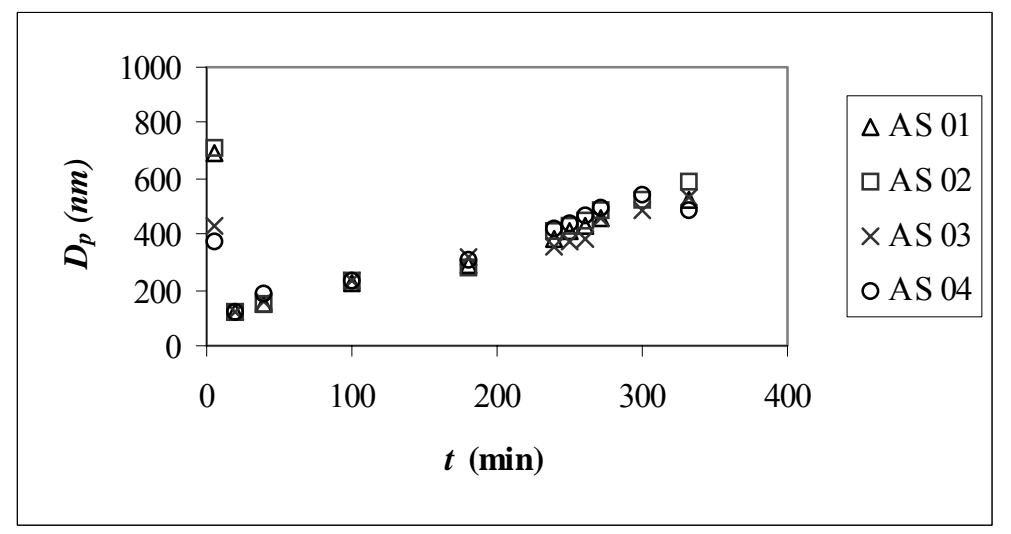

Figura 5.1.2 - Diâmetro médio das partículas, $D_{p}$, como função do tempo para os ensaios de reprodutibilidade.

Foram também realizadas análises do produto final obtido nos ensaios de reprodutibilidade. Para estes ensaios, especificamente, tais análises incluíram determinações da temperatura de transição vítrea $(T g)$ e temperatura mínima de formação de filme (TMFF) realizadas nos equipamentos da Rhodia, unidade de Paulínia. Os resultados, indicados na Tabela 5.1.2, também indicam reprodutibilidade satisfatória. 
Tabela 5.1.2 - Propriedades finais dos látices obtidos para os ensaios de reprodutibilidade.

\begin{tabular}{|c|c|c|c|c|c|}
\hline Ensaio & $\begin{array}{c}\text { Viscosidade } \\
\eta \text { (mPas) }\end{array}$ & $\begin{array}{l}\text { TS } \\
(\%)\end{array}$ & $\begin{array}{l}T P \\
(\%)\end{array}$ & $\begin{array}{l}\mathrm{Tg} \\
\left({ }^{\circ} \mathrm{C}\right)\end{array}$ & $\begin{array}{c}\text { TMFF } \\
\left({ }^{\circ} \mathrm{C}\right)\end{array}$ \\
\hline AS-01 & 18,1 & 48,3 & 46,0 & 22,0 & 20,0 \\
\hline AS-02 & 22,1 & 48,5 & 45,9 & 21,0 & 20,0 \\
\hline AS-03 & 20,8 & 47,7 & 45,4 & 20,0 & 20,0 \\
\hline AS-04 & 20,1 & 49,2 & 47,0 & 19,0 & 20,0 \\
\hline Média & $20,3+/-1,7$ & $48,4+/-0,6$ & $46,1+/-0,7$ & $20,5+/-0,7$ & $20,0+/-0,5$ \\
\hline
\end{tabular}




\subsection{Ensaios Exploratórios}

Os ensaios exploratórios constituem uma série de três ensaios com $T S_{R E C E I T A}$ variando entre 53 e 57\%. (Ensaios AS-05, AS-06 e AS-07, com TS RECEITA de 53, 55 e 57\%, respectivamente). Os resultados foram comparados com resultados de copolimerização em emulsão de acetato de vinila e acrilato de butila na proporção de $80 \%$ de acetato de vinila e receitas com teores de sólido na faixa de 69 a 73\% (PALMA et al., 2004), investigando a influência do teor de sólidos sobre a cinética de polimerização, tamanho médio de partículas e da viscosidade.

\subsubsection{Introdução}

Os látices do copolímero acetato de vinila e acrilato de butila, $A B / A V$, da mesma forma que os de acrilato de butila e estireno, $A B / S$, apresentam grande importância industrial. $O$ copolímero $A B / A V$ com porcentagem mássica de $A B$ de 15 a 25\% (LAZARIDIS et al., 2001) é amplamente utilizado na composição de tintas para arquitetura. Este sistema é caracterizado por grandes diferenças de razões de reatividade $\left(r_{A V}=0,05\right.$ e $\left.r_{A B}=5,5\right)$, solubilidades em água (25 e 1,4 g/L para o $A V$ e $A B$, respectivamente, a $25^{\circ} \mathrm{C}$ ), constantes da taxa de propagação $\left(k_{P(A V)}=4000 \mathrm{~L} / \mathrm{mol} . \mathrm{s}\right.$ e $k_{P(A B)}=200 \mathrm{~L} / \mathrm{mol} . \mathrm{s}$, ambos a $\left.60^{\circ} \mathrm{C}\right)$ e de Temperatura de Transição Vítrea, $T_{g}\left(T_{g(A V)}=32^{\circ} \mathrm{C}\right.$ e $\left.T_{g(A B)}=-54^{\circ} \mathrm{C}\right)$. Devido a estas diferenças significativas nas propriedades dos monômeros, os látices resultantes podem ter diferenças significativas de propriedades morfológicas moleculares e de partículas dependendo da composição do copolímero, que também influencia a $T_{g}$ das emulsões. $O$ sistema $A B / S$ apresenta diferenças menores de várias propriedades relativamente ao sistema $A B / A V$, como, por exemplo, as razões de reatividade $\left(r_{A B}=0,25\right.$ e $\left.r_{S}=0,65\right)$, constantes da taxa de propagação a $60^{\circ} \mathrm{C}\left(\mathrm{k}_{P(A B)}\right.$ $=200 \mathrm{~L} / \mathrm{mol} . \mathrm{s}$ e $\left.k_{P(S)}=389 \mathrm{~L} / \mathrm{mol} . \mathrm{s}\right)$ e solubilidades em água a $25^{\circ} \mathrm{C}(1,4 \mathrm{~g} / \mathrm{L}$ para o $A B$ e 0,7 
$\mathrm{g} / \mathrm{L}$ para o $S)$. A diferença dos valores de $T_{g}$ é maior do que para o sistema $A B / A V\left(T_{g(A B)}=\right.$ $-54^{\circ} \mathrm{C}$ e $\left.T_{g(S)}=100^{\circ} \mathrm{C}\right)$. Esta diferença significativa dos valores de $T_{g}$ permite obter copolímeros de propriedades de aplicação distintas, variando-se a composição do copolímero. As propriedades relativas dos sistemas $A B / A V$ e $A B / S$ são muito distintas e, por isso, o processo, as características morfológicas dos copolímeros e das partículas também serão significativamente diferentes. As razões de reatividade do sistema $A B / S$ têm valores próximos e assim a composição química deste copolímero será mais homogênea do que para o sistema $A B / A V$. As constantes das taxas de propagação do sistema $A B / S$ também têm valores próximos entre si e cerca de 20 vezes inferiores ao valor da constante do $A V$. Assim a taxa de reação será significativamente menor que para o sistema $A B / S$, o que implicará em tempo de reação maior para este sistema, para as mesmas condições reacionais.

Os produtos químicos utilizados na copolimerização do sistema $A V / A B$ incluem: acetato de vinila de grau comercial (contendo $15 \mathrm{ppm}$ de hidroquinona), fornecido pela Rhodia S.A. e utilizado sem purificação; poli(álcool vinílico), protetor coloidal; hidroperóxido de t-butila 70\% em solução aquosa (Trigonox AW-70 fornecido pela AKZO-Nobel) e formaldeído sulfato de sódio (Cosmolit fornecido pela Cosmoquímica S.A.) iniciadores. As receitas de polimerização para os copolímeros $A B / A V$ e $A B / S$ estão mostradas nas Tabelas 5.2.1 e 5.2.2, respectivamente.

\subsubsection{Resultados e discussão}

Devido à baixa temperatura de ebulição do acetato de vinila em relação aos monômeros acrilato de butila e estireno, foi observada uma alta taxa de evaporação e refluxo de monômero no condensador para a copolimerização do sistema $A V / A B$, não observada no sistema $A B / S$. Devido ao refluxo, a temperatura no reator apresentava um perfil peculiar, atingindo o set-point apenas após o término da adição da pré-emulsão. Por não apresentar 
refluxo, o controle de temperatura no sistema $A B / S$ foi mais uniforme. Para o sistema $A V / A B$ foi utilizado par de iniciadores redox, pois permitem trabalhar a temperaturas mais baixas. No sistema $A B / S$ foi utilizado iniciador térmico.

Tabela 5.2.1 - Receita empregada na polimerização $A V / A B$

\begin{tabular}{|l|c|c|c|}
\hline \multicolumn{4}{|c|}{ REATOR } \\
\hline \multirow{2}{*}{ Reagente } & \multicolumn{3}{|c|}{ \% Mássica } \\
\cline { 2 - 4 } & $T S=69 \%$ & $T S=71 \%$ & $T S=73 \%$ \\
\hline Água & 15,6 & 13,5 & 11,4 \\
\hline Ultrawet 230 & 2,58 & 2,66 & 2,75 \\
\hline Disponil 25S & 0,504 & 0,517 & 0,535 \\
\hline PVA & 0,277 & 0,286 & 0,294 \\
\hline NaHCO $_{3}$ & 0,324 & 0,334 & 0,343 \\
\hline \multicolumn{4}{|c|}{ PRÉ-EMULSÃO } \\
\hline AV & 51,7 & 53,3 & 54,8 \\
\hline AB & 12,9 & 13,3 & 13,7 \\
\hline Ultrawet 230 & 0,462 & 0,477 & 0,490 \\
\hline Disponil 25S & 0,0900 & 0,0926 & 0,0952 \\
\hline Água & 6,52 & 6,52 & 6,52 \\
\hline NDDM & 0,125 & 0,129 & 0,133 \\
\hline \multicolumn{4}{|c|}{ INICIADORES } \\
\hline Cosmolit & 4,40 & 4,40 & 4,40 \\
\hline Trigonox & 4,40 & 4,40 & 4,40 \\
\hline
\end{tabular}

Tabela 5.2.1 - Receita empregada na polimerização $A B / S$

\begin{tabular}{|l|c|c|c|}
\hline \multicolumn{4}{|c|}{ REATOR } \\
\hline \multirow{2}{*}{ Reagente } & \multicolumn{3}{|c|}{ \% Mássica } \\
\cline { 2 - 4 } & TS=53\% & TS $=55 \%$ & TS $=57 \%$ \\
\hline Água & 25,2 & 28,0 & 25,8 \\
\hline Ultrawet 230 & 1,43 & 1,49 & 1,54 \\
\hline Disponil 25S & 0,279 & 0,290 & 0,301 \\
\hline NaHCO $_{3}$ & 0,250 & 0,260 & 0,270 \\
\hline \multicolumn{4}{|c|}{ PRE-EMULS ̃̂O } \\
\hline $\mathrm{S}$ & 25,0 & 26,0 & 27,0 \\
\hline AB & 25,0 & 26,0 & 27,0 \\
\hline AA & 0,750 & 0,779 & 0,810 \\
\hline Ultrawet 230 & 0,357 & 0,372 & 0,386 \\
\hline Disponil 25S & 0,0700 & 0,0725 & 0,0750 \\
\hline Água & 17,3 & 12,5 & 12,5 \\
\hline $\mathrm{NDDM}^{4}$ & 0,0500 & 0,0525 & 0,0537 \\
\hline \multicolumn{4}{|c|}{ INICIADORES } \\
\hline $\mathrm{Na}_{2} \mathrm{~S}_{2} \mathrm{O}_{8}$ & 0,165 & 0,172 & 0,179 \\
\hline Água & 4,05 & 4,05 & 4,05 \\
\hline
\end{tabular}

A figura 5.2.1 mostra resultados de taxa de polimerização, $R_{p}$, para o sistema $A V / A B$ com $T S_{\text {RECEITA }}=69 \%$, e para o sistema $A B / S$, com $T S_{\text {RECEITA }}=52 \%$. Os resultados mostrados na 
Figura 5.2.1a evidenciam que a taxa de polimerização do sistema $A V / A B$ está limitada pela taxa de adição de monômeros. Esta condição é conhecida por "starved condition" ou de avidez de monômeros. Em contrapartida, os resultados mostrados na Figura 5.2.1b evidenciam que a taxa de polimerização do sistema $A B / S$ é inferior à taxa de adição de monômeros. Esta condição é de excesso de monômeros, para se contrapor à condição de avidez de monômeros observada na figura 5.2.1a.
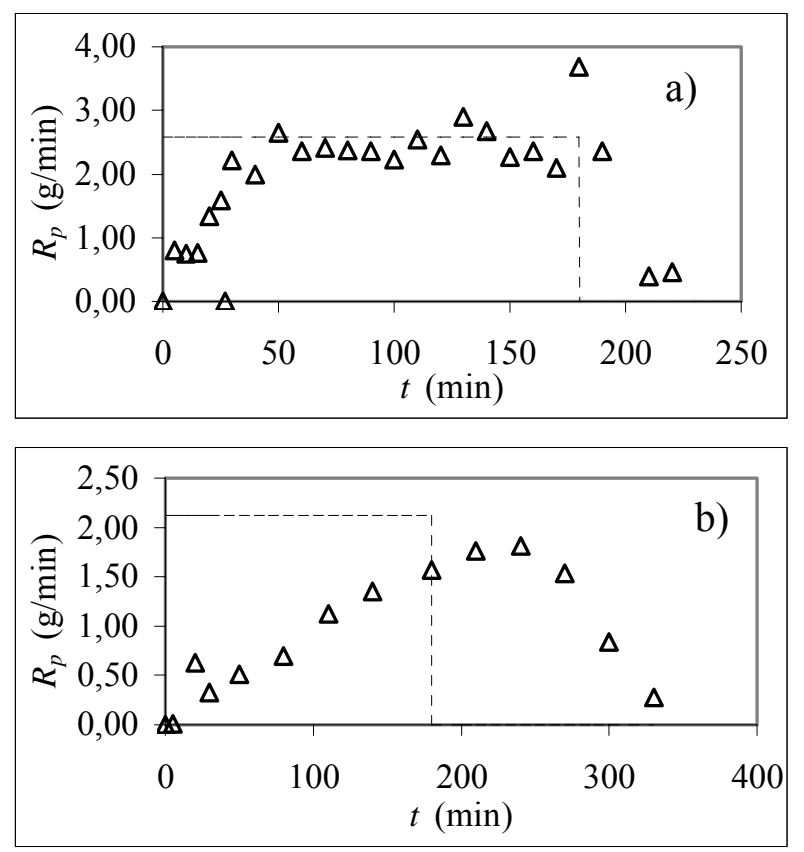

Figura 5.2.1 - Taxa de polimerização, $R p(\Delta)$ e de adição de monômeros (......) dos sistemas: a) $A V / A B(T S=69 \%)$ e b) $A B / S(T S=52 \%)$.

Na Figura 5.2.2 estão mostrados os resultados de fração de sólidos, tamanho médio de partículas e de viscosidade para o sistema $A V / A B$ e $T S_{R E C E I T A}=69,71$ e $73 \%$. A Figura 5.2.2a mostra que a taxa de polimerização (proporcional à inclinação das curvas) é pouco influenciada por $T S_{\text {RECEITA. }}$ Observa-se que com o término da alimentação de pré-emulsão, aos 180 min., ocorre um salto na fração de sólidos devido ao aumento da temperatura de cerca de 87 para $90^{\circ} \mathrm{C}$. Este pequeno aumento de temperatura provoca um aumento significativo da taxa de polimerização devido, principalmente, ao elevado valor da constante da taxa de 
polimerização do $A V\left(k_{p(A V)}=8000 \mathrm{~L} / \mathrm{mol} . \mathrm{s}\right.$ a $\left.90^{\circ} \mathrm{C}\right)$. A Figura 5.2.2b mostra que as partículas são estáveis para os três teores de sólido estudados e, dentro das imprecisões experimentais, os tamanhos médios durante a reação são semelhantes. A Figura 5.2.2c mostra que a viscosidade cresce com o teor de sólidos, sendo o comportamento da emulsão para teor de sólidos $69 \%$ praticamente Newtoniano, e para teor de sólidos $71 \%$ observa-se comportamento dilatante. Para teor de sólidos $73 \%$ foi possível obter apenas um valor de viscosidade de $365.000 \mathrm{mPa} . \mathrm{s}$ a uma taxa de cisalhamento de $0,07 \mathrm{~s}^{-1}$, a $20^{\circ} \mathrm{C}$.
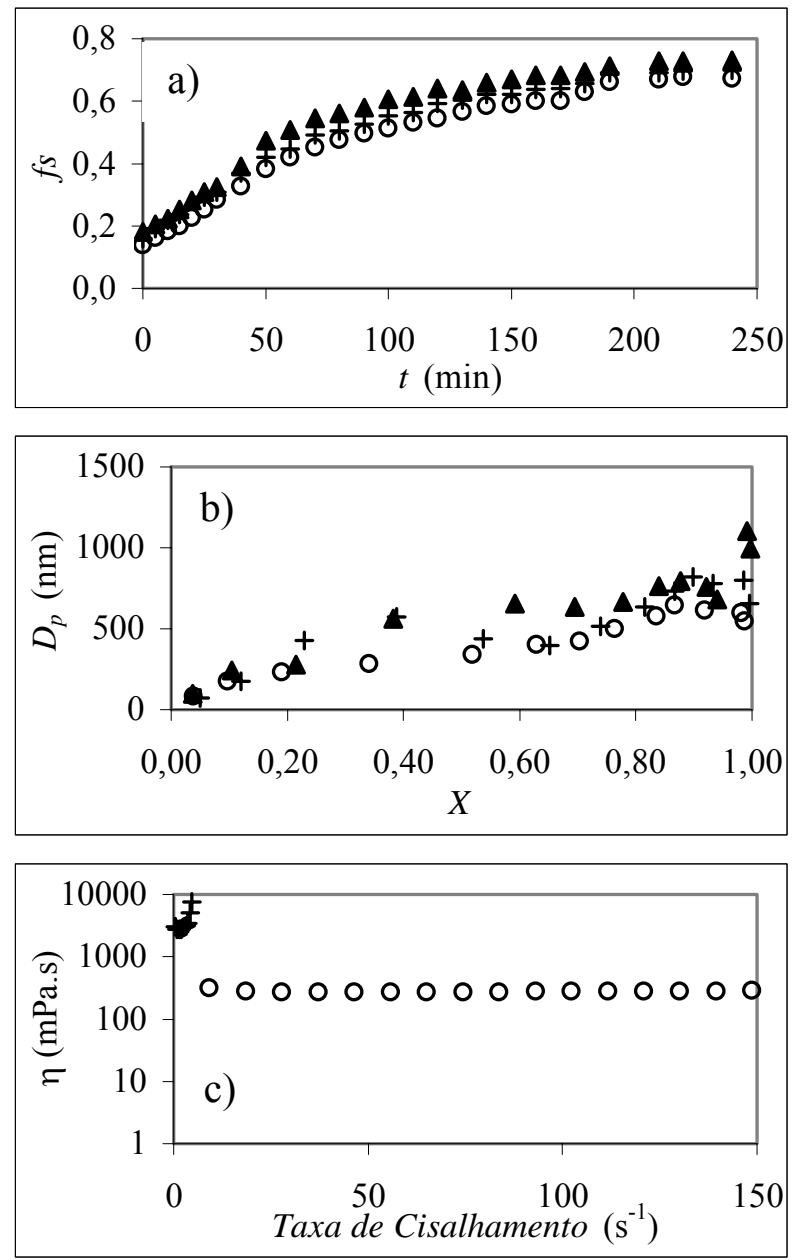

Figura 5.2.2 - Resultados de a) fração de sólidos, $f s$, b) tamanho médio de partículas, $D_{p}$, e de c) viscosidade, $\eta$, a $20^{\circ} \mathrm{C}$ do copolímero $A V / A B$ para os teores de sólidos, $T S_{\text {RECEITA }}=69 \%(\mathrm{O}), T S_{\text {RECEITA }}=71 \%(+)$ e $T S_{\text {RECEITA }}=73 \%(\mathbf{\Delta})$.

Na Figura 5.2.3 estão mostrados os resultados de fração de sólidos, tamanho médio de partículas e de viscosidade para o sistema $A B / S$ e $T S_{R E C E I T A}=52,54$ e $57 \%$. A Figura 5.2.3a mostra que a taxa de polimerização não tem influência significativa para $T S_{\text {RECEITA }}=52$ e $54 \%$. 
Para $T S_{R E C E I T A}=57 \%$ a taxa de polimerização é maior no período compreendido entre 150 e 210 min. A Figura 5.2.3b mostra que as partículas são estáveis durante a reação para $T S_{R E C E I T A}=52,54$ e $57 \%$, e que os tamanhos médios são semelhantes desde o início da reação até conversão de $85 \%$. Para valores maiores de conversão as partículas crescem com $T S_{\text {RECEITA }}$.
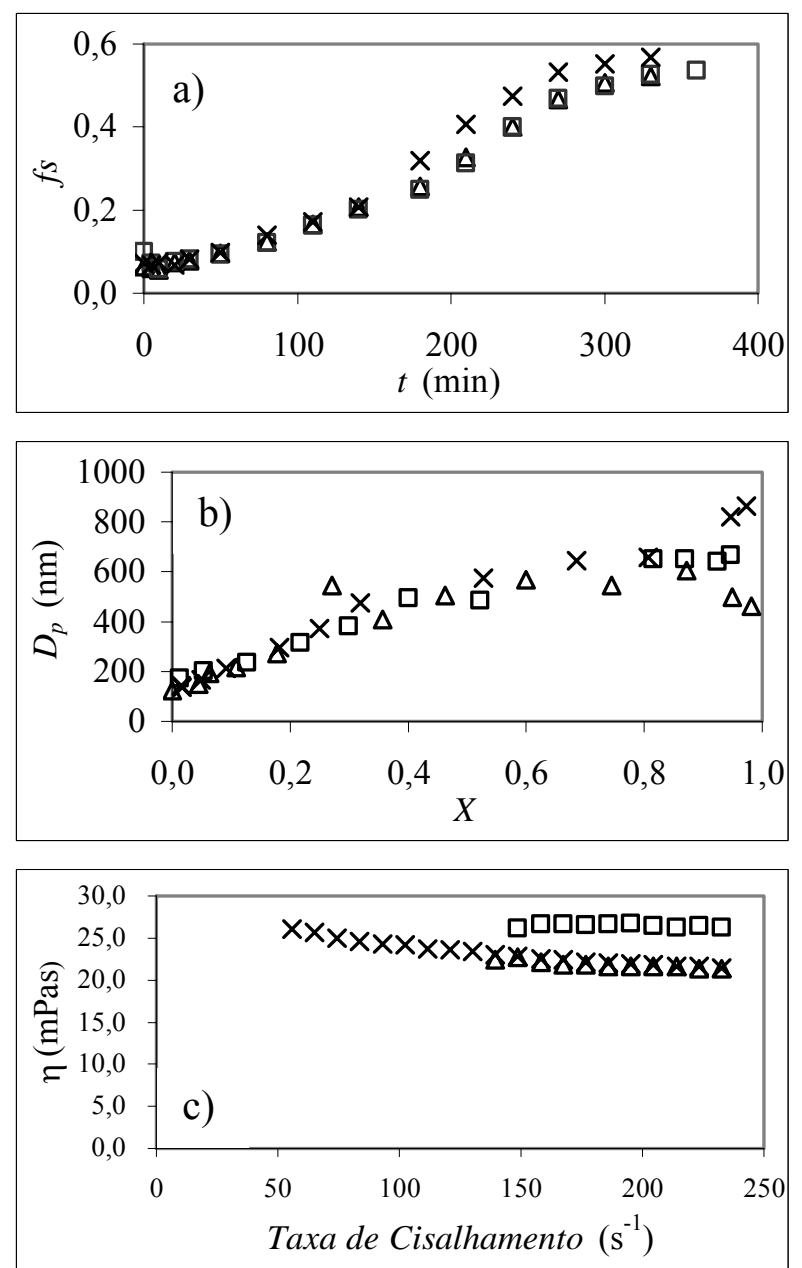

Figura 5.2.3 - Resultados de a) fração de sólidos, $f s$, b) tamanho médio de partículas, $D_{p}$, e de c) viscosidade, $\eta$, a $20^{\circ} \mathrm{C}$ do copolímero $A B / S$ para os teores de sólidos, $T S_{\text {RECEITA }}=52 \%(\Delta), T S_{\text {RECEITA }}=54 \%(\square)$ e $T S_{\text {RECEITA }}=57 \%(\mathrm{x})$.

A Figura 5.2.3c mostra que a viscosidade é muito pouco influenciada pelo teor de sólidos variando de 52 a $57 \%$. Os resultados para $T S_{R E C E I T A}=52$ e $57 \%$ foram coincidentes, tendo valor aproximado de $22 \mathrm{mPa} . \mathrm{s}$, enquanto que para $T S_{\text {RECEITA }}=54 \%$ a viscosidade foi de $27 \mathrm{mPa} . \mathrm{s}$, para taxa de cisalhamento $230 \mathrm{~s}^{-1}$. O comportamento reológico das emulsões é 
predominantemente Newtoniano para os três valores de $T S_{R E C E I T A}$ estudados e para toda a faixa de taxa de cisalhamento. O comportamento Newtoniano é uma característica desejável das emulsões, pois permite diminuir custos de equipamentos de agitação, bombas e de tubulações para transferência.

\subsubsection{Conclusões}

A alta taxa de polimerização do $A V$ fez com que o processo de polimerização $A V / A B$ ocorresse sob condição de avidez de monômeros ao longo de quase toda a reação, para as condições estudadas. Esta condição de operação é interessante porque assim é possível obter copolímeros com composição química mais uniforme, independentemente das razões de reatividade dos monômeros. Por outro lado, as baixas taxas de polimerização do $A B$ e $S$ fizeram com que o processo de polimerização $A B / S$ ocorresse sob condição de excesso de monômeros, havendo formação de gotas de monômeros na fase aquosa. Mas, devido às razões de reatividade do $A B$ e $S$ na copolimerização $A B / S$ serem próximas, se espera que o copolímero formado tenha composição razoavelmente homogênea. Para se proceder a reação na condição de avidez de monômeros, e garantir uma melhor homogeneidade do copolímero formado, a melhor possibilidade seria diminuir a taxa de alimentação de monômeros, visto que a temperatura da reação e as concentrações de iniciador e emulsificantes já são relativamente altas. É importante lembrar que a concentração de sais é um fator muito importante na estabilidade coloidal.

Os tamanhos de partículas obtidos para as emulsões $A V / A B$ foram relativamente grandes (500 a 1000nm) mostrando condição limite de estabilidade coloidal e de teor de sólidos. Contudo, as viscosidades destas emulsões foram relativamente baixas, menores que $500 \mathrm{mPa} . \mathrm{s}$ na temperatura da reação, indicando que tal processo, mesmo para os elevados teores de sólidos alcançados, poderia ser assimilado aos equipamentos atualmente utilizados 
na indústria. As emulsões obtidas para o sistema $A B / S$ apresentaram até $57 \%$ de sólidos totais, que é o valor praticado atualmente na indústria. Os tamanhos de partículas foram grandes (400 a $800 \mathrm{~nm}$ ) e da mesma ordem que para o sistema $A B / A V$, também evidenciando a condição limite do processo e o compromisso dos componentes da receita de polimerização com a estabilidade coloidal. Contudo, as viscosidades destas emulsões foram extremamente baixas, da ordem de $25 \mathrm{mPa} . \mathrm{s}$ a $20^{\circ} \mathrm{C}$, indicando que há possibilidade de se explorar maiores valores de teor de sólidos para este sistema e que a formulação e processo utilizados representam uma inovação tecnológica. 


\subsection{Influência do emulsificante e do ácido acrílico sobre a copolimerização de acrilato de butila/estireno com alto teor de sólidos em processo semibatelada}

O estudo dos efeitos do ácido acrílico e do emulsificante foi realizado a partir de receita com teor de sólidos de $57 \%$ (teor de polímeros $T P_{\text {RECEITA }}=54 \%$ ). Este estudo compreende os ensaios $A S-07$ a $A S-17$.

\subsubsection{Introdução}

A estabilidade de um látice é um assunto de importância, pois afeta as aplicações possíveis para este látice. Para aplicações onde se deseja separar o polímero da emulsão, a separação pode ser auxiliada por uma redução na estabilidade. Por outro lado, nas aplicações onde o produto é utilizado na forma de látice, a estabilidade ajuda a manter as características do produto e o seu prazo de validade. Durante a reação, a estabilidade do látice é ainda mais importante, pois, em alguns casos, a desestabilização pode ocasionar danos em equipamentos.

Na polimerização em emulsão com alto teor de sólidos a interação entre as partículas é um assunto ainda mais delicado, pois, neste caso, as partículas estão bastante próximas. A proximidade influencia na interação entre as partículas e nos fenômenos de coalescência entre as mesmas. A coalescência entre as partículas pode resultar na formação de partículas maiores ou agregados de partículas que tendem a se separar da emulsão quanto maior for o seu tamanho.

O papel empenhado pelos emulsificantes na estabilização do látice é de suma importância, pois estes são compostos de uma parte hidrofóbica que se fixa às partículas e uma parte hidrofílica que garante a estabilidade da partícula na emulsão. Além disso, o uso de emulsificantes iônicos e não-iônicos ajuda a conferir forças de repulsão elétrica e entrópica entre as partículas evitando assim a coagulação entre partículas. Contudo, os emulsificantes 
também apresentam outros papéis na polimerização em emulsão, sendo responsáveis pela nucleação de novas partículas quando sua concentração está acima da $C M C$.

O uso de monômeros funcionais, como o ácido acrílico, também auxilia na estabilização do látice. Tais monômeros atuam no processo como um estabilizante polimérico formando cadeias relativamente hidrofílicas firmemente ligadas à superfície das partículas auxiliando na estabilização estérica entre as partículas.

Neste estudo, uma série de ensaios foi realizada visando verificar a influência destes dois componentes, os emulsificantes e o ácido acrílico, na polimerização em emulsão de acrilato de butila e estireno. Para tanto, foram realizados os ensaios AS-07 a $A S-13$, cujas receitas se encontram na Tabela 5.3.1.

As quantidades de emulsificante não-iônico, E1, emulsificante iônico, E2, e ácido acrílico, AA1, empregadas na carga inicial da receita e as propriedades finais dos látices obtidos se encontram na Tabela 5.3.2.

Tabela 5.3.1 - Receita de polimerização de $\mathrm{AB} / \mathrm{S}(\%$ em relação à massa total de monômero da receita)

\begin{tabular}{|c|c|c|c|}
\hline Reagente & $\%$ mássica & Reagente & $\%$ mássica \\
\hline \multicolumn{2}{|c|}{ REATOR } & \multicolumn{2}{|c|}{ PRÉ-EMULSÃO } \\
\hline Água & 47,8 & $\mathrm{~S}$ & 50,0 \\
\hline Ultrawet 230 & E1 & $\overline{\mathrm{AB}}$ & 50,0 \\
\hline Disponil 25S & E2 & $\mathrm{AA}$ & 1,50 \\
\hline$\overline{\mathrm{AA}}$ & $\overline{\text { AA1 }}$ & Ultrawet 230 & 0,72 \\
\hline $\mathrm{NaHCO}_{3}$ & 0,50 & Disponil 25S & 0,14 \\
\hline \multicolumn{2}{|c|}{ INICIADORES } & Água & 23,2 \\
\hline $\mathrm{Na}_{2} \mathrm{~S}_{2} \mathrm{O}_{8}$ & 0,33 & $\overline{\text { NDDM }}$ & 0,10 \\
\hline Água & 7,48 & & \\
\hline
\end{tabular}

\subsubsection{Resultados e Discussão}

A Tabela 5.3.2 mostra as propriedades finais dos látices obtidos nos ensaios AS-07 a AS-13, em termos de teor de polímeros, teor de sólidos, diâmetro médio das partículas, 
conversão global e viscosidade. A Tabela 5.3.3 relaciona os resultados de teor de coágulos de amostras retiradas logo após os ensaios e de amostras armazenadas durante um período de cerca de 1 ano em temperatura ambiente.

Tabela 5.3.2 - Quantidades de emulsificante não-iônico, E1, emulsificante iônico, E2, ácido acrílico, AA1, empregadas na carga inicial das receitas $A S-07$ a $A S-13$ (\% em relação à massa total de monômero da receita), e as propriedades finais de teor de polímeros, TP, teor de sólidos, TS, diâmetro médio das partículas, $D_{P}$, conversão global, $X_{\text {global }}$ e viscosidade, $\eta$, dos látices obtidos.

\begin{tabular}{|c|c|c|c|c|c|c|c|c|c|}
\hline Ensaio & $E 1$ & $E 2$ & AA1 & $\begin{array}{l}T P \\
(\%) \\
\end{array}$ & $\begin{array}{l}T S \\
(\%)\end{array}$ & $\begin{array}{l}D_{P} \\
(n m)\end{array}$ & $X_{\text {global }}$ & $\begin{array}{c}\text { Queda Final } \\
\text { de Dp }\end{array}$ & $\begin{array}{c}\eta \\
\text { (mPa.s) }\end{array}$ \\
\hline$A S-07$ & 2,86 & 0,56 & 0,00 & 53,9 & 56,8 & 862 & 0,889 & Não & 23,0 \\
\hline AS-08 & 2,86 & 0,56 & 1,00 & 52,1 & 54,4 & 593 & 0,915 & Não & 53,5 \\
\hline AS-09 & 2,86 & 0,56 & 2,00 & 53,9 & 56,8 & 862 & 0,919 & Não & 301,4 \\
\hline$A S-10$ & 3,75 & 0,73 & 0,00 & 50,7 & 53,0 & 310 & 0,894 & Sim & 68,5 \\
\hline AS-12 & 3,75 & 0,73 & 1,00 & 51,3 & 53,8 & 571 & 0,910 & Não & 158,3 \\
\hline$A S-11$ & 4,64 & 0,91 & 0,00 & 41,9 & 44,5 & 642 & 0,743 & Sim & 59,4 \\
\hline AS-13 & 4,64 & 0,91 & 2,00 & 51,9 & 54,8 & 778 & 0,923 & Não & 263,9 \\
\hline
\end{tabular}

Tabela 5.3.3 - Teor de coágulos após ensaio e após 1 ano de armazenamento para os ensaios AS-07 a $A S-13$.

\begin{tabular}{|c|c|c|c|c|c|}
\hline Ensaio & $\boldsymbol{E 1}$ & $\boldsymbol{E} 2$ & $\boldsymbol{A A 1}$ & $\begin{array}{c}\text { Coágulos após } \\
\text { ensaio (PPM) }\end{array}$ & $\begin{array}{c}\text { Coágulos após } \\
\text { 1 ano (PPM) }\end{array}$ \\
\hline$A S-07$ & 2,86 & 0,56 & 0,00 & 12809 & 12173 \\
\hline$A S-08$ & 2,86 & 0,56 & 1,00 & 10809 & 10074 \\
\hline$A S-09$ & 2,86 & 0,56 & 2,00 & 5602 & 6692 \\
\hline$A S-10$ & 3,75 & 0,73 & 0,00 & 40467 & 21695 \\
\hline$A S-12$ & 3,75 & 0,73 & 1,00 & 7052 & 8672 \\
\hline$A S-11$ & 4,64 & 0,91 & 0,00 & 76738 & 14408 \\
\hline$A S-13$ & 4,64 & 0,91 & 2,00 & 14101 & 16869 \\
\hline
\end{tabular}

As Tabelas 5.3.2 e 5.3.3 mostram que, aumentando-se a concentração de ácido acrílico na receita obtêm-se um produto final com maior viscosidade, mas com maior estabilidade e com um teor de coágulos menor. Acréscimos maiores na concentração de ácido acrílico aumentam demasiadamente a viscosidade, e ocasiona a separação de duas fases dentro do reator. 
Por outro lado, aumentando-se a quantidade de emulsificante na carga inicial, o látice se tornou muito instável, com uma grande quantidade de coágulos formados.

A coluna "Queda Final no $D_{P}$ " refere-se à tendência de queda no diâmetro médio das partículas, observada nos ensaios $A S-10$ e $A S-11$, a partir de certo ponto do ensaio. Tal queda revela a instabilidade das partículas formadas, que se separaram da emulsão provavelmente por processo de coagulação, restando na emulsão apenas as partículas de menor diâmetro. A Figura 5.3.1a nos dá uma visão da magnitude desta queda.
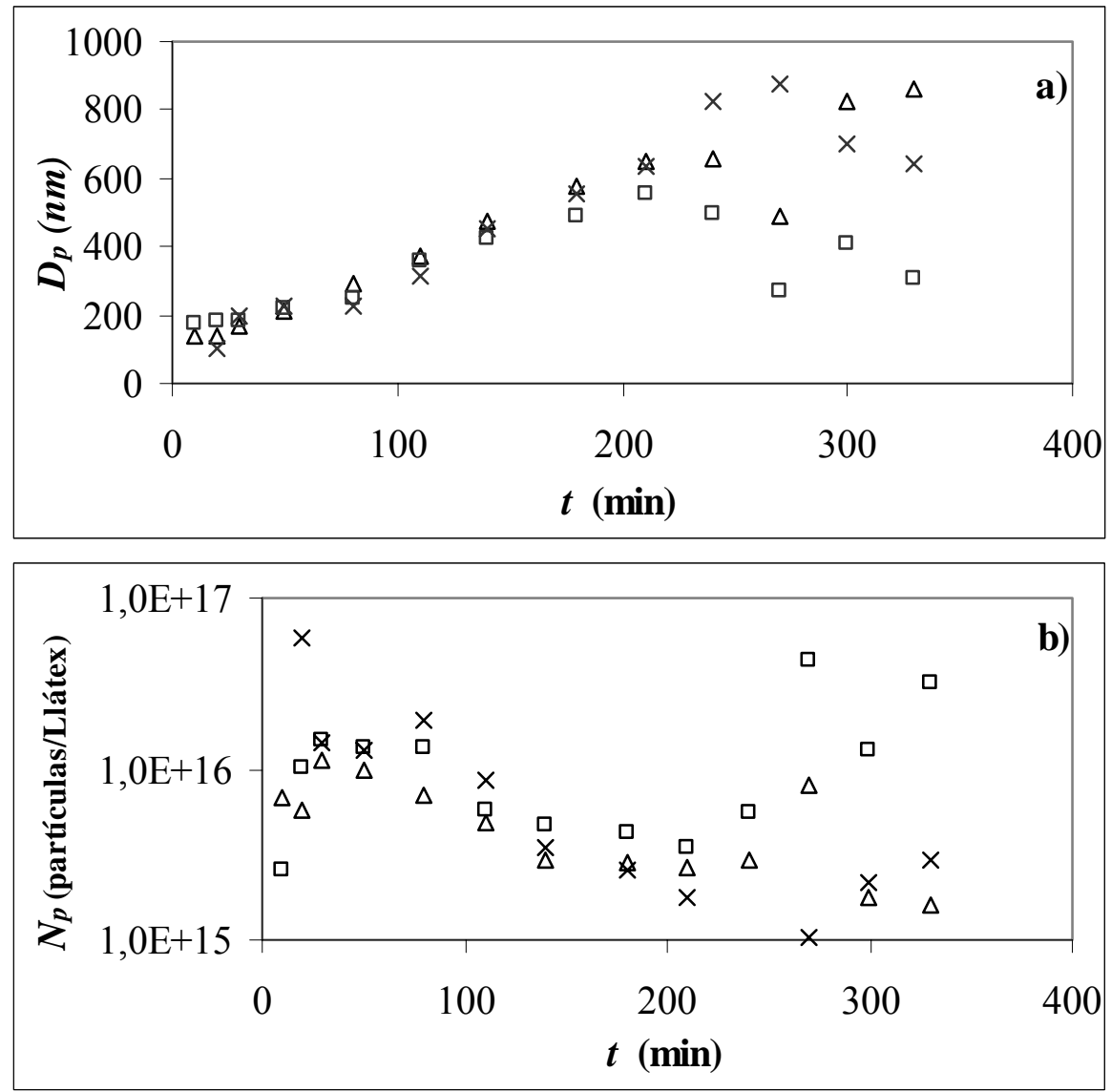

Figura 5.3.1 - a) Diâmetro médio das partículas; e b) Concentração de partículas para diferentes concentrações de emulsificante na receita $(4.3 \%(\Delta), 5.3 \%(\square)$ e $6.4 \%$ (x) em massa do total de emulsificante em relação aos monômeros, respectivamente $A S-07, A S-10$ e $A S-11)$.

Tal instabilidade encontrada nos ensaios $A S-10$ e $A S-11$ deve-se à formação de um maior número de partículas devido à maior concentração de emulsificantes (Figura 5.3.1b). O 
aumento no número de partículas reduziu a distância entre as partículas, facilitando a sua coalescência. Os valores finais de TS para estes ensaios confirmam a instabilidade destes ensaios, pois foram mais baixos em relação aos outros ensaios, mostrando que parte do polímero separou-se da emulsão.

Embora mostrassem a tendência de formar depósitos no fundo do frasco, os látices mostraram boa estabilidade durante o tempo de armazenamento. Após agitação, a análise do teor de coágulos das amostras armazenadas mostrou pouca variação em relação aos valores medidos logo após os ensaios. A queda no teor de coágulos verificada para os ensaios $A S-10$ e AS-11 provavelmente deve referir-se às perdas de polímero durante as etapas de armazenamento e transferência, em virtude da baixa estabilidade destes ensaios.

A influência do ácido acrílico da receita na viscosidade do látice pode ser melhor observada na Figura 5.3.2.

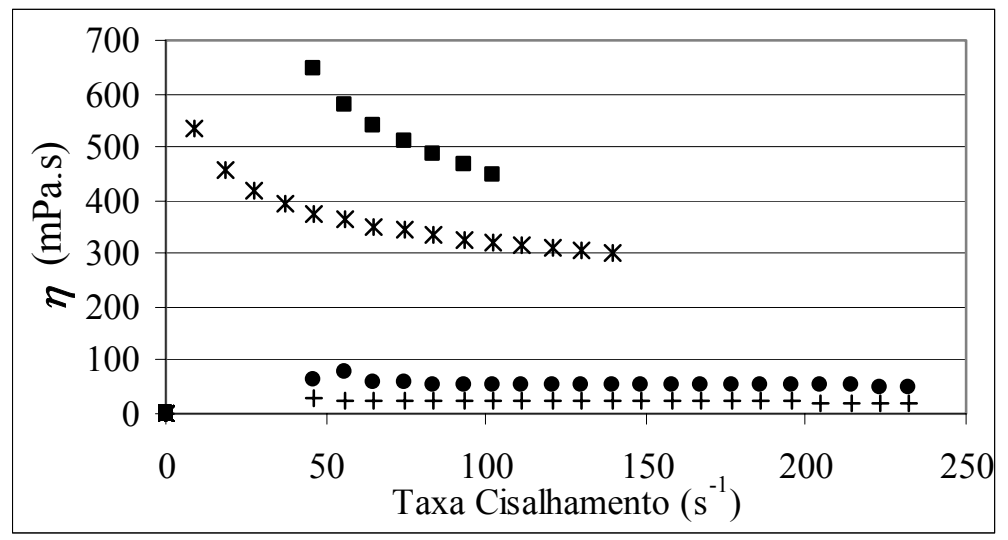

Figura 5.3.2 - Viscosidade, $\eta$, do látice em função da taxa de cisalhamento para diferentes concentrações de ácido acrílico na receita $\left(1,5 \%(+), 2,5 \%(\bullet), 3,5 \%\left(^{*}\right)\right.$ e $5,0 \%$ (匹) em massa do total de ácido acrílico na receita em relação aos monômeros, respectivamente AS-07, AS-08, AS-09 e AS-17).

A Figura 5.3.2 mostrou um aumento significativo da viscosidade dos látices com maior quantidade de ácido acrílico na receita. $\mathrm{O}$ aumento na quantidade de ácido acrílico na receita provavelmente ocasiona uma maior formação de cadeias de poli(ácido acrílico) não ligadas às partículas (livres) e que, por apresentarem razoável solubilidade na fase aquosa, 
atuam como espessante da mesma. Para os ensaios AS-09 e AS-17 observou-se a separação de fases no reator. Tal separação é possivelmente efeito do fenômeno de "floculação por esgotamento". Este fenômeno é resultado de duas regiões na emulsão: uma região entre as partículas onde há dificuldade de acesso e desta forma apresenta baixa concentração de cadeias de poli(ácido acrílico) livres, e uma região com alta concentração destas cadeias. Esta diferença de concentrações na emulsão acarreta uma força de atração entre as partículas que floculam e se separam da emulsão, por efeito da pressão osmótica.

\subsubsection{Conclusões}

Neste estudo verificaram-se os efeitos da quantidade de ácido acrílico como monômero funcional e emulsificantes iônico e não-iônico na polimerização em emulsão de acrilato de butila e estireno com alto teor de sólidos. Apesar de sua função estabilizante, o aumento na concentração de emulsificante para as condições estudadas ocasionou uma desestabilização das partículas devido à maior formação de partículas no início do processo.

O aumento na concentração de ácido acrílico na receita levou a uma maior estabilidade das partículas acompanhada de um aumento na viscosidade. Contudo, para altas concentrações de ácido acrílico, a viscosidade aumenta significativamente e ocorre uma desestabilização da emulsão com a separação em duas fases.

Neste estudo, a receita do ensaio AS-08, com 4,3\% de emulsificante (iônico e não iônico) e 2,5\% de ácido acrílico (totais em relação aos monômeros, incluindo a carga inicial e a pré-emulsão), foi considerada como a mais estável, em virtude dos valores relativamente baixos de teor de coágulos e viscosidade. 


\subsection{Influência do teor de sólidos sobre a copolimerização de acrilato de butila/estireno com alto teor de sólidos em processo semibatelada}

Este estudo corresponde a uma série de quatro ensaios com $T S_{\text {RECEITA }}$ variando entre

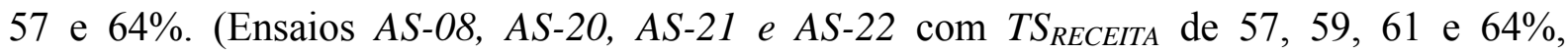
respectivamente). Teores de sólidos com valores entre 54 e $58 \%$ em massa foram obtidos e sua influência, tanto no processo como no produto, foram verificadas. Durante o período de reação foram obtidas curvas de conversão, diâmetro médio das partículas, concentração de partículas, número médio de radicais por partícula e taxa de polimerização. Do produto final, foi caracterizado o diâmetro das partículas, a concentração das partículas, a viscosidade e a fração de coágulos.

\subsubsection{Introdução}

Látices com altos teores de sólidos são interessantes devido a muitos fatores, como redução de custos de transporte e estocagem e melhores características de cobrimento e secagem dos filmes (BOUTTI et al., 2004). Por outro lado, processos com altos teores de sólidos tendem a apresentar características de processo mais severas principalmente devido à maior viscosidade e menor estabilidade do látex. Nestas condições, pequenas variações no teor de sólidos produzem drásticas mudanças na viscosidade. A fração de sólidos é, portanto, um dos fatores mais importantes no controle da viscosidade do látex. Para teores de sólidos abaixo de 1\% (em volume), não há significativa interação entre as partículas e a reologia é Newtoniana. Para teores de sólidos acima de 25\%, as partículas estão relativamente próximas umas das outras, predominando a interação entre partículas sobre a interação partícula-fluído. Nestas condições, a viscosidade aumenta rapidamente, sobretudo, próximo ao valor máximo 
de teor de sólidos possível, ou seja, 74\% para esferas monodispersas com empacotamento hexagonal.

A distribuição de tamanhos de partículas e a estabilidade do látex são as características mais importantes a serem consideradas nos látices com alta concentração de sólidos, pois influem significativamente na viscosidade e no teor máximo de sólidos possível de ser atingido (SCHALLER, 1997).

Para alto teor de sólidos, uma das equações que relacionam a fração volumétrica das partículas, $\phi$, em uma dispersão com a sua viscosidade relativa, $\eta_{r}$, é a equação de DoughertyKrieger:

$$
\eta_{r}=\left(1-\frac{\phi}{\phi_{m}}\right)^{-2,5 \phi_{m}}
$$

Nesta equação, à medida que a fração de partículas (esféricas e de mesmo tamanho) se aproxima da fração máxima, $\phi_{m}$, a viscosidade tende a um valor infinito. A fração máxima é estimada através da compactação máxima de partículas esféricas rígidas e situa-se entre 0,74 (compactação hexagonal) e 0,52 (compactação esférica). Contudo, partículas em um látex dificilmente podem ser consideradas como esferas rígidas. Forças de atração, de repulsão eletrostática e estérica, e o diâmetro das partículas interferem no comportamento reológico do látex.

\subsubsection{Resultados e discussão}

As receitas de polimerização para os diferentes teores de polímero, $T P_{\text {receita, estão }}$ mostradas nas Tabela 5.4.1, para uma massa total na receita de $800 \mathrm{~g}$. A Figura 5.4.1 mostra os dados de evolução, durante o período de reação, da conversão global $\left(X_{\text {global }}\right)$, diâmetro médio das partículas $\left(D_{p}\right)$, concentração de partículas $\left(N_{p}\right)$, número médio de radicais por partículas

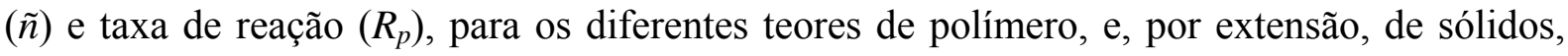


empregados na receita.

Tabela 5.4.1 - Receitas de Polimerização de $A B / S$ (\% em relação à massa total da receita)

\begin{tabular}{|c|c|c|c|c|}
\hline \multirow{2}{*}{ Reagente } & \multicolumn{5}{|c|}{ REATOR } \\
\cline { 2 - 5 } & $\mathbf{5 4}$ & $\mathbf{5 6}$ & $\mathbf{5 8}$ & $\mathbf{6 0}$ \\
\hline Água & 25,3 & 22,2 & 19,5 & 16,9 \\
\hline Ultrawet 230 & 1,54 & 1,59 & 1,65 & 1,70 \\
\hline Disponil 25S & 0,30 & 0,31 & 0,33 & 0,33 \\
\hline AA & 0,55 & 0,56 & 0,58 & 0,60 \\
\hline $\mathrm{NaHCO}_{3}$ & 0,27 & 0,28 & 0,29 & 0,30 \\
\hline & \multicolumn{5}{|c|}{ PRÉ-EMULSÃO } \\
\hline $\mathrm{S}$ & 27,0 & 28,0 & 29,0 & 30,0 \\
\hline $\mathrm{AB}$ & 27,0 & 28,0 & 29,0 & 30,0 \\
\hline $\mathrm{AA}$ & 0,81 & 0,84 & 0,86 & 0,89 \\
\hline Ultrawet 230 & 0,39 & 0,40 & 0,41 & 0,43 \\
\hline Disponil 25S & 0,08 & 0,08 & 0,08 & 0,08 \\
\hline Água & 12,5 & 13,9 & 14,4 & 14,9 \\
\hline $\mathrm{NDDM}^{2}$ & 0,05 & 0,06 & 0,06 & 0,06 \\
\hline \multicolumn{5}{|c|}{ INICIADOR } \\
\hline $\mathrm{Na}_{2} \mathrm{~S}_{2} \mathrm{O}_{8}$ & 0,18 & 0,18 & 0,19 & 0,20 \\
\hline Água & 4,04 & 4,02 & 4,01 & 3,99 \\
\hline
\end{tabular}

OBS: Os valores de teores de sólidos na receita, $T S_{R E C E I T A}$, foram 57.6, 59.3, 61.4 e 63.5\%, respectivamente.

$\mathrm{Na}$ análise dos resultados da Figura 5.4.1a observa-se que o $T P_{R E C E I T A}$ não influencia significativamente a conversão global ao longo da reação para os quatro teores de sólidos estudados. Isto se deve à pequena variação entre os $T P_{R E C E I T A}$ estudados.

A análise dos resultados da Figura 5.4.1b mostra que $T P_{R E C E I T A}$ não influencia significativamente os resultados de $D_{p}$ ao longo da reação para $T P_{R E C E I T A}=54,56$ e $58 \%$, variando de cerca de $200 \mathrm{~nm}$, no início da reação, a cerca de $600 \mathrm{~nm}$, no final da reação. Os resultados para $T P_{\text {RECEITA }}=60 \%$ são significativamente maiores, e variaram de cerca de $400 \mathrm{~nm}$, no início da reação, a $800 \mathrm{~nm}$, no final da reação. $O$ aumento de $D_{p}$ para $T P_{R E C E I T A}=$ $60 \%$ deve-se à redução da quantidade de água da receita ao aumentar-se o teor de sólidos. Ocorre, desta forma, uma maior concentração de outros componentes na fase aquosa, como o tampão, ocasionando um aumento da força iônica do meio. $\mathrm{O}$ aumento da força iônica induz a 
coalescência das partículas recém-formadas resultando na formação de partículas estáveis maiores. $\mathrm{O}$ maior teor de sólidos para $T P_{\text {RECEITA }}=60 \%$ também provocou maior coalescência das partículas como resultado da maior proximidade e interação partícula-partícula resultando em partículas finais maiores.

O número de partículas formadas é reduzido quanto maior o $T P_{\text {RECEITA }}$ (Figura 5.4.1c). Para este sistema, isto ocorre principalmente devido à maior força iônica do meio quanto mais alto o $T P_{R E C E I T A}$ e resultou na formação de um menor número de partículas estáveis de maior diâmetro. A queda na concentração de partículas observada para os ensaios com $T P_{\text {RECEITA }}=$ 54, 56 e 58\%, é resultado da diluição das partículas formadas no início devido à alimentação da pré-emulsão.
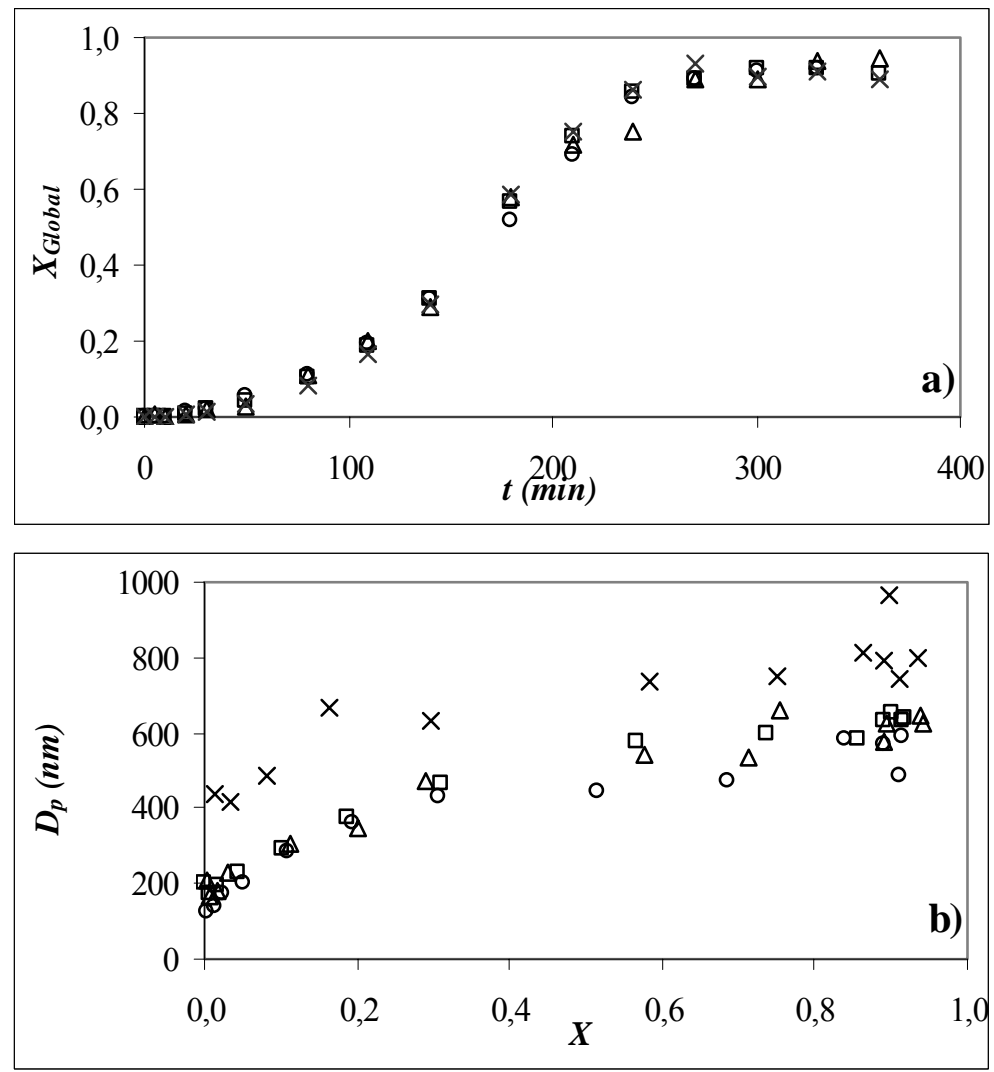

Figura 5.4.1 - Evolução durante o período de reação de: a) Conversão global, $X_{\text {Global; b) }}$ Diâmetro médio das partículas, $D_{p}$; c) Concentração de partículas, $\mathrm{N}_{\mathrm{p}} ;$ d) Número médio de radicais por partícula, $\tilde{n}$; e e) Taxa de polimerização*, $R p$, para: $T P_{\text {RECEITA }}=54 \%(\mathrm{o}) ; T P_{\text {RECEITA }}=56 \%(\Delta) ; T P_{\text {RECEITA }}=58 \% \quad(\square) ; \quad \mathrm{e}$ $T P_{\text {RECEITA }}=60 \%(\times)$ * (-------) Taxa de adição de monômeros. (continua) 

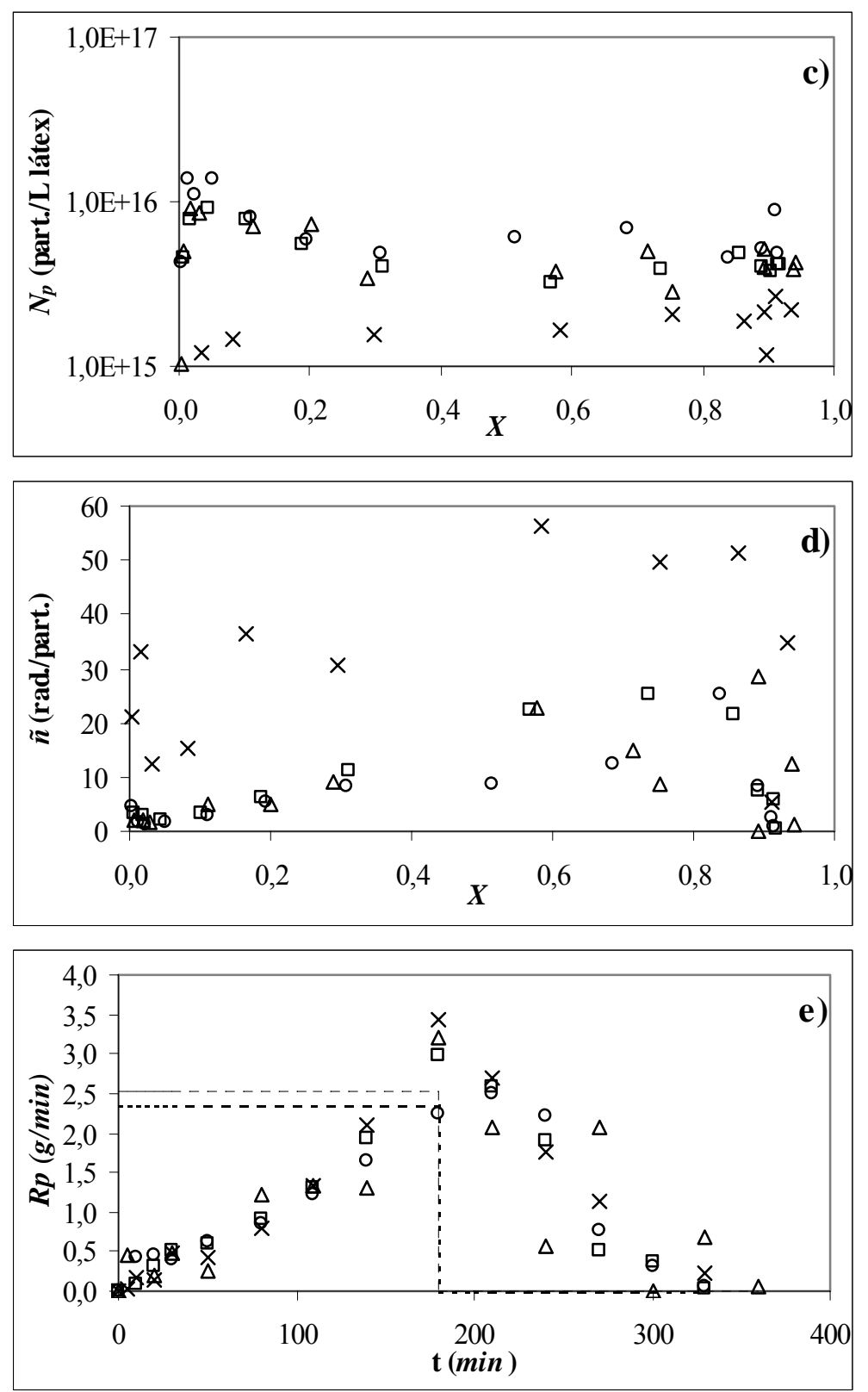

Figura 5.4.1 - Evolução durante o período de reação de: a) Conversão global, $X_{\text {Global }}$; b) Diâmetro médio das partículas, $D_{p}$; c) Concentração de partículas, $\mathrm{N}_{\mathrm{p}} ;$ d) Número médio de radicais por partícula, $\tilde{n}$; e e) Taxa de polimerização*, $R p$, para: $T P_{\text {RECEITA }}=54 \%(\mathrm{o}) ; T P_{\text {RECEITA }}=56 \%(\Delta) ; T P_{\text {RECEITA }}=58 \%(\square) ; \mathrm{e}$ $T P_{\text {RECEITA }}=60 \%(\times) *(------)$ Taxa de adição de monômeros. (conclusão).

Os valores de número médio de radicais por partícula (Figura 5.4.1d) apresentaram uma tendência de aumento quanto maior o $T P_{R E C E I T A}$ empregado. Isto concorda com o aumento no diâmetro médio das partículas observado, uma vez que as partículas maiores apresentam maior dificuldade à difusão dos radicais, o que pode dificultar a dessorção dos radicais ou as reações de terminação dos radicais oligoméricos ou poliméricos dentro das 
partículas.

A figura 5.4.1e mostra que as taxas de polimerização foram menores que as taxas de adição de monômeros durante quase todo o período de adição. Tal ocorrência era esperada em vista dos relativamente baixos coeficientes das taxas de propagação dos monômeros $\left(k_{p(A B)}=390 \mathrm{~L} / \mathrm{mol} . \mathrm{s}\right.$ e $k_{p(S)}=800 \mathrm{~L} / \mathrm{mol} . \mathrm{s}$, a $\left.85^{\circ} \mathrm{C}\right)$. Isto significa que o processo operou em condição de excesso de monômeros, o oposto da condição de avidez de monômeros. Esta última é desejável para a obtenção de um produto de composição homogênea, sendo, neste caso, condição necessária quando os monômeros apresentam razões de reatividade muito diferentes. Como os monômeros empregados apresentam razões de reatividade razoavelmente próximas $\left(r_{A B}=0,2\right.$ e $\left.r_{S}=0,65\right)$, a composição química dos polímeros é pouco influenciada pelas taxas de adição de monômero e devendo ser, portanto, razoavelmente homogênea. A taxa de polimerização apresenta uma pequena variação entre os ensaios, próxima ao final da adição de monômeros, quando a concentração de monômeros é máxima. Analisando os termos da expressão para taxa de polimerização (eq. 4.5.9), verifica-se que a concentração de monômeros dentro das partículas, $M_{p}$, não sofre alteração com relação ao teor de sólidos.

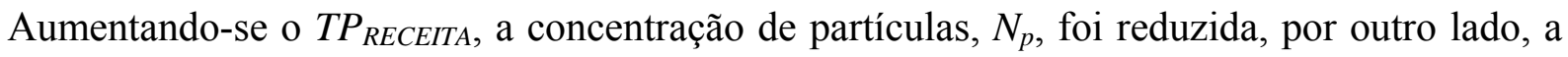
maior quantidade de radicais por partícula, $\tilde{n}$, foi suficiente para aumentar a taxa de polimerização.

Em virtude da conversão final ser abaixo de $100 \%$, os valores finais de TS e de TP foram inferiores aos valores de $T S_{R E C E I T A}$ e $T P_{R E C E I T A}$. Os valores experimentais de $T S$ obtidos no final do processo foram 54.4, 56.7, 57.4 e $58.0 \%$, respectivamente. Os valores de TP finais obtidos foram 52.1, 54.8, 54.8 e $55.3 \%$ respectivamente.

A Figura 5.4.2 mostra os valores finais de diâmetro médio das partículas $\left(D_{p}\right)$, concentração de partículas $\left(N_{p}\right)$, conversão global $(X)$, viscosidade $(\eta)$ e fração de coágulos em função do teor de sólidos (TS), do polímero final obtido. 
A análise dos resultados da Figura 5.4.2a mostra que $D_{p}$ não é influenciado significativamente por TS variando de 54,4 a 57,4\%, sendo de aproximadamente $600 \mathrm{~nm}$. Para $T S=58,0 \%, D_{p}$ tem valor de cerca de $800 \mathrm{~nm}$. A concentração de partículas (Figura 5.4.2b) tem comportamento inverso ao observado para $D_{p}$, visto que as conversões são semelhantes para todos os TS ensaiados. Pode-se dizer que se observa um crescimento exponencial de $D_{p}$ para valores de TS a partir de 58\%, indicando proximidade do limite superior de teor de sólidos e da estabilidade coloidal do látex.

Os valores de conversão final dos ensaios mostraram leve tendência de queda quanto maior o teor de sólidos empregado (figura 5.4.2c). Esta leve tendência pode ser resultado de maior dificuldade em se esgotar o monômero livre dentro das partículas maiores. Em condições próximas à de conversão total, os fenômenos difusivos dentro das partículas passam a ter influência no processo.
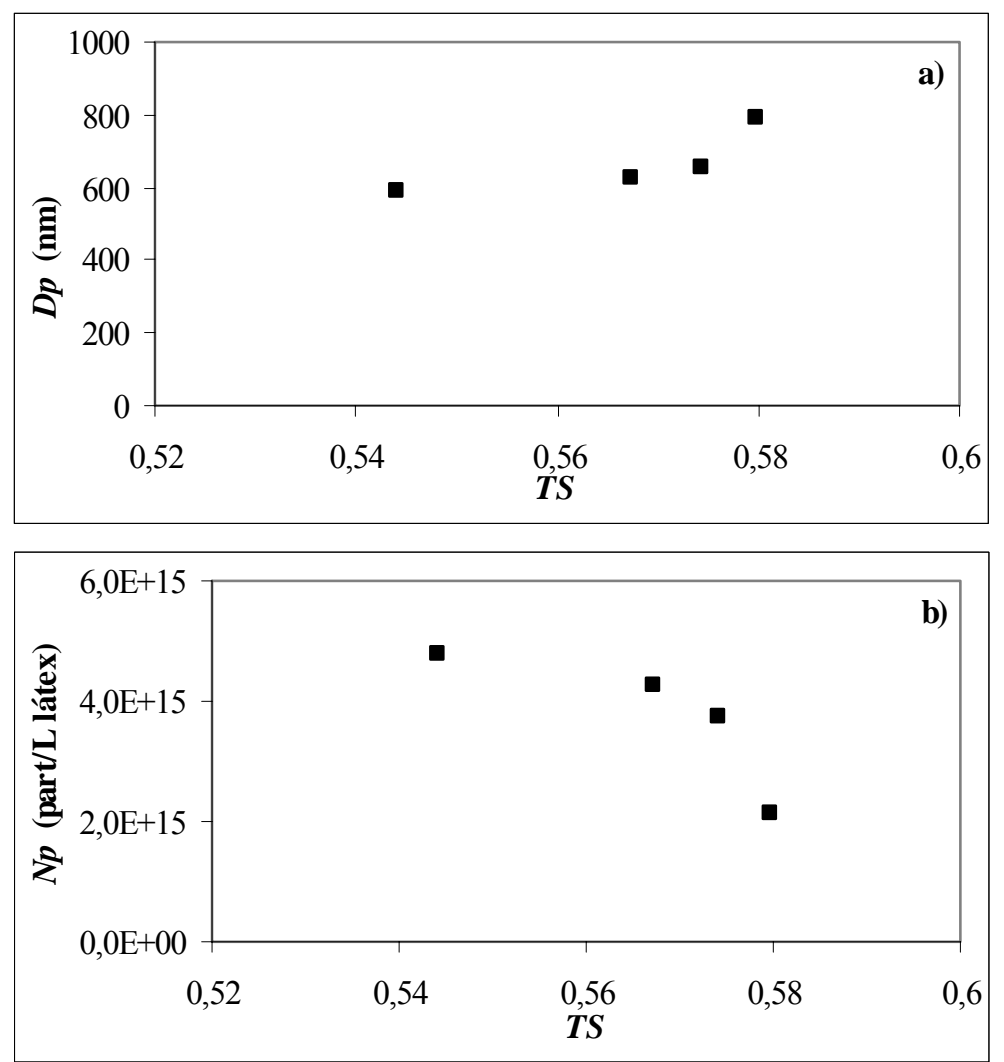

Figura 5.4.2 - Propriedades finais do látex em função do teor de sólidos final obtido: a) Diâmetro médio das partículas, $D_{p}$; b) Concentração de partículas, $N_{p}$; c) Conversão global, $X$; d)Viscosidade, $\eta\left(T=20^{\circ} \mathrm{C}\right.$, taxa de cisalhamento $=46,5$ $\mathrm{s}^{-1}$ ); e e) Teor de Coágulos (continua). 

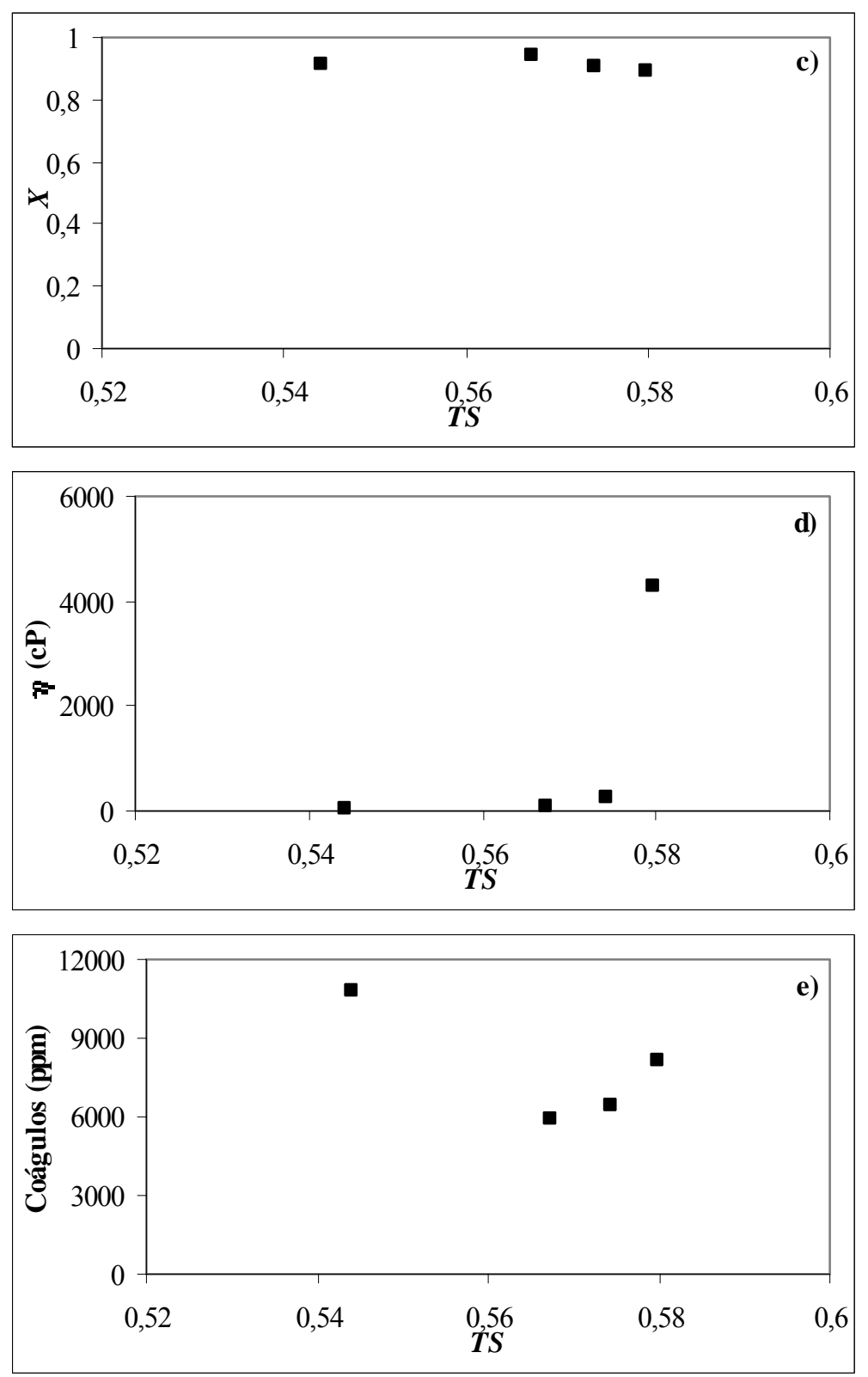

Figura 5.4.2 - Propriedades finais do látex em função do teor de sólidos final obtido: a) Diâmetro médio das partículas, $D_{p}$; b) Concentração de partículas, $N_{p}$; c) Conversão global, $X$; d) Viscosidade, $\eta\left(\mathrm{T}=20^{\circ} \mathrm{C}\right.$, taxa de cisalhamento $=46,5$ $\mathrm{s}^{-1}$ ); e e)Teor de Coágulos ( conclusão).

A figura 5.4.2d nos mostra o aumento na viscosidade advindo do maior teor de sólidos. Na faixa de valores estudada a viscosidade aumenta exponencialmente para pequenas variações no teor de sólidos, mostrando que se trabalha realmente no limite de teor de sólidos para este sistema. O aumento no teor de sólidos reduziu ao limite a distância entre as partículas, aumentando a sua interação. Contudo, embora tenha sido observado elevado 
aumento na viscosidade chegando a valores da ordem de $4000 \mathrm{mPa} . \mathrm{s}$, a $20^{\circ} \mathrm{C}$, a viscosidade do polímero à temperatura de processamento foi relativamente baixa, da ordem de 330mPa.s, a $91^{\circ} \mathrm{C}$

A figura 5.4.2e exibe um comportamento de aumento no teor de coágulos para o acréscimo no teor de sólidos no intervalo de 56 a 58\%. Coágulos são formados pela coalescência das partículas até atingir um tamanho que as tornam instáveis e precipitam. Isto era esperado, pois com o aumento no teor de sólidos a estabilidade do látex é reduzida. Aumentando-se o teor de sólidos reduz-se a distância entre as partículas. Aumenta-se então a probabilidade das partículas atingirem a região de mínimo potencial de repulsão entre partículas (OTTEWILL, 1997). A variação na concentração de íons na solução também pode influenciar a estabilidade do látex e a cinética de formação de coágulos, pois diminui o perfil da curva de energia potencial por distância entre as partículas. A alta quantidade de coágulos obtida para o valor mais baixo de teor de sólidos não pôde ser explicada com os dados disponíveis.

\subsubsection{Conclusões}

É apresentado através deste estudo como o teor de sólidos empregado na formulação de uma receita de copolimerização em emulsão afeta as propriedades do látex. Verificou-se que a variação no teor de sólidos empregado influencia bastante o tamanho das partículas formadas e sua concentração. Conseqüentemente, a variação no diâmetro das partículas ocasionou alterações no número médio de radicais por partícula. Quanto ao látex final, características como o diâmetro médio e concentração das partículas sofreram alteração. O perfil da viscosidade em função do teor de sólidos obtido mostrou comportamento exponencial, revelando que se trabalhou próximo ao limite de estabilidade para este sistema. 


\subsection{Influência do taxa de adição de monômeros sobre a copolimerização de acrilato de butila/estireno com alto teor de sólidos em processo semibatelada}

Este estudo corresponde a uma série de três ensaios com $T S_{\text {RECEITA }}$ de 57\% (Ensaios AS-07, AS-18 e AS-19, com tempo de adição de monômeros de 3, 4 e 5 horas, respectivamente). O tempo total de reação foi mantido constante e igual a 6 horas. Foram determinados a taxa de polimerização, $R_{p}$, e o número médio de radicais por partícula, $\tilde{n}$, durante a reação e o teor de sólidos, TS, conversão, $X$, diâmetro médio das partículas, $D_{p}$, concentração de partículas, $N_{p}$, viscosidade, $\eta$, e teor de coágulos das emulsões finais.

\subsubsection{Introducão}

Os reatores semibatelada são bastante empregados na polimerização em emulsão devido à sua flexibilidade. Na polimerização em emulsão em semibatelada, o controle da adição do monômero tem bastante influência sobre o processo e o produto formado. Usualmente, é realizado um controle da taxa de adição de monômero quando a polimerização envolve vários comonômeros, podendo-se assim alterar a homogeneidade do copolímero. Outras características das emulsões poliméricas afetadas pela taxa de adição de monômeros são a viscosidade e o teor de coágulos. A cinética de polimerização também é afetada pela taxa de adição de monômeros.

\subsubsection{Resultados e discussão}

A Tabela 5.5.1 contém a composição dos ensaios. A Tabela 5.5.2 mostra os efeitos do tempo de alimentação de monômeros (pré-emulsão), $t_{A}$, nos resultados de teores de sólido, $T S$, conversão final, $X$, diâmetro médio das partículas, $D_{p}$, concentração de partículas, $N_{p}$, viscosidade, $\eta$, e teor de coágulos. 
Tabela 5.5.1 - Composição dos ensaios

\begin{tabular}{|c|c|c|c|}
\hline Reagente & \% mássica* & Reagente & \% mássica* \\
\hline \multicolumn{2}{|c|}{ REATOR } & \multicolumn{2}{|c|}{ PRÉ-EMULSÃO } \\
\hline Água & 47,8 & $\mathrm{~S}$ & 50,0 \\
\hline Ultrawet 230 & 2,86 & $\mathrm{AB}$ & 50,0 \\
\hline Disponil 25S & 0,56 & $\mathrm{AA}$ & 1,50 \\
\hline $\mathrm{NaHCO}_{3}$ & 0,50 & Ultrawet 230 & 0,72 \\
\hline \multicolumn{2}{|c|}{ INICIADORES } & Disponil 25S & 0,14 \\
\hline $\mathrm{Na}_{2} \mathrm{~S}_{2} \mathrm{O}_{8}$ & 0,33 & Água & 23,2 \\
\hline Água & 7,48 & NDDM & 0,10 \\
\hline
\end{tabular}

*em rel. aos monômeros

Tabela 5.5.2 - Propriedades finais dos látices $A B / S$

\begin{tabular}{|c|c|c|c|c|c|c|}
\hline $\boldsymbol{t}_{\boldsymbol{A}}$ (min) & $\boldsymbol{T S}$ & $\boldsymbol{X}$ & $\boldsymbol{D}_{\boldsymbol{p}}(\mathbf{n m})$ & $\boldsymbol{N}_{\boldsymbol{p}} \mathbf{( p a r t}_{\mathbf{g})}$ & $\boldsymbol{\eta}$ (mPas) & coag. (ppm) \\
\hline 180 & 0,568 & 0,93 & 862 & $1,6 \mathrm{E}+12$ & 27,0 & $1,30 \mathrm{E}+04$ \\
240 & 0,571 & 1,00 & 264 & $5,8 \mathrm{E}+13$ & 84,5 & $1,80 \mathrm{E}+04$ \\
300 & 0,507 & 0,90 & 1160 & $6,1 \mathrm{E}+11$ & 49,8 & $3,00 \mathrm{E}+04$ \\
\hline
\end{tabular}

$* 20^{\circ} \mathrm{C}$, taxa de cisalhamento $46,5 \mathrm{~s}^{-1}$

A Tabela 5.5.2 mostra altos valores de teores de sólido e de conversão, exceto para $t_{A}=300 \mathrm{~min}$. Para este ensaio, as quantidades de iniciador e de emulsificante no reator foram menores do que para os ensaios com $t_{A}=180$ e $240 \mathrm{~min}$, durante o tempo de alimentação. Estas menores concentrações de emulsificante e iniciador ocasionaram uma menor nucleação de partículas e, conseqüentemente, uma menor taxa de polimerização. Os valores observados de $D_{p}$ e $N_{p}$ mostraram uma inversão de tendências com o aumento de $t_{A}$. Para $t_{A}=180$ e $300 \mathrm{~min}$, $D_{p}$ cresceu durante todo o ensaio, enquanto que para $t_{A}=240 \mathrm{~min}, D_{p}$ decresceu para valores de conversão acima de $85 \%$. $D_{p}$ aumentou com $t_{A}$ aumentando de 180 para 300 min devido ao menor número de partículas formadas neste último. A viscosidade aumentou significativamente aumentando-se $t_{A}$ de 180 para 240min. A viscosidade obtida para $t_{A}=300$ min poderia exibir um valor razoavelmente mais alto se a conversão final atingisse $100 \%$ e $T S=57 \%$, visto que a viscosidade usualmente cresce exponencialmente com TS nesta faixa de teores de sólidos. Maiores teores de coágulos foram obtidos aumentando-se $t_{A}$, devido às menores concentrações de emulsificante no reator durante o período de 
alimentação. A Figura 5.5.1 mostra os resultados de taxa de polimerização para os três tempos de alimentação estudados.
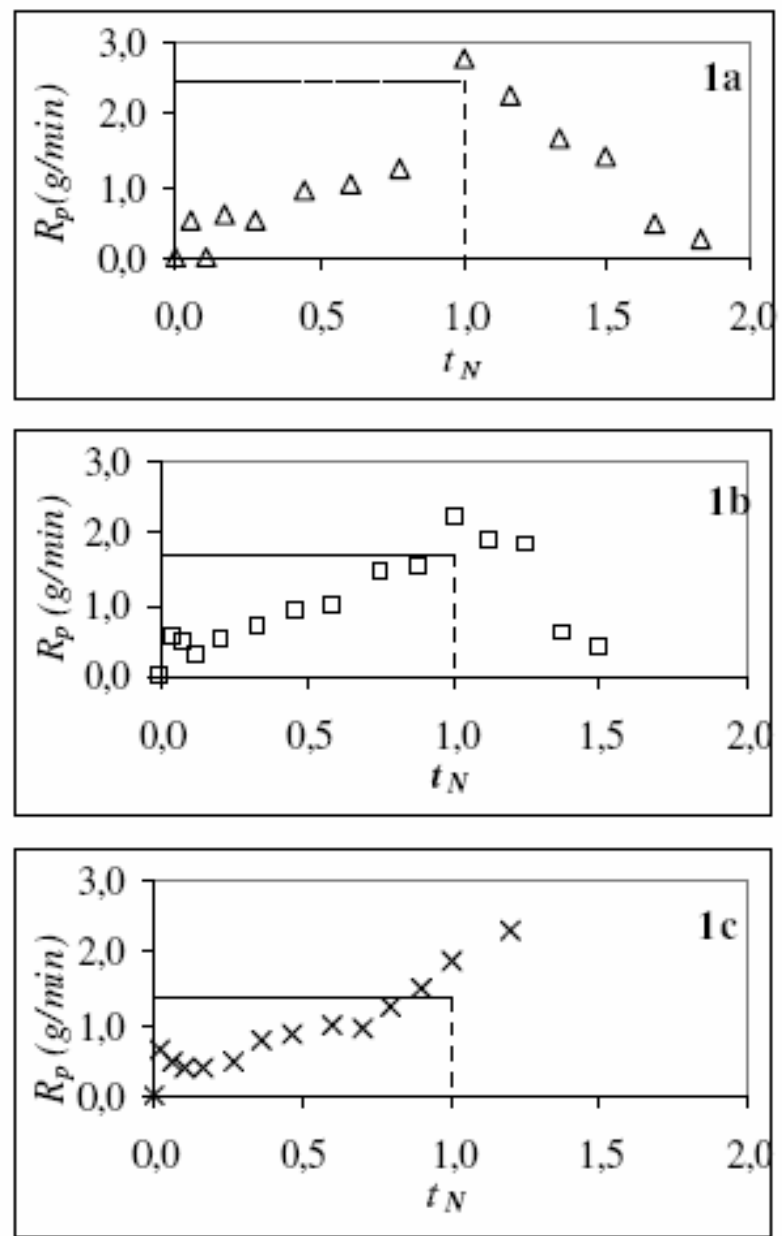

Figura 5.5.1 - Taxas de polimerização, $R_{p}$, para a) $t_{A}=180 \mathrm{~min}$, b) $\left.t_{A}=240 \mathrm{~min}, \mathrm{c}\right) t_{A}=300 \mathrm{~min}$ e taxa de alimentação de monômeros (..............). ( $t_{N}=$ tempo normalizado $\left.=t_{\text {reação }} / t_{A}\right)$

A Figura 5.5.1a mostra que a taxa de polimerização foi inferior à taxa de adição de monômeros durante toda a alimentação, evidenciando condição de excesso de monômeros, na polimerização com $t_{A}=180 \mathrm{~min}$. Na Figura $5.5 .1 \mathrm{~b}$, observou-se condição de avidez de monômeros para $t_{N} \sim 0,9$, para $t_{A}=240 \mathrm{~min}$. Para $t_{A}=300 \mathrm{~min}$, tal condição foi observada para $t_{N} \sim 0,8$. Embora tenha sido obtida condição de excesso de monômeros durante quase toda a alimentação para os três casos estudados, espera-se um copolímero de razoável homogeneidade devido às relativamente próximas razões de reatividade para este sistema 
$\left(r_{A B}=0,25\right.$ e $r_{S}=0,65$; GINSBURGER et al., 2003). A Figura 5.5.2 mostra os resultados de número médio de radicais por partícula durante a reação. Esta figura mostra um comportamento similar para $t_{A}=180$ e $240 \mathrm{~min}$, onde ñ atinge um valor máximo para $t_{N} \sim 1,25$.

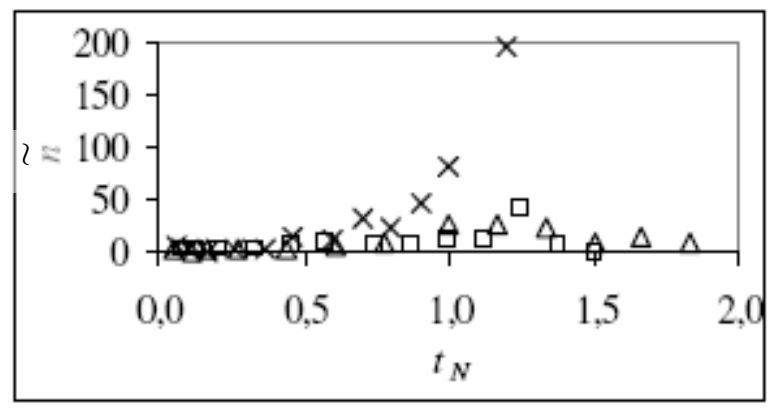

Figura 5.5.2 - Número médio de radicais por partícula, $\tilde{n}$, durante a reação $\left(t_{N}=t_{\text {reação }} / t_{A}\right)$ para $t_{A}=180 \mathrm{~min}(\Delta), t_{A}=240 \mathrm{~min}(\square)$ e $t_{A}=300 \mathrm{~min}(\mathrm{x})$.

Para $t_{A}=300 \mathrm{~min}, \tilde{n}$ apresentou um comportamento diferente exibindo um valor final de $t_{N} \sim 200$. Este alto valor de $\tilde{n}$ obtido deve-se principalmente à baixa concentração de partículas e, conseqüentemente, ao seu elevado diâmetro médio. Partículas maiores podem conter um maior número de radicais em crescimento devido à menor probabilidade de dois radicais sofrerem terminação mútua.

\subsubsection{Conclusões}

Foram obtidas emulsões de $A B / S$ razoavelmente estáveis com teor de sólidos da ordem de $57 \%$. Os valores de $D_{p}$ obtidos foram elevados mostrando ser um processo em condição limite de estabilidade. O decréscimo nos valores de $D_{p}$ para $t_{A}=240 \mathrm{~min}$ para conversões maiores que $85 \%$ não pôde ser explicada com os dados disponíveis. Embora um aumento no período de alimentação possa ocasionar a obtenção de um copolímero mais homogêneo, características da emulsão também se mostraram afetadas pelo tempo de alimentação, como a viscosidade e o teor de coágulos. A cinética de reação, em termos do número médio de radicais por partícula, também se mostrou afetada pelo tempo de alimentação. 


\subsection{Distribuição de tamanhos de partícula}

\subsubsection{Introdução}

A distribuição de tamanhos de partículas é uma característica fundamental na polimerização em emulsão com alto teor de sólidos, visto que influencia na distância entre as partículas e na área de interação entre as partículas. Estudos realizados demonstraram que emulsões com distribuições multimodais com cerca de $80 \%$ de partículas maiores e $20 \%$ de partículas com diâmetro de 6 a 11 vezes menores apresentam melhor relação teor de sólidos/ viscosidade (GUYOT et al., 2002).

Procurando-se observar o comportamento geral da distribuição de tamanhos de partículas nos ensaios de polimerização deste trabalho, foram realizadas algumas análises em microscopia eletrônica de transmissão, TEM, para o ensaio AS-23, utilizando receita com teor de polímeros de $58 \%$.

\subsubsection{Resultados e discussão}

Para verificar a evolução da distribuição de tamanhos de partículas durante o período de reação, foram analisadas amostras retiradas nos instantes 110min, 180min, 270min e 360min. As amostras retiradas foram estabilizadas em solução contendo emulsificante e hidroquinona. Em seguida, as amostras foram diluídas em cerca de 400 vezes, colocadas em placas de cobre e deixadas para secar à temperatura ambiente. Por fim, as placas com as amostras foram analisadas no microscópio eletrônico. A Figura 5.6.1 mostra as fotografias obtidas por TEM para o ensaio AS-23. A Figura 5.6.2 mostra a evolução das distribuições de tamanhos de partículas numérica e mássica, nos tempos amostrados. Os resultados mostrados nas Figuras 5.6.1 e 5.6.2 mostram a obtenção de uma distribuição essencialmente monomodal, sendo mais evidente aproximando-se do final da reação. Além disso, as distribuições finais 
foram razoavelmente estreitas, mostrando que as partículas foram formadas no início da reação.

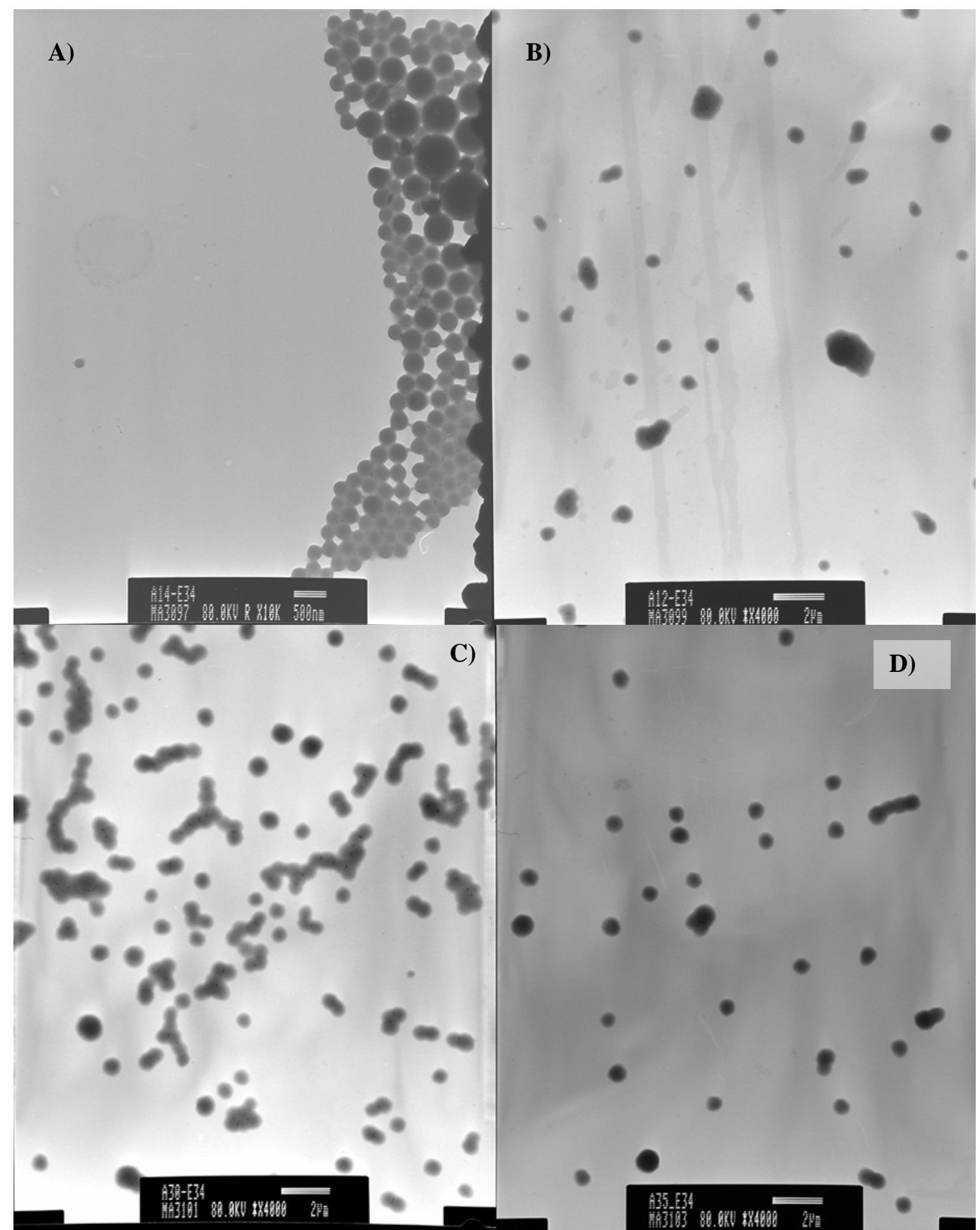

Figura 5.6.1 - Fotografias obtidas por TEM para o ensaio AS-23 para os tempos de reação a) $110 \mathrm{~min}, \mathrm{~b}) 180 \mathrm{~min}, \mathrm{c}) 270 \mathrm{~min}$ e d) $360 \mathrm{~min}$. (A barra de referência indica uma medida de: a) $500 \mathrm{~nm}$, b) $2000 \mathrm{~nm}$, c) $2000 \mathrm{~nm}$ e d) $2000 \mathrm{~nm}$ ) 

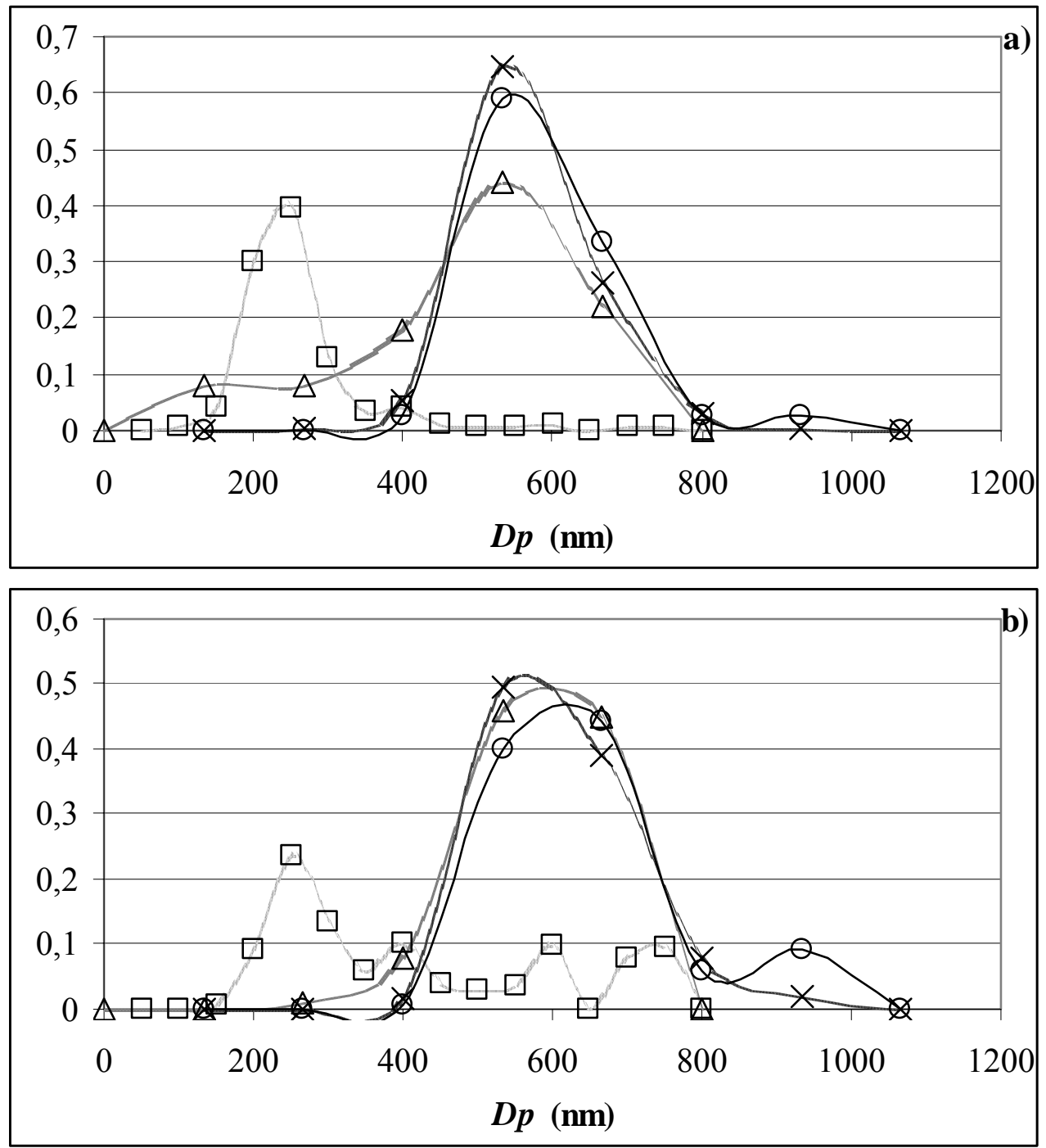

Figura 5.6.2 - Distribuições de tamanhos de partículas a)numérica e b)mássica para $t=110 \mathrm{~min}(\square), t=180 \mathrm{~min}(\Delta), t=270 \mathrm{~min}(\mathrm{x})$ e $t=360 \mathrm{~min}(\mathrm{o})$, para o ensaio $A S$ 23.

\subsubsection{Conclusões}

As análises de TEM mostraram que as condições de processo resultaram na obtenção de um látice de DTP basicamente monomodal e relativamente estreita considerando o objetivo estudado, ou seja, alto teor de sólidos. Isto mostra que as altas quantidades de emulsificante e iniciador empregados levaram à formação de partículas apenas no início do processo. A alta temperatura, por sua vez, favoreceu as reações de propagação e o crescimento das partículas, que passaram capturar todos os radicais formados e evitando novas nucleações. 


\section{Modelagem do processo de copolimerização em emulsão de estireno e acrilato de butila em reator semi-batelada}

\subsection{Introdução}

Apesar de amplamente empregada, a polimerização em emulsão é um processo de difícil modelagem, devido a seu complexo mecanismo cinético e outros fenômenos envolvidos no processo. Entretanto, hipóteses simplificadoras podem ser empregadas dependendo das características do sistema estudado, levando a um modelo mais simples de ser implementado computacionalmente. O emprego dessas hipóteses limita, contudo, a quantidade de casos em que o modelo possa ser empregado. De qualquer forma, a elaboração de um modelo é fundamental para um maior entendimento do processo e o esclarecimento dos fenômenos envolvidos.

De acordo com a teoria de Harkins (1947), a cinética de um processo de polimerização em emulsão pode ser dividida em 3 intervalos:

Intervalo I: Produção de radicais livres na fase aquosa pela decomposição do iniciador. Estes são capturados por micelas contendo monômero. Esta etapa corresponde à nucleação de partículas e termina quando todas as micelas desaparecerem.

Intervalo II: Crescimento das partículas saturadas com monômero. A concentração de monômero nas partículas permanece constante, uma vez que o monômero disponível em gotas difunde-se rapidamente pelo meio para as micelas. Este intervalo termina quando todo o monômero nas gotas é consumido.

Intervalo III: Diminuição da concentração de monômero nas partículas. 
Numerosos trabalhos posteriores ajudaram a aperfeiçoar o mecanismo proposto por Harkins (1947) e a torná-lo aplicável a uma maior variedade de sistemas (GILBERT, 1995).

O modelo matemático desenvolvido no presente trabalho foi baseado no modelo apresentado por Ginsburger et al. (2003). Assim, como no trabalho de Ginsburger et al. (2003) foram adotadas as hipóteses na elaboração do modelo:

-Devido à alta concentração de emulsificante, as partículas são formadas apenas através de nucleação micelar;

-Tanto as partículas como as gotas de monômeros são consideradas monodispersas;

-Devido à relativa hidrofobicidade dos monômeros, reações de propagação, transferência, terminação na fase aquosa e dessorção de radicais foram desprezadas;

-A coagulação entre as partículas foi desprezada;

$-O$ reator é semibatelada de mistura perfeita.

Outras hipóteses comumente empregadas em sistemas de polimerização são:

-Hipótese de estado pseudo-estacionário para os radicais;

-A velocidade das reações independe do comprimento dos radicais.

\subsection{Mecanismo cinético}

As reações químicas envolvidas na polimerização em emulsão podem ocorrer tanto na fase aquosa como na fase polimérica (partículas), e a predominância de determinada reação em uma destas fases dependerá da partição dos reagentes entre as fases.

O mecanismo cinético pode ser assim escrito:

Iniciação: A iniciação envolve as seguintes reações: 
-Decomposição térmica de iniciador solúvel na fase aquosa, $I_{2}$, com coeficiente da taxa de decomposição $k_{d}$ :

$$
I_{2} \rightarrow 2 . I_{a q} *
$$

-Reação, quase-instantânea, do radical do iniciador, $I_{a q}{ }^{*}$, com uma molécula de monômero dissolvida na fase aquosa, $M$, com a subseqüente formação de um radical oligomérico de grau de polimerização igual a $1, R_{a q, 1} *$ :

$$
I_{a q} *+M \rightarrow R_{a q, 1} *
$$

Tais radicais oligoméricos podem reagir com outras moléculas de monômero atingindo outros graus de polimerização. Contudo, assim como em (GINSBURGER et al, 2003), tais radicais oligoméricos não serão diferenciados, assumindo a hipótese de que as reações envolvendo esses radicais são independentes de seu grau de polimerização, sendo representados pela notação $R_{a q}$ *

Captura de Radicais: Os radicais oligoméricos na fase aquosa podem ser capturados pelas partículas e pelas micelas. A entrada de radicais nas gotas de monômero pode ser desprezada em vista do reduzido número de gotas em relação ao número de partículas e micelas. As reações são as seguintes:

-Captura de radical por uma micela, formando uma nova partícula contendo um radical ativo, $R^{*}$ :

$$
R_{a q}^{*}+\text { micela } \rightarrow \text { partícula }+R^{*}
$$

-Captura de radical por uma partícula contendo i radicais, resultando numa partícula com $n+1$ radicais $(n=0,1,2, \ldots)$ :

$$
R_{a q}{ }^{*}+\text { partícula } \rightarrow \text { partícula }+R^{*}
$$


Propagação: Assim como para os radicais oligoméricos, assumindo a hipótese de que as reações envolvendo os radicais poliméricos não dependam do tamanho do radical (com exceção à dessorção dos radicais nas partículas), estes não serão diferenciados quanto ao seu tamanho. Contudo, na copolimerização, a reação de propagação depende da espécie do radical que constitui o grupo terminal da cadeia. A reação de um radical polimérico com um monômero da espécie j é descrita como:

$$
P_{i}^{*}+M_{j} \rightarrow P_{j}^{*} ; \quad i, j=\text { monômero } A \text { ou } B
$$

Outras reações envolvendo os radicais: Além da reação de propagação os radicais podem sofrer outros tipos de reação:

-Reação com uma molécula de inibidor ou impurezas, $Z$, resultando em uma macromolécula ou polímero morto, $P$, e outros inertes:

$$
\begin{aligned}
& R_{a q}{ }^{*}+\mathrm{Z} \rightarrow P+\text { Inertes } \\
& R_{i}^{*}+\mathrm{Z} \rightarrow P+\text { Inertes }
\end{aligned}
$$

-Reação de transferência de cadeia para monômero ou agente de transferência de cadeia, CTA:

$$
\begin{aligned}
& R_{i}^{*}+M_{j} \rightarrow P+R_{j}^{*} \\
& R_{i}^{*}+C T A \rightarrow P+C T A^{*}
\end{aligned}
$$

-Reações de terminação por combinação ou por desproporcionamento dos radicais:

$$
\begin{array}{ll}
P_{i}^{*}+P_{j}^{*} \rightarrow P & \text { combinação } \\
P_{i}^{*}+P_{j}^{*} \rightarrow 2 P & \text { desproporcionamento }
\end{array}
$$

-O fenômeno de dessorção de radical da partícula é mais efetivo quanto menor o radical, ocorrendo principalmente com radicais provenientes das reações de transferência de cadeia. Pode ser descrita como:

$$
R_{i}^{*} \rightarrow R_{a q}^{*}
$$


Devido à hidrofobicidade dos monômeros, as reações de dessorção serão desconsideradas neste trabalho.

\subsection{Balanços das espécies}

Balanço Volumétrico: A variação do volume do reator, $d V_{r}$, inclui o termo de alimentação, $Q_{e}$, e de variação devido à conversão de monômero e é dada por:

$$
\frac{d V_{r}}{d t}=\sum_{i \in\{A, B\}}\left(\frac{1}{\rho_{\text {pol }}}-\frac{1}{\rho_{i}}\right) R_{p i} P M_{\text {moni }}+Q_{e}
$$

Onde $P M_{\text {moni }}$ é a massa molecular do monômero $i, \rho_{p o l}$ e $\rho_{i}$ são as densidades do polímero e do monômero $i$, respectivamente, e $R_{p i}$ é a taxa de propagação do monômero $i$. A evolução da fração volumétrica de água no reator, $\varphi$, é dada por:

$$
\frac{d\left(V_{r} \varphi\right)}{d t}=Q_{e} \varphi_{e}
$$

Balanço do Iniciador: O balanço do iniciador inclui a sua decomposição térmica na fase aquosa e a concentração de iniciador na alimentação:

$$
\frac{d\left(\left[I_{2}\right] V_{r} \varphi\right)}{d t}=-R_{d}+Q_{e}\left[I_{2 e}\right]
$$

Balanço dos Monômeros: Os balanços da quantidade de monômero i presente no reator, $M_{i}$, e da quantidade total de monômero $i$ já inserida, $M_{i 0}$, são dados por:

$$
\begin{aligned}
& \frac{d\left(\left[M_{i}\right] V_{r}\right)}{d t}=-R_{P i}+Q_{e}\left[M_{e i}\right] \\
& \frac{d\left(\left[M_{i 0}\right] V_{r}\right)}{d t}=Q_{e}\left[M_{e i}\right]
\end{aligned}
$$

A conversão instantânea, $X$, é, desta forma, expressa por: 


$$
X=\frac{\sum_{i \in\{A, B\}} P M_{\text {moni }}\left(\left[M_{i 0}\right]-\left[M_{i}\right]\right)}{\sum_{i \in\{A, B\}} P M_{\text {moni }}\left[M_{i 0}\right]}
$$

Balanço do Emulsificante: A variação da quantidade total de emulsificante no reator é dada por:

$$
\frac{d\left(\left[S_{0}\right] V_{r} \varphi\right)}{d t}=Q_{e}\left[S_{e}\right]
$$

Número de partículas: Assumindo as hipóteses em que as partículas sejam formadas apenas por nucleação micelar e que não haja coagulação entre as partículas (GINSBURGER et al, 2003), o balanço do número de partículas, $N_{p}$, é dado por:

$$
\frac{d\left(N_{p} V_{r} \varphi\right)}{d t}=R_{\text {mic }} \cdot N_{A}
$$

Onde $R_{\text {mic }}$ é a taxa de formação de partículas por nucleação micelar e $N_{A}$ é o Número de Avogadro.

Número de radicais por partícula: O número médio de radicais por partícula foi obtido através de equações de balanço do número de partículas contendo $j$ radicais, $N(j)$. Para implementação numérica, um número máximo de radicais por partícula, $j_{\max }$, foi fixado, resultando no seguinte conjunto de $j_{\max }+1$ equações diferenciais:

$j=0$ :

$$
\frac{d N(0)}{d t}=-\frac{R_{c p} N_{A}}{N_{p} V_{r} \varphi} N(0)+2 \frac{k_{t p}}{N_{A} V} N(2)
$$

$j=1$ :

$$
\frac{d N(1)}{d t}=R_{\text {mic }} N_{A}+\frac{R_{c p} N_{A}}{N_{p} V_{r} \varphi}(N(0)-N(1))+6 \frac{k_{t p}}{N_{A} V} N(3)
$$


$j>1:$

$$
\begin{aligned}
\frac{d N(j)}{d t} & =\frac{R_{c p} N_{A}}{N_{p} V_{r} \varphi}(N(j-1)-N(j)) \\
& +\frac{k_{t p}}{N_{A} V}((j+2)(j+1) N(j+2)-j(j-1) N(j))
\end{aligned}
$$

$j=j_{\text {max }}-1$ :

$$
\begin{aligned}
\frac{d N\left(j_{\max }-1\right)}{d t} & =\frac{R_{c p} N_{A}}{N_{p} V_{r} \varphi}\left(N\left(j_{\max }-2\right)-N\left(j_{\max }-1\right)+N\left(j_{\max }\right)\right) \\
& -\frac{k_{t p}}{N_{A} V}\left(j_{\max }-1\right)\left(j_{\max }-2\right) N\left(j_{\max }-1\right)
\end{aligned}
$$

$j=j_{\max }:$

$$
\begin{aligned}
\frac{d N\left(j_{\max }\right)}{d t} & =\frac{R_{c p} N_{A}}{N_{p} V_{r} \varphi}\left(N\left(j_{\max }-1\right)-N\left(j_{\max }\right)\right) \\
& -\frac{k_{t p}}{N_{A} V} j_{\max }\left(j_{\max }-1\right) N\left(j_{\max }\right)
\end{aligned}
$$

O número médio de radicais por partícula, ñ, é calculado pela expressão:

$$
\tilde{n}=\frac{\sum_{j=0}^{j \max } j N(j)}{N_{p} V_{r} \varphi}
$$

\subsection{Taxas de reação}

Decomposição do Iniciador:

$$
R_{d}=k_{d}\left[I_{2}\right] V_{r} \varphi
$$

Propagação: A taxa de propagação do monômero $i, R_{p i}$, é dada por:

$$
R_{p i}=k_{p i} \cdot\left[M_{p i}\right] \frac{N_{p}}{N_{A}} \tilde{n} V_{r} \varphi
$$

Onde $k_{p i}$ é o coeficiente da taxa de propagação do monômero $i$, sendo dado por: 


$$
k_{p i}=\sum_{j=A, B} k_{p j i} P_{j}
$$

Para o cálculo do coeficiente da taxa de propagação de um radical terminado em $i$ com uma unidade monomérica $j, k_{p i j}$, foi usada a definição da razão de reatividade, $r_{i j}$ :

$$
r_{i j}=\frac{k_{p i i}}{k_{p i j}}
$$

A probabilidade de um radical tiver uma unidade monomérica $j$ como grupo terminal, $P_{j}$, é dada por:

$$
P_{j}=\frac{k_{p i j}\left[M_{p j}\right]}{k_{p i j}\left[M_{p j}\right]+k_{p j i}\left[M_{p i}\right]}
$$

A concentração de monômero nas partículas, $M_{p}$, permanece praticamente constante durante os intervalos I e II, quando ainda há gotas presentes no sistema, e decresce no intervalo III. De acordo com a abordagem empírica (GAO e PENLIDIS, 2002), a transição entre os intervalos II e III ocorre em uma conversão crítica, $X_{c}$. Assim, $M_{p}$ fica:

$$
M_{p}=M_{p c}=\frac{\left(1-X_{c}\right) \rho_{\text {mon }}}{\left[\left(1-X_{c}\right)+X_{c} \rho_{m o n} / \rho_{\text {pol }}\right] P M_{\text {mon }}} \text { para } \mathrm{X} \leq \mathrm{X}_{\mathrm{c}}
$$

e

$$
M_{p}=\frac{(1-X) \rho_{\text {mon }}}{\left[(1-X)+X \rho_{\text {mon }} / \rho_{\text {pol }}\right] P M_{\text {mon }}} \text { para } \mathrm{X} \geq \mathrm{X}_{\mathrm{c}}
$$

Terminação: Considerando a hipótese de que os comprimentos das cadeias não influenciem as constantes cinéticas, as constantes de terminação entre um radical terminado em uma unidade monomérica $i$ e um radical terminado em uma unidade $j, k_{t i j}$ e $k_{t j i}$, podem ser consideradas iguais, sendo calculadas a partir das constantes de terminação para a homopolimerização:

$$
k_{t i j}=\sqrt{k_{t i i} \cdot k_{t j j}}
$$


A constante de terminação global, $k_{t p}$, e a taxa de terminação global, $R_{t p}$, são obtidas por:

$$
\begin{aligned}
& k_{t p}=\alpha \sum_{i=A, B} \sum_{j=A, B} k_{t i j} P_{i} P_{j} \\
& R_{t p}=2 \frac{k_{t p}}{N_{A}{ }^{2} V}\left(\sum_{i=2}^{\infty}(i-1)(i) N(i)\right)
\end{aligned}
$$

Onde $\alpha$ é um fator de "eficiência" da reação de terminação.

Captura de Radicais: As taxas de captura de radicais pelas partículas, $R_{c p}$, e pelas micelas, $R_{\text {mic }}$, são dadas por:

$$
\begin{gathered}
R_{c p}=k_{c p}\left[R_{a q}\right] r_{p} N_{p} V_{r} \varphi \\
R_{\text {mic }}=k_{\text {mic }}\left[R_{a q}\right] r_{\text {mic }} N_{\text {mic }}
\end{gathered}
$$

Onde constantes de captura pelas partículas e pelas micelas, $k_{c p}$ e $k_{m i c}$, podem ser relacionadas por um fator de eficiência, $\delta$ :

$$
k_{\text {mic }}=\delta \cdot k_{c p}
$$

Realizando um balanço para os radicais na fase aquosa, obtemos:

$$
\frac{d\left[R_{a q}\right]}{d t}=2 f R_{d}-k_{c p}\left[R_{a q}\right] r_{p} N_{p} V_{r} \varphi-\delta . k_{c p}\left[R_{a q}\right] r_{m i c} N_{m i c}
$$

E utilizando a hipótese de estado pseudo-estacionário para os radicais:

$$
\frac{d\left[R_{a q}\right]}{d t}=0
$$

obtemos:

$$
k_{c p}\left[R_{a q}\right]=\frac{2 f R_{d}}{N_{p} r_{p} V_{r} \varphi+\delta . N_{\text {mic }} r_{\text {mic }}}
$$

O emulsificante total adicionado, $\left[S_{0}\right]$, é particionado no meio em emulsificante adsorvido nas partículas de polímero, emulsificante adsorvido nas gotas de monômero e emulsificante livre na fase aquosa. Micelas estão presentes no meio quando o emulsificante 
livre na fase aquosa está acima da concentração micelar crítica, CMC. Devido à pequena quantidade de gotas presentes em relação à grande quantidade de partículas, é razoável desprezar o emulsificante adsorvido nas gotas de monômero. Assim, a concentração de emulsificante livre na fase aquosa, [S], é dada por:

$$
[S]=\left[S_{0}\right]-\frac{4 \cdot \pi \cdot r_{s}^{2} N_{p}}{N_{A} \cdot a_{e}}
$$

Onde $a_{e}$ é a área de cobrimento do emulsificante, e o raio da partícula inchada com monômero, $r_{s}$, relaciona-se com o raio da partícula sem monômero, $r_{p}$, da seguinte forma:

$$
\frac{r_{s}}{r_{p}}=\left[\frac{\rho_{\text {mon }}}{\rho_{\text {mon }}-M_{p} P M_{\text {mon }}}\right]^{1 / 3}
$$

Assim, podemos descrever a concentração de emulsificante livre, [S], da forma:

$$
S=S_{0}-\frac{4 \cdot \pi \cdot N_{p}}{N_{A} \cdot a_{e}}\left[\left(\frac{3 \cdot \pi \cdot P M_{\text {mon }} \cdot X \cdot M_{0}}{\rho_{\text {pol }} \cdot N_{p}}\right)\left(\frac{\rho_{\text {mon }}}{\rho_{\text {mon }}-M_{p} P M_{\text {mon }}}\right)\right]^{2 / 3}
$$

Quando $S$ estiver acima da $C M C$, o número de micelas no meio, $N_{\text {mic }}$, será dado por:

$$
N_{\text {mic }}=\frac{(S-C M C)}{n_{s}} V_{r} \varphi N_{A}
$$

Onde $n_{s}$ é o número de moléculas de emulsificante necessárias para formar uma micela.

\subsection{Simulação do modelo}

Para a simulação do modelo proposto, foi elaborado um programa para a resolução das equações diferenciais. Usou-se o algoritmo de Euler explícito para a resolução do modelo, sendo o tempo a variável independente. O passo de integração utilizado $(\mathrm{dt}=0,02 \mathrm{~s}$ para $\mathrm{t}<60 \mathrm{~s}$ e $d t=0,1$ s para $t>60$ s) mostrou-se suficientemente pequeno uma vez que se obtiveram resultados idênticos quando o passo foi reduzido pela metade. 
A simulação foi realizada nas condições dos ensaios AS-05, AS-08 e AS-21 (TP RECEITA $=50 \%, 54 \%$ e $58 \%$ respectivamente). As composições destes ensaios são relacionadas na Tabela 6.1.

Tabela 6.1 - Composições empregadas na simulação dos ensaios AS-05, AS-08 e AS-21 $\left(T P_{\text {RECEITA }}=50 \%, 54 \%\right.$ e $\left.58 \%\right)$.

\begin{tabular}{|c|c|c|c|}
\hline \multirow{4}{*}{ Reagente } & REATOR \\
\cline { 2 - 4 } & $\mathbf{5 0}$ & $\mathbf{5 4}$ & $\mathbf{5 8}$ \\
\hline Água & 25,3 & 25,3 & 19,5 \\
\hline Ultrawet 230 & 1,43 & 1,54 & 1,65 \\
\hline Disponil 25S & 0,28 & 0,301 & 0,33 \\
\hline $\mathrm{AA}$ & 0 & 0,55 & 0,58 \\
\hline $\mathrm{NaHCO}_{3}$ & 0,25 & 0,27 & 0,29 \\
\hline \multicolumn{4}{|c|}{ PRÉ-EMULSÃO } \\
\hline $\mathrm{S}$ & 25,0 & 27,0 & 29,0 \\
\hline $\mathrm{AB}$ & 25,0 & 27,0 & 29,0 \\
\hline $\mathrm{AA}$ & 0,75 & 0,81 & 0,86 \\
\hline Ultrawet 230 & 0,36 & 0,39 & 0,41 \\
\hline Disponil 25S & 0,07 & 0,08 & 0,08 \\
\hline Água & 17,3 & 12,5 & 14,4 \\
\hline $\mathrm{NDDM}^{4}$ & 0,05 & 0,05 & 0,06 \\
\hline \multicolumn{4}{|c|}{ INICIADOR } \\
\hline Na $_{2} \mathrm{~S}_{2} \mathrm{O}_{8}$ & 0,16 & 0,18 & 0,19 \\
\hline Água & 4,05 & 4,04 & 4,01 \\
\hline
\end{tabular}

Em vista da complexidade dos fenômenos envolvidos e a dificuldade em se obter valores na literatura ou experimentalmente para todos os coeficientes empregados, é comum o ajuste de parâmetros baseando-se em resultados experimentais. Os parâmetros $X_{c r}, \delta$ e $\alpha$ foram ajustados para os resultados experimentais do ensaio AS-05. Verificou-se, em seguida, o comportamento do modelo ajustado, quando o teor de sólidos é elevado (ensaios AS-08 e $A S-21)$.

Os valores dos parâmetros utilizados na simulação do modelo encontram-se na Tabela 6.2. 
Tabela 6.2 - Parâmetros utilizados na simulação do modelo ( $A=$ acrilato de butila; $B=$ estireno).

\begin{tabular}{|c|c|c|c|}
\hline Parâmetro & Valor & Unidade & Referência \\
\hline$a_{e}$ & $0,75 \exp (1,12-361 / \mathrm{T})$ & $\mathrm{m}^{2} /$ molecula & (Ginsburger et al., 2003) \\
\hline$C M C$ & 0,003 & $\mathrm{kmol} / \mathrm{m}^{3}$ & (Zeaiter et al., 2002) \\
\hline$f$ & $\exp \left(-0,92 \cdot f_{b}\right)$ & adimensional & (Ginsburger et al., 2003) \\
\hline$k_{d}$ & $1 \mathrm{E}-6 \exp (50,27-16237 / \mathrm{T})$ & $\mathrm{s}^{-1}$ & (Ginsburger et al., 2003) \\
\hline$k_{p A A}$ & 2,73E6exp $(-3170 / \mathrm{T})$ & $\mathrm{m}^{3} / \mathrm{kmol} . \mathrm{s}$ & (McKenna et al., 1995) \\
\hline$k_{p B B}$ & 4,57E7exp(-3921/T) & $\mathrm{m}^{3} / \mathrm{kmol} . \mathrm{s}$ & (Manders et al., 1996) \\
\hline$k_{t A A}$ & $7,5 \mathrm{E} 14 \exp (-9216 / \mathrm{T})$ & $\mathrm{m}^{3} / \mathrm{kmol} . \mathrm{s}$ & (Casella, 1999) \\
\hline$k_{t i j}$ & $8,5 \mathrm{E} 9 \exp (-1761 / \mathrm{T})$ & $\mathrm{m}^{3} / \mathrm{kmol} . \mathrm{s}$ & (Casella, 1999) \\
\hline$N_{A}$ & $6,02 \mathrm{E}+26$ & número/kmol & \\
\hline$n_{s}$ & 40 & moléculas & (Ginsburger et al, 2003) \\
\hline$P M_{\text {monA }}$ & 128 & $\mathrm{~kg} / \mathrm{kmol}$ & \\
\hline$P M_{\text {monB }}$ & 104,1 & $\mathrm{~kg} / \mathrm{kmol}$ & \\
\hline$r_{A B}$ & 0,25 & adimensional & (Ginsburger et al, 2003) \\
\hline$r_{B A}$ & 0,65 & adimensional & (Ginsburger et al, 2003) \\
\hline$r_{\text {mic }}$ & $2,50 \mathrm{E}-09$ & $\mathrm{~m}$ & (Ginsburger et al, 2003) \\
\hline$X_{c}$ & 0,09 & adimensional & Ajustado \\
\hline$\alpha$ & $3,50 \mathrm{E}-03$ & adimensional & Ajustado \\
\hline$\delta$ & $3,00 \mathrm{E}-07$ & adimensional & Ajustado \\
\hline$\rho_{A}$ & 869 & $\mathrm{~kg} / \mathrm{m}^{3}$ & (Ullmann's ..., 2002) \\
\hline$\rho_{B}$ & 878 & $\mathrm{~kg} / \mathrm{m}^{3}$ & (Ullmann's ..., 2002) \\
\hline$\rho_{\text {pol }}$ & 1035 & $\mathrm{~kg} / \mathrm{m}^{3}$ & (Ullmann's ..., 2002) \\
\hline
\end{tabular}

\subsection{Resultados e Discussão}

Os gráficos da Figura 6.1 mostram os resultados experimentais e da modelagem de diâmetro médio das partículas, $D_{p}$, número total de partículas, $N_{T}$, concentração de partículas, $N_{P}$, conversão global, $X_{\text {global, }}$ número médio de radicais por partícula, $\tilde{n}$, e fração molar de 
acrilato de butila, $f_{a}$, e estireno, $f_{b}$, na quantidade total de monômero livre no reator, para o experimento $A S-05$.
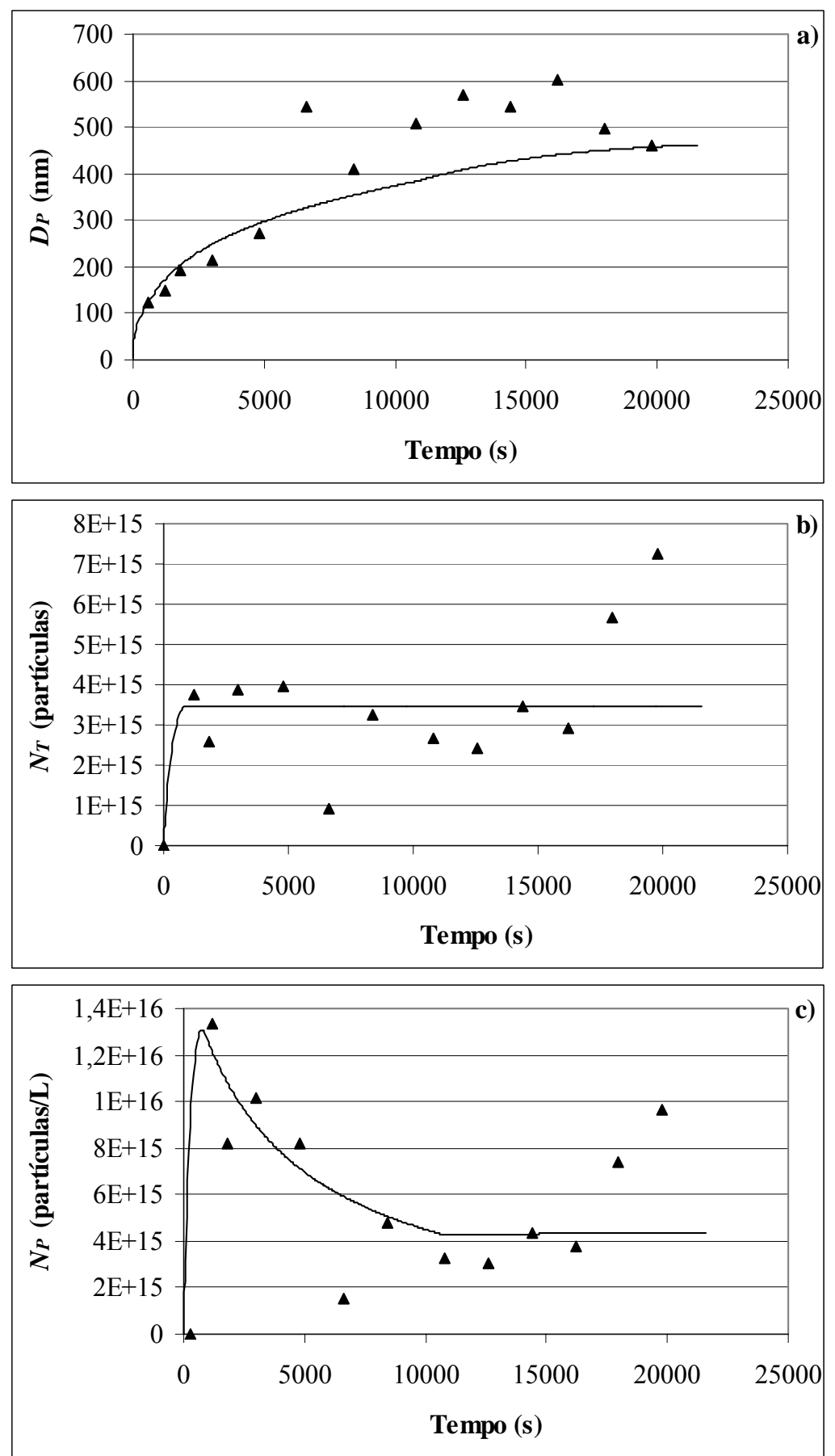

Figura 6.1 - Evolução durante o período de reação de: a) diâmetro médio das partículas, $D_{p} ;$ b) número total de partículas, $N_{T} ;$ c) concentração de partículas, $N_{P} ;$ d) conversão global, $X_{\text {global }}$; e) número médio de radicais por partícula, $\tilde{n}$, para o modelo (-) e para o experimento AS-05 ( $\boldsymbol{\Delta})$; e f) fração molar de acrilato de butila, $f_{a}$, e estireno, $f_{b}$, na quantidade total de monômero no reator $\left(f_{\text {aexp }}=\boldsymbol{\Lambda}\right.$, $f_{\text {bexp }}=\Delta, f_{\text {amodel }}=(-)$ e,$\left.f_{\text {bmodel }}=(\cdots \cdots \cdot \cdots)\right)$ (continua). 

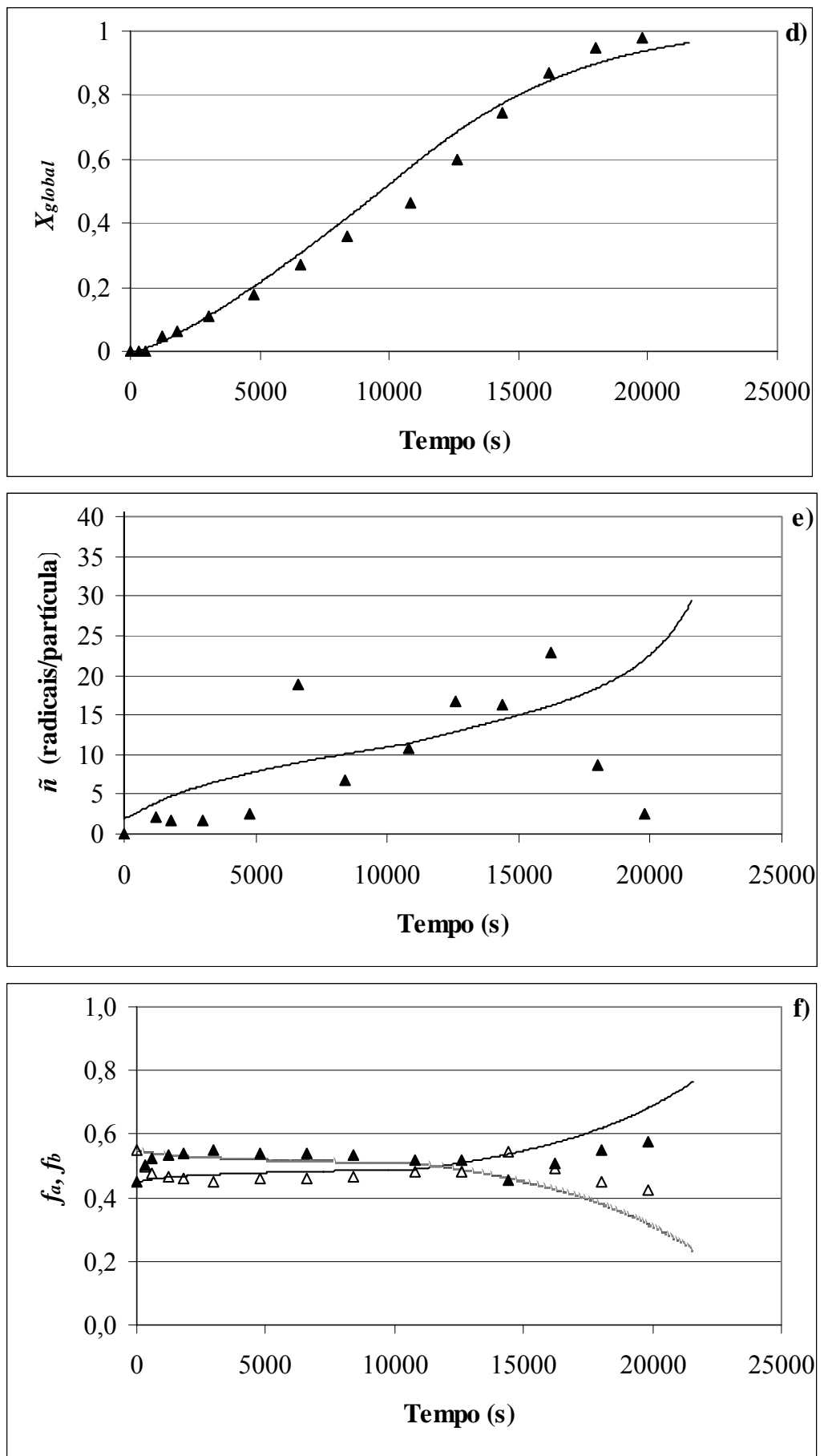

Figura 6.1 - Evolução durante o período de reação de: a) diâmetro médio das partículas, $D_{p}$; b) número total de partículas, $N_{T}$; c) concentração de partículas, $N_{P} ;$ d) conversão global, $X_{\text {global; }}$ e) número médio de radicais por partícula, $\tilde{n}$, para o modelo (-) e para o experimento AS-05 ( $\mathbf{\Delta})$; e f) fração molar de acrilato de butila, $f_{a}$, e estireno, $f_{b}$, na quantidade total de monômero no reator $\left(f_{a e x p}=\mathbf{\Lambda}\right.$, $f_{\text {bexp }}=\Delta, f_{\text {amodel }}=(-)$ e,$\left.f_{\text {bmodel }}=(\cdots \cdots \cdots \cdot)\right)$ (conclusão).

Os resultados da Figura 6.1 mostram razoável adequação do modelo para os dados experimentais. As Figuras $6.1 \mathrm{~b}$ e $6.1 \mathrm{c}$ mostram que as partículas são formadas basicamente 
nos primeiros minutos de reação, desta forma, a hipótese de que as partículas foram formadas apenas por nucleação micelar foi razoável. A queda na concentração de partículas mostrada na Figura 6.1c refere-se à diluição do número de partículas em virtude da adição de préemulsão.

$\mathrm{Na}$ Figura 6.1d, é possível observar um aumento na taxa de reação por volta dos 200 minutos de reação para os dados experimentais. Tal fenômeno, não observado no modelo, pode significar a ocorrência de efeito gel, que tende a aumentar a taxa de reação devido à menor terminação dos radicais nas partículas (GILBERT, 1995). Tal possibilidade é atestada pelo significativo aumento no número de radicais por volta dos 200 minutos de reação nos resultados experimentais (Figura 6.1e). A Figura 6.1f mostra que as frações molares de acrilato de butila e estireno no total de monômero livre no reator permanecem razoavelmente constantes durante toda a alimentação, sofrendo um pequeno desvio após o término desta. Os valores experimentais e os do modelo apresentaram razoável concordância, sendo que as curvas mais acentuadas do modelo perto do final da reação podem ser resultantes dos valores de razão de reatividade empregados.

Os gráficos na Figura 6.2 mostram os resultados experimentais e da modelagem de $N_{T}$, $N_{P}, D_{P}, X_{\text {global }}$ e $\tilde{n}$ para os experimentos AS-08 e AS-21. Os resultados da Figura 6.2 mostram que o modelo com os parâmetros ajustados para o ensaio AS-05 ainda mostrou boa concordância com os resultados experimentais dos ensaios AS-08 e AS-21. Contudo, é possível observar pelas Figuras $6.2 \mathrm{a}$ e $6.2 \mathrm{~b}$ que, à medida que se aumentou o teor de sólidos na receita, ocorreu uma maior discrepância entre a quantidade de partículas obtida experimentalmente e a quantidade esperada pelo modelo. Tal discrepância pode ser relacionada à ocorrência de coagulação das partículas recém-formadas (partículas precursoras) que tendem a ser instáveis (GILBERT, 1995). A estabilidade das partículas precursoras é função de vários fatores, entre eles a concentração de sais dissolvidos no meio. 
Uma vez que o aumento no teor de sólidos na receita significou uma redução na quantidade de água na carga inicial do reator, tem-se então uma maior possibilidade de coagulação destas partículas. Devido ao maior número de partículas formadas no modelo, o diâmetro final das partículas resultante foi inferior (Figura 6.2c).
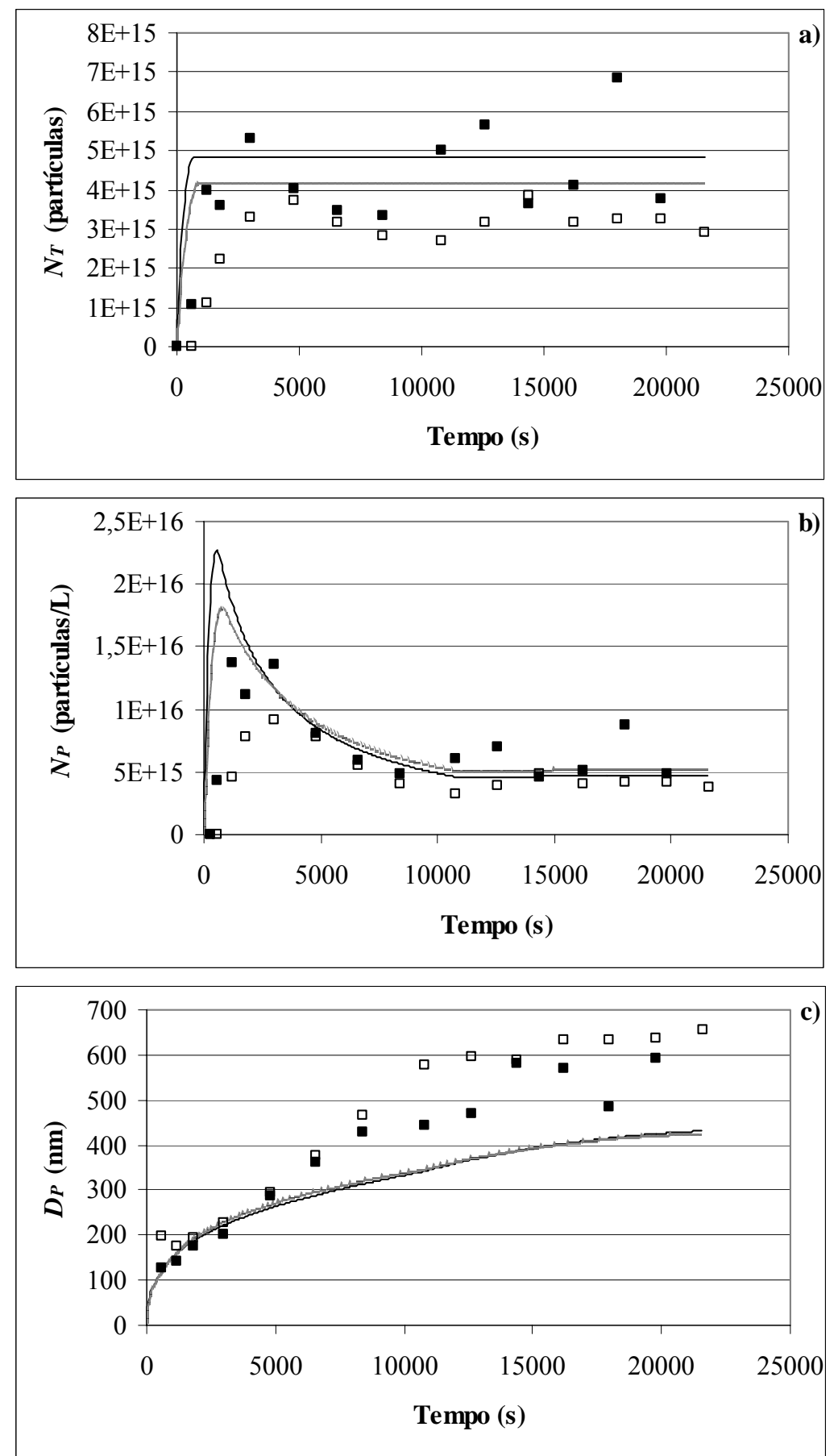

Figura 6.2 - Evolução durante o período de reação de: a) Número total de partículas; b) concentração de partículas; c)diâmetro médio das partículas; d) conversão global; e e) número médio de radicais por partícula para os experimentos AS-08 e AS-21 ( $A S-08_{\text {exp }}=\mathbf{\varpi}, A S-21_{\text {exp }}=\square, A S-08_{\text {model }}=(-)$ e,$A S-21_{\text {model }}=(\cdots \cdots \cdots)$ ). (continua) 

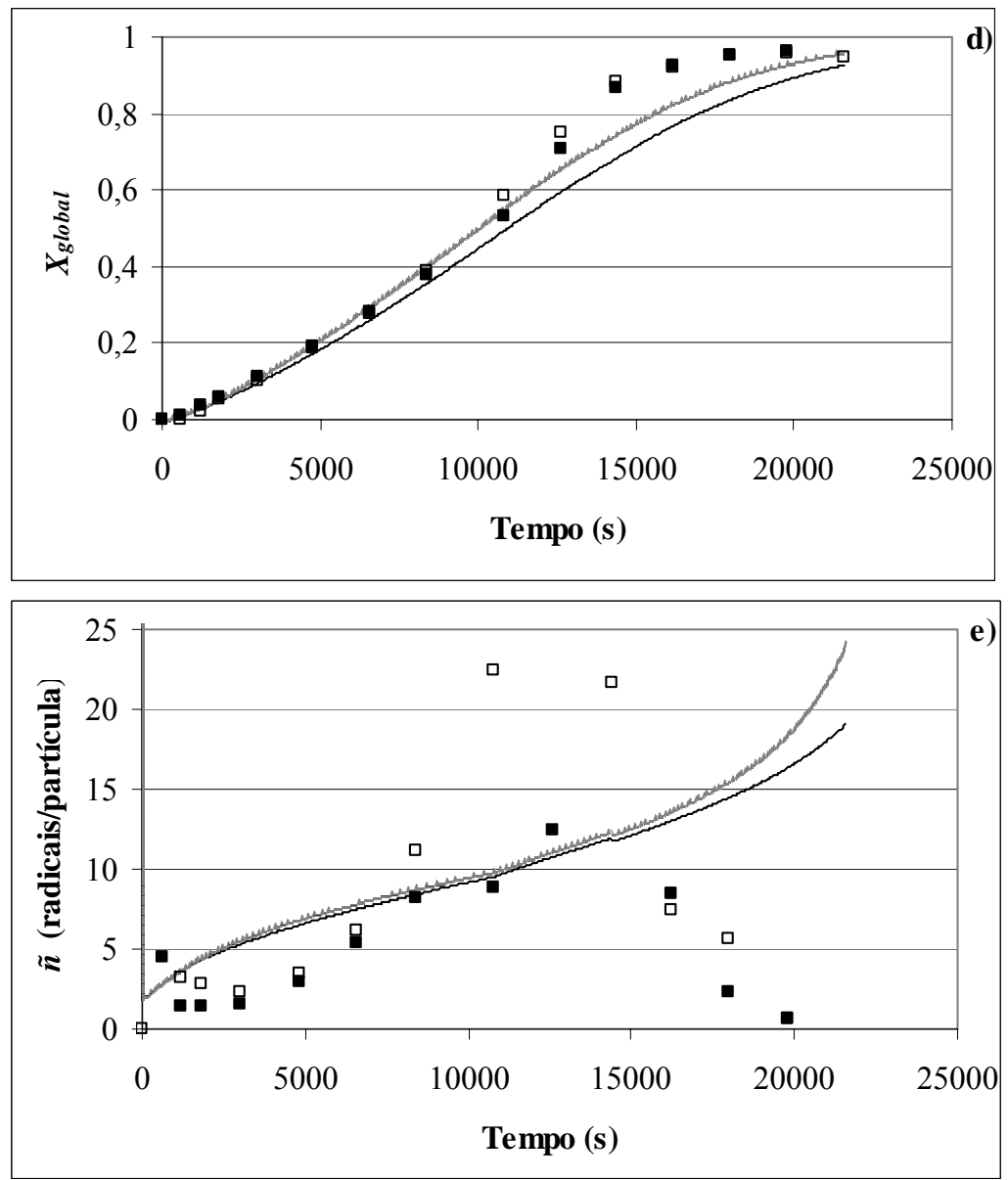

Figura 6.2 - Evolução durante o período de reação de: a) Número total de partículas, $N_{T}$; b) concentração de partículas, $N_{P} ;$ c) diâmetro médio das partículas, $D_{P} ;$ d) conversão global, $X_{\text {global }}$; e e) número médio de radicais por partícula, $\tilde{n}$, para os experimentos $A S-08$ e $A S-21\left(A S-08_{\text {exp }}=\mathbf{\square}, A S-21_{\text {exp }}=\square, A S-08_{\text {model }}=(-)\right.$ e , $\left.A S-21_{\text {model }}=(\cdots \cdots \cdots \cdot)\right)$ (conclusão).

\subsection{Conclusões}

O modelo utilizado, desenvolvido a partir de informações da literatura e observações experimentais, mostrou boa adequação aos dados experimentais para a polimerização em emulsão de acrilato de butila e estireno com alto teor de sólidos. As hipóteses adotadas mostraram-se razoáveis e simplificaram significativamente o modelo resultante, que pôde ser simulado em computadores de capacidade mediana. 
Contudo, sugestões para aprimoramento do modelo considerado podem incluir a consideração do efeito gel na taxa de terminação de radicais e na taxa de reação. Como outra sugestão, temos a verificação do efeito da composição do meio inicial, em termos da concentração de sais, na coagulação de partículas precursoras e no número resultante de partículas. 


\section{Conclusões}

Foram obtidos resultados com razoável reprodutibilidade através da metodologia empregada nos ensaios. Os resultados dos ensaios mostram, contudo, que o processo e o produto são sensíveis a variações na receita e nas condições dos ensaios.

Os ensaios exploratórios mostraram como as diferenças entre o sistema $A B / S$ e $A V / A B$ influenciaram no processo. Desta forma, as particularidades do sistema $A B / S$ se mostraram importantes na definição da metodologia empregada neste estudo.

Os resultados do estudo dos efeitos do emulsificante e do ácido acrílico no processo de polimerização e no produto revelaram que, apesar de sua atuação como estabilizantes na emulsão, as outras funções que estes componentes desempenham no processo também podem afetar a estabilidade do sistema. Desta forma, foi observada uma desestabilização da emulsão quando se aumentou a concentração de emulsificante visto que isto ocasionou a formação de um maior número de partículas. O ácido acrílico, como monômero funcional, também desempenhou um papel fundamental na obtenção de uma emulsão estável e com baixos teores de coágulos. Contudo, a utilização de maiores concentrações de ácido acrílico ocasionou um aumento significativo na viscosidade e, em alguns casos, levou à separação de fases no reator.

Verificou-se também que, além da composição da receita, a composição instantânea do reator afeta as características do processo e do produto, conforme foi observado através da variação nos tempos de adição da pré-emulsão.

Utilizando-se 4,3\% de emulsificante total (iônico e não-iônico) e 2,5\% de ácido acrílico (percentuais totais, na carga inicial e na alimentação, em relação aos monômeros), foi possível praticar a polimerização empregando receitas com até $64 \%$ de sólidos. Nesta faixa de teor de sólidos, foi verificado um aumento exponencial na viscosidade do látice para pequenas variações no teor de sólidos, mostrando que se trabalha no limite de estabilidade do sistema. 
Verificou-se que, além da viscosidade, a variação no teor de sólidos influencia também o tamanho médio das partículas, o número médio de radicais por partícula e a taxa de polimerização.

Contudo, observou-se que a metodologia empregada levou à obtenção de partículas distribuídas de maneira essencialmente monomodal. Desta forma, teores de sólidos ainda maiores poderiam ser alcançados através do desenvolvimento de uma metodologia que resulte em distribuições multimodais, com a promoção de um maior empacotamento das partículas.

O modelo aplicado ao processo, baseado em informações experimentais e da literatura mostrou boa concordância com o processo e ajudou a elucidar os fenômenos envolvidos nas várias fases da reação. 


\section{Sugestões futuras}

A partir dos resultados deste trabalho, sugere-se o aprofundamento no conhecimento da copolimerização em emulsão de estireno e acrilato de butila com alto teor de sólidos através de:

- Desenvolvimento de uma metodologia reprodutiva para a obtenção de látices multimodais com alto teor de sólidos e distribuição definida;

- Desenvolvimento de um modelo que permita a previsão da distribuição de tamanhos de partículas;

- Verificação da influência dos fatores estudados na interação entre as partículas, igualando os teores de sólidos através de diluição ou uso de um roto-evaporador. 


\section{Referências bibliográficas}

ABELE, S.; GAUTHIER, C.; GRAILLAT, C.; GUYOT, A. Films from styrene-butyl acrylate lattices using maleic or succinic surfactants: mechanical properties, water rebound and grafting of the surfactants, Polymer 41 (2000) pp.1147-1155

ARAÚJO, P.H.H. Distribuição de tamanhos de partícula em sistemas heterogêneos de polimerização, Rio de Janeiro, 1999. Tese (Doutorado), 273p. - COPPE/UFRJ.

ARBINA, L. L.; BARANDIARAN, M. J.; GUGLIOTTA, L. M.; ASUA, J. M. Kinetics of the emulsion copolymerization of styrene and butyl acrylate, Polymer 38 (1997) pp.143148

BADRAN, A. S. ; AYOUB, M. M. H. ; EL-GHAFFAR, M. A. Abd ; NASER , H. E.; ELHAKIN, A. A. Abd Preparation and Characterization of Polystyrene and Styrene-Butyl Acrylate Copolymer Latices, European Polymer Journal 33, N ${ }^{0} .4$ (1997) pp. 537-541

BLACKLEY, D.C. Emulsion polymerization - Theory and Practice, London, Applied Science Publishers Ltd., 1975.

BOUTTI, S.; GRAILlAT, C.; MCKENNA, T.F. New Routes to High Solid Content Latexes: A process for in situ particle nucleation and growth, Macromolecular Symposia 206, (2004) pp.383-398.

CAPEK, I.; POTISK, P. Microemulsion and emulsion polymerization of butyl acrylate I. Effect of the initiator type and temperature, European Polymer Journal 31, $\mathrm{N}^{\mathrm{o}} .12$ (1995) pp 1269-1277.

CASELLA, E. L. Modelagem Matemática e Estudo Experimental de Sistemas de Polimerização em Emulsão, São Paulo, 1999. Tese (Doutorado). Escola Politécnica/USP.

CHU, F. ; GUYOT, A. High solids content latexes with low viscosity, Colloid Polymer Science 279 (2001) pp 361-367.

GAO, J.; PENLIDIS, A. Mathematical modeling and computer simulator/database for emulsion polymerizations, Progress in Polymer Science 27 (2002) pp 403-535. 
GILBERT, R.G. Emulsion polymerization a mechanistic approach, San Diego, Academic Press Inc., 1995.

GINSBURGER, E.; PLA, F.; FONTEIX, C.; HOPPE, S.; MASSEBEUF, S.; HOBBES, P.; SWAELS, P. Modelling and simulation of batch and semi-batch emulsion copolymerization of styrene and butyl acrylate, Chemical Engineering Science 58 (2003) pp 4493-4514.

GUYOT, A.; CHU, F.; SCHNEIDER, M.; GRAILlAT, C.; MCKENNA, T.F. High solid content latexes, Progress in Polymer Science 27 (2002) pp.1573-1615.

HARKINS, W.D. A general theory of the mechanism of emulsion polymerization, Journal of American Chemical Society 69 (1947) pp. 1428-1444.

KEMMERE, M.F. Batch emulsion polymerization: A chemical engineering approach, Eindhoven, 1999. Tese (Doutorado), 153 p. - Universidade Técnica de Eindhoven.

KONG, X. Z.; PICHOT, C.; GUILLOT, J. Kinetics of emulsion copolymerization of vinyl acetate with butyl acrylate, European Polymer Journal 24 (1988), pp.485-492.

LAZARIDIS, N.; ALEXOPOULOS, A.H.; KIPARISSIDES, C. Semi-batch emulsion copolymerization of vinyl acetate and butyl acrylate using oligomeric noionic surfactants, Macromolecular Chemistry and Physics 202 (2001), pp.2614-2662.

LESKO, M.L.; SPERRY, P.R. Acrylic and styerene-acrylic polymers, in: Emulsion polymerization and emulsion polymers, eds. LOVELL, P.A.; EL-AASSER, M.S., John Wiley and Sons, Chichester (1997) p. 619-655.

LOVELL, P. A.; EL-AASSER, M. S., Emulsion Polymerization and Emulsion Polymers, Ed. John Wiley and Sons, Chichester (1997).

MANDERS, B. G.; CHAMBARD, G.; KINGMA, W. J.; KLUMPERMAN, B.; HERK, A. M.; GERMAN, A. L. Estimation of activation parameters for the propagation rate constant of styrene, Journal of Polymer Science Part A: Polymer Chemistry 34, (1996), pp. 2473-2479.

MARINANGELO, G.; PALMA, M.; SAYER, C.; GIUDICI, R. Efeito do oxigênio nas reações de polimerização em emulsão de acetato de vinila com alimentações discretas, Anais do 6o. Congresso Brasileiro de Polímeros (2001) pp. 1658-1661. 
MARINANGELO, G.; PALMA, M.; SAYER, C.; GIUDICI, R. Efeito da alimentação discreta de emulsificante nas reações de polimerização de acetato de vinila em emulsão, Anais do 6o. Congresso Brasileiro de Polímeros (2001) pp. 1650-1653.

MCKENNA, T. F.; GRAILLAT, C.; GUILLOT, J. Contributions to defining the rate constants for the homopolymerization and copolymerization of butyl acrylate and vinylacetate, Polymer Bulletin 34, (1995) p.361-368.

OTTEWILL, R.H. em: Emulsion polymerization and emulsion polymers, eds. Lovell, P.A.; El-Aasser, M.S., John Wiley and Sons, Chichester, 1997.

PALMA, M.; SAYER, C.; GIUDICI, R. Comparação entre reações contínuas de polimerização em emulsão em uma coluna pulsada com pratos perfurados com reações em batelada, Anais do 6o. Congresso Brasileiro de Polímeros (2001) pp. 1628-1631.

PALMA, M.; VALIM, A.F.O.; MARINANGELO, G.; SILVA, F.E.C.; GIUDICI, R. Copolimerização de acrilato de butila/acetato de vinila e acrilato de butila /estireno em emulsão em processo semibatelada com alto teor de sólidos, Anais do XV Congresso Brasileiro de Engenharia Química (2004) em CD-ROM.

PRIEST, W.J. Particle growth in the aqueous polymerization of vinyl acetate, Journal of Physical Chemistry 56 (1952) pp. 1077-1082.

SCHALLER, E.J. em: Emulsion polymerization and emulsion polymers, eds. Lovell, P.A.; El-Aasser, M.S., John Wiley and Sons, Chichester, 1997.

SCHNEIDER, M.; GRAILLAT, C.; GUYOT, A.; MCKENNA, T.F. High solids content emulsions. Part II: Preparation of seed latexes, Journal of Applied Polymer Science 84 (2002) pp. 1897-1915.

ULLMANN, F. Encyclopedia of Industrial Chemistry, 6 Ed., Wiley-VCH, 2002

YOKOTE, A.; PALMA, M.; GIUDICI, R. Polimerização em emulsão do acetato de vinila em batelada: Estudo da influência da temperatura e do tipo de iniciação, Anais do 60 . Congresso Brasileiro de Polímeros (2001) pp 1724-1727.

ZEAITER, J.; ROMAGNOLI, J.A.; BARTON, G.W.; GOMES, V.G; HAWKETT, B.S.; GILBERT, R.G. Operation of semi-batch emulsion polymerization reactors: Modelling, validation and effect of operating conditions, Chemical Engineering Science 57 (2002) pp.2955-2969 
ZUBITUR, M.; ASUA, J. M. - Factors affecting kinetics and coagulum formation during the emulsion copolymerization of styrene/butyl acrylate, Polymer 42 (2001) pp.5979-5985 


\section{Apêndice}

Tabelas de dados dos ensaios 


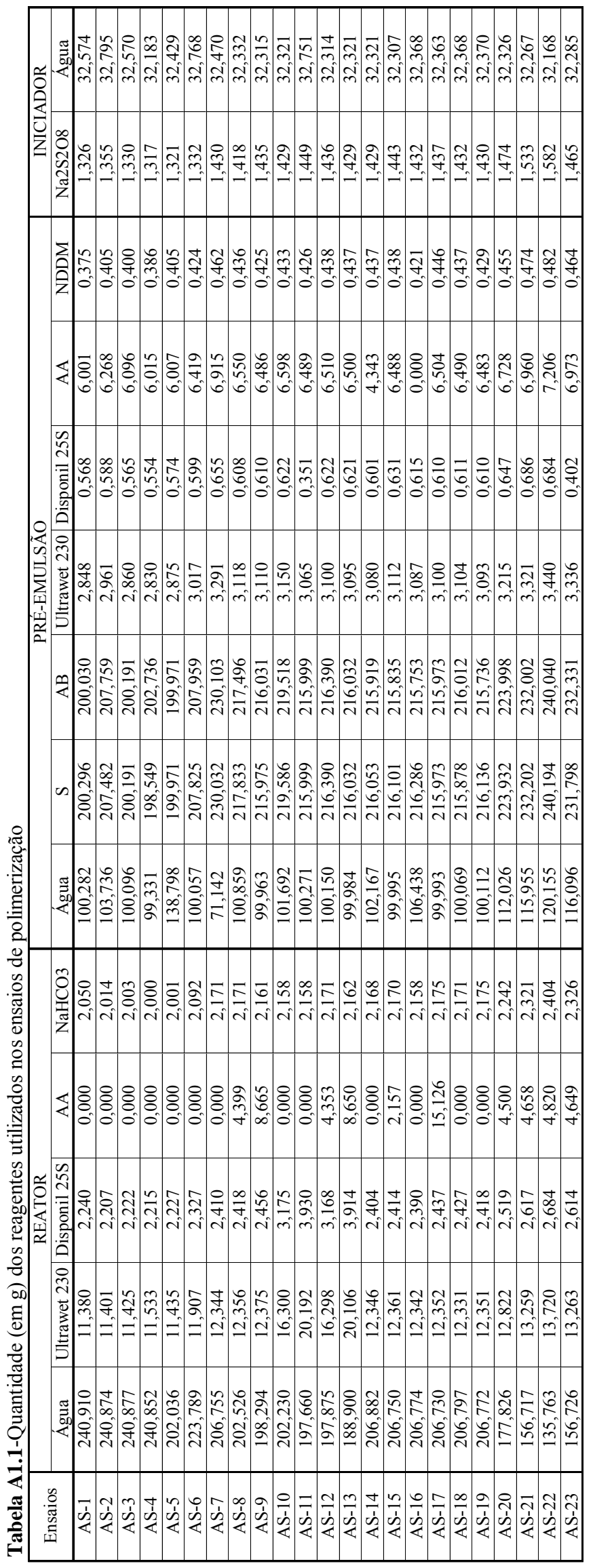




\begin{tabular}{|c|c|c|c|c|c|c|c|c|c|c|c|c|c|c|c|c|c|c|c|}
\hline & $\AA$ & $\begin{array}{l}\overrightarrow{0} \\
\dot{m}\end{array}$ & & : & & $\mid \begin{array}{l}0 \\
\infty \\
\infty \\
\infty\end{array}$ & & & & $\frac{m}{\tilde{\imath}}$ & & & $\overrightarrow{\hat{d}}$ & $\begin{array}{l}0 \\
\infty \\
7 \\
7\end{array}$ & \begin{tabular}{c}
0 \\
$\dot{0}$ \\
\hdashline
\end{tabular} & 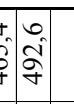 & & 帒 & $\begin{array}{l}\vec{a} \\
\vec{\sigma} \\
\vec{\sigma}\end{array}$ \\
\hline & U. & $\begin{array}{l}0 \\
0 \\
0 \\
0 \\
0\end{array}$ & & \begin{tabular}{|l|}
0 \\
0 \\
0 \\
0
\end{tabular} & & $\begin{array}{l}\overrightarrow{0} \\
0 \\
0\end{array}$ & & & & $\begin{array}{l}m \\
- \\
0\end{array}$ & & & 0 & శె. & 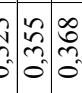 & 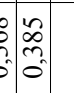 & & 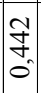 & g) \\
\hline 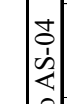 & $\tilde{\varepsilon}$ & $=0$ & $\Rightarrow$ & $\stackrel{0}{\circ}$ & & $t_{0}^{+}$ & & & & $\mid$\begin{tabular}{l}
$\infty$ \\
\hdashline \\
\hdashline
\end{tabular} & & & $\overrightarrow{\hat{i}}$ & $\vec{i} \bar{i}$ & $\bar{n}=\frac{m}{m}$ & $=m^{n}$ & & & $\Leftrightarrow$ \\
\hline & & $m^{2}$ & & $\frac{m}{2}$ & & 2 & 8 & & & 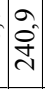 & & & $\begin{array}{c}m \\
\hat{\gamma} \\
\hat{y}\end{array}$ & 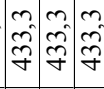 & 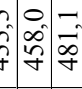 & 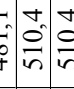 & & & 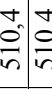 \\
\hline & & 6 & & in & & $\approx$ & $f$ & & & 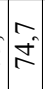 & & & $\begin{array}{l}0 \\
i\end{array}$ & 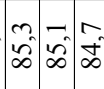 & $=0 \begin{array}{c}m \\
\infty \\
\infty\end{array}$ & $6=0$ & & & $\vec{\infty}=$ \\
\hline & 窵 & in & & i & & f & & $?$ & & 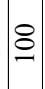 & & & $\stackrel{\infty}{-}$ & & جै & 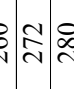 & & & $\stackrel{m}{m} \approx$ \\
\hline & คิ & 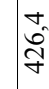 & & $\begin{array}{l}0 \\
\Xi \\
\Xi\end{array}$ & & $\begin{array}{l}+ \\
\hat{n} \\
\end{array}$ & & & & $\begin{array}{l}\overrightarrow{\tilde{A}} \\
\text { ते }\end{array}$ & & & $\bar{m}$ & $\vec{m}$ & 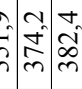 & $\begin{array}{l}0 \\
\vdots \\
0 \\
0 \\
0\end{array}$ & & $\begin{array}{l}n \\
0 \\
0 \\
\infty \\
+ \\
\end{array}$ & $\hat{n}$ \\
\hline & sis & $\begin{array}{l}0 \\
0 \\
0 \\
0 \\
0\end{array}$ & & $\begin{array}{l}\bar{b} \\
0 \\
0\end{array}$ & & $\begin{array}{l}0 \\
0 \\
0 \\
0\end{array}$ & & & & $\begin{array}{l}n \\
0 \\
0\end{array}$ & & & $\frac{t}{0}$ & 今 & 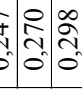 & $\begin{array}{l}0 \\
0 \\
0\end{array}$ & & $\mid \begin{array}{l}0 \\
\infty \\
0 \\
0 \\
0\end{array}$ & 竎 \\
\hline & & $\therefore$ & & $\stackrel{\sim}{\sim}$ & & $t_{0}^{\circ}$ & $=0$ & & & $\begin{array}{l}\infty \\
- \\
-1\end{array}$ & 4 & & \begin{tabular}{l}
$\infty$ \\
$\infty$ \\
$\infty$ \\
\multirow{N}{*}{}
\end{tabular} & 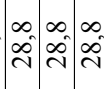 & $\begin{array}{lll}0 \\
\dot{s}\end{array}$ & î ले ले & & & ले ले \\
\hline 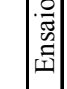 & & i & & $\mid \begin{array}{c}\alpha \\
\alpha \\
\alpha \\
\alpha\end{array}$ & & वृ & 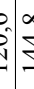 & & & $\frac{0}{d}$ & & 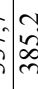 & m. & 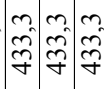 & 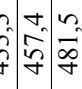 & 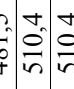 & & & \begin{tabular}{l|l}
$\stackrel{t}{*}$ \\
$\dot{0}$ \\
$n$
\end{tabular} \\
\hline & & : & $\stackrel{+}{I} \stackrel{+}{i}$ & $=$ & & i & tr & & & $\left\{\begin{array}{l}n \\
n \\
n\end{array}\right.$ & 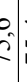 & & से & 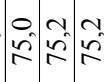 & 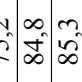 & 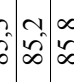 & & & $\begin{array}{ll}\hat{\infty} \\
\vec{\infty}\end{array}$ \\
\hline & 离 & in & & ¿ & & f & & & & 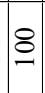 & & & $\stackrel{\infty}{-}$ & & 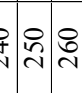 & 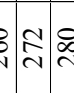 & & & $\stackrel{\circ}{m}$ \\
\hline & $\AA$ & $\begin{array}{l}0 \\
0 \\
0 \\
2\end{array}$ & & $\begin{array}{l}0 \\
\stackrel{\vec{I}}{\Xi}\end{array}$ & & $\begin{array}{l}n \\
a \\
a \\
-1\end{array}$ & & & & $\begin{array}{l}\dot{0} \\
\vec{\AA}\end{array}$ & & & $\vec{\infty}$ & $\begin{array}{l}\infty \\
\vec{F}\end{array}$ & 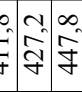 & $\begin{array}{l}1 \\
0 \\
0 \\
0 \\
8\end{array}$ & & 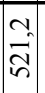 & i \\
\hline & 車 & \begin{tabular}{c|c}
0 \\
0 \\
0 \\
0
\end{tabular} & & $\begin{array}{l}n \\
0 \\
0 \\
0\end{array}$ & & $\begin{array}{l}\infty \\
0 \\
0 \\
0\end{array}$ & & & & $\bar{\Xi}$ & & & $0^{\circ}$ & ? & $\begin{array}{l}b \\
:\end{array}$ & 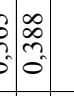 & & 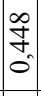 & 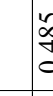 \\
\hline & & $50^{\circ}$ & & $\stackrel{\sim}{\sim}$ & & 6 & & & & 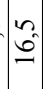 & 8 & & $\stackrel{\infty}{\sim}$ & 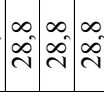 & 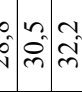 & 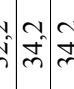 & & & 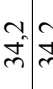 \\
\hline & & $\stackrel{\theta}{=}$ & 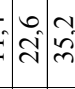 & $\frac{a}{8}$ & & $\begin{array}{l}3 \\
2 \\
2\end{array}$ & $f$ & $\hat{\Omega}$ & & $\vec{d}$ & & $=$ & $\begin{array}{c}m \\
\text { ले } \\
\vartheta\end{array}$ & 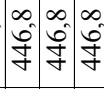 & 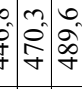 & 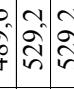 & & & 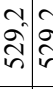 \\
\hline & $H$ & $\begin{array}{ll}0 \\
i\end{array}$ & $\therefore$ & 2 & & $\stackrel{2}{i}$ & 8 & $\frac{n}{7}$ & & $\begin{array}{c}2 \\
2 \\
2\end{array}$ & & & in & 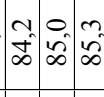 & 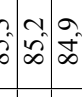 & 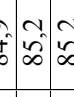 & & & 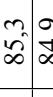 \\
\hline & & in & & $\underset{\sim}{\sim}$ & & f & & $?$ & & 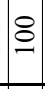 & & & $\stackrel{\infty}{-}$ & ¿ిసి సి & 蛹 & 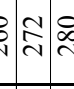 & & & $\stackrel{\circ}{m} \cong$ \\
\hline & ฉิ & 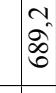 & & $\begin{array}{l} \pm \\
\stackrel{d}{I} \\
-\end{array}$ & & 10 & & & & 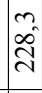 & & & $\stackrel{\wedge}{*}$ & $\begin{array}{l}\infty \\
\dot{\infty} \\
\infty\end{array}$ & 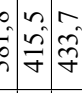 & $\frac{3}{4}$ & & & है \\
\hline & 50 & 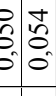 & & 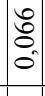 & & 今. & & & & 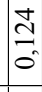 & & & $0^{\circ}$ & 离 & 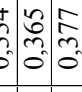 & के & & & 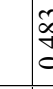 \\
\hline & $1=10$ & 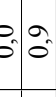 & & & & & & & & d & & & & 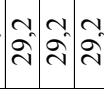 & $\hat{v} \vec{m} \bar{n}$ & री ले ले & & & ले \\
\hline & & i & $\hat{i}$ & & $\left.\int_{0}^{m}\right|_{0} ^{0}$ & T & & - & & $\vec{d}$ & & & $\nabla$ & 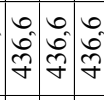 & \begin{tabular}{c|c|c} 
\\
\hdashline \\
\hdashline
\end{tabular} & 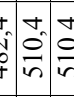 & & & \begin{tabular}{l|l}
$t$ \\
$\dot{s}$ \\
$\dot{s}$
\end{tabular} \\
\hline & & & 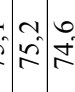 & & & & & 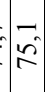 & & $\approx$ & & & & 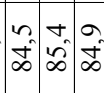 & $\begin{array}{l}n= \\
0 \\
\infty\end{array}$ & 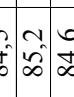 & & & 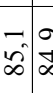 \\
\hline & 亩 & & 11 & & & & & & & & & & & ¿ి సి ఫి & 守 & 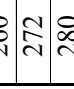 & & & $\stackrel{\circ}{m}$ \\
\hline
\end{tabular}




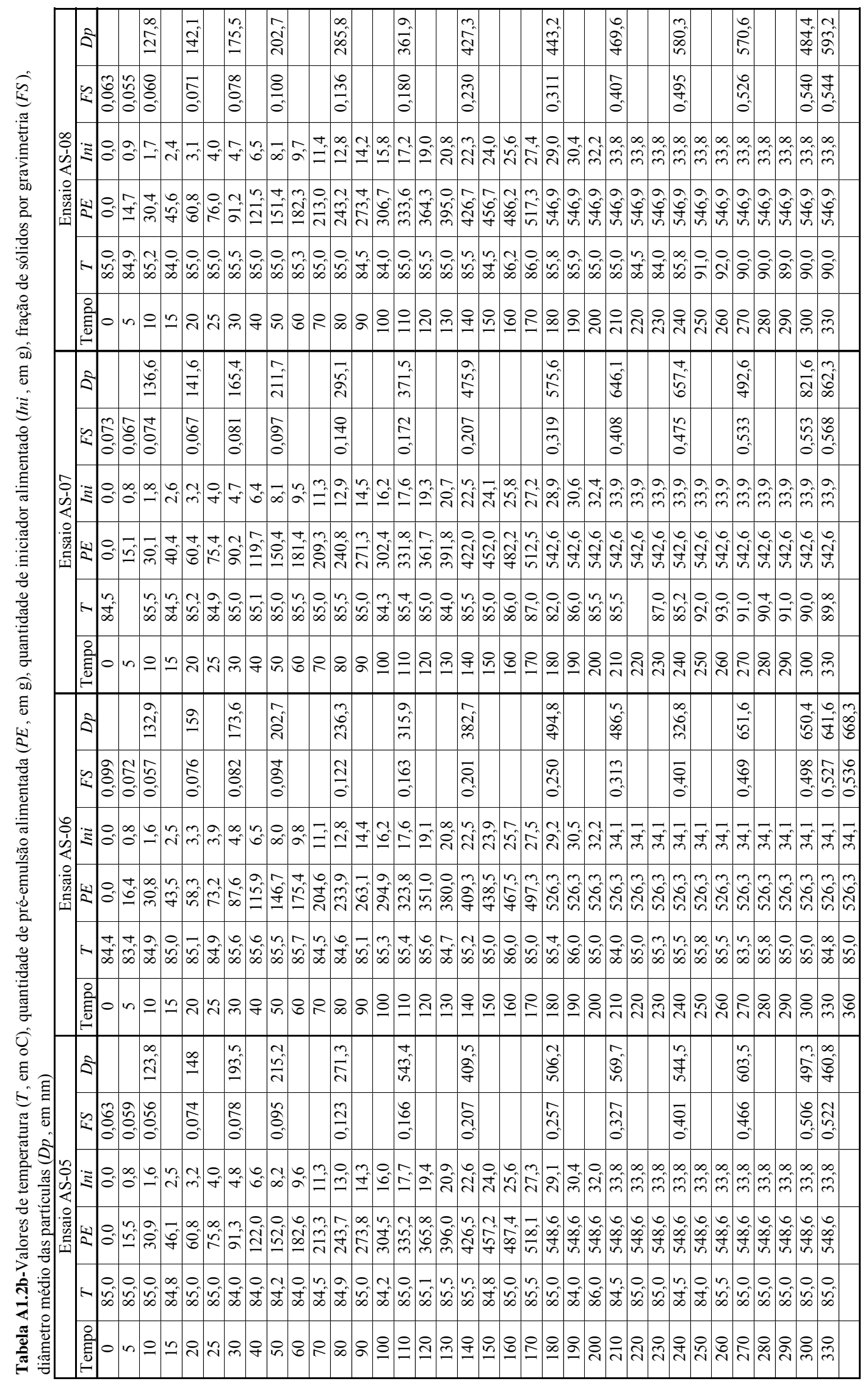




\begin{tabular}{|c|c|c|c|c|c|c|c|c|c|c|c|c|c|c|c|c|c|c|c|c|c|c|c|c|}
\hline & $\AA$ & & ڤ్ & 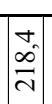 & 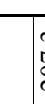 & 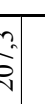 & $\overrightarrow{0}$ & & : & & & & $\vec{a}$ & & & 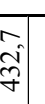 & & . & & 袋 & $\vec{D}$ & & & : \\
\hline & 红路 & $\mid \begin{array}{l}0 \\
0 \\
0 \\
0\end{array}$ & & $\begin{array}{l}0 \\
0 \\
0 \\
0 \\
0\end{array}$ & 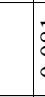 & 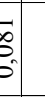 & 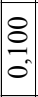 & & $\frac{f}{0}$ & & $\frac{2}{2}$ & & 范 & & & हे & & 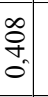 & & $\begin{array}{l}0 \\
0 \\
0 \\
0 \\
0\end{array}$ & ถి & & & 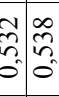 \\
\hline 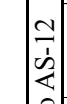 & $\approx$ & & & $\stackrel{s}{m}$ & & $\begin{array}{l}\infty \\
f^{\prime}\end{array}$ & & & $\approx$ & & 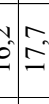 & & id & $\mid \begin{array}{c}c \\
d \\
d\end{array}$ & $\begin{array}{l}\vec{i} \\
\vec{\lambda}\end{array}$ & & $\dot{b}$ & ले $^{\infty}$ & & 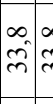 & $\aleph^{\infty} \mid \infty m^{\infty} \infty$ & $\begin{array}{l}\infty \\
i \\
i \\
\infty\end{array}$ & $\begin{array}{l}\infty \\
\tilde{m}^{\infty}\end{array}$ & ले \\
\hline | & 20 & & & 它 & & $=\frac{0}{I}$ & $\begin{array}{l}\vec{t} \\
\dot{2} \\
\overrightarrow{2}\end{array}$ & 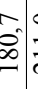 & $\frac{d}{d}$ & & $\frac{n}{m}$ & & î & 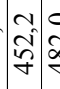 & & & \begin{tabular}{c}
0. \\
\hdashline
\end{tabular} & 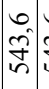 & & \begin{tabular}{l|l}
0 \\
0 \\
$f$ \\
$n$ \\
$n$
\end{tabular} & 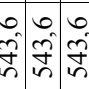 & 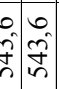 & 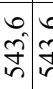 & 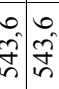 \\
\hline & & $\left|\begin{array}{l}n \\
\infty \\
\infty\end{array}\right|$ & & $\begin{array}{l}0 \\
\dot{\infty} \\
\infty\end{array}$ & $\hat{\infty}$ & $=0$ & {$\left[\begin{array}{l}n \\
\infty \\
\infty\end{array}\right.$} & $\begin{array}{l}0 \\
\dot{+} \\
\infty\end{array}$ & 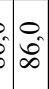 & $\mid \begin{array}{l}n \\
+ \\
\infty\end{array}$ & $\begin{array}{l}0 \\
\infty\end{array}$ & & 6 & $\begin{array}{cc}0 & 4 \\
\infty & 0\end{array}$ & $\begin{array}{l}n \\
\infty \\
\infty \\
\infty\end{array}$ & $\begin{array}{lll}n & \\
\infty & \infty\end{array}$ & 6.0 & $\left|\begin{array}{l}n \\
n \\
\infty \\
\infty\end{array}\right|$ & & 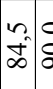 & 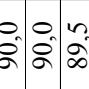 & & $\stackrel{8}{8}$ & 80 \\
\hline & 总 & & & $\AA$ & & 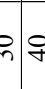 & 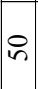 & 8 & 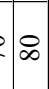 & & $\stackrel{\varrho}{\varrho}$ & & 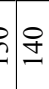 & 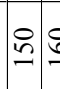 & & & Dे & $\stackrel{\circ}{\sim} \delta$ & & $\stackrel{9}{9}$ & chl & & & : \\
\hline & ฉి & & $\begin{array}{l}\infty \\
\infty \\
\infty \\
\tilde{y} \\
n\end{array}$ & $\hat{8}$ & & $\begin{array}{l}0 . \\
+ \\
0\end{array}$ & 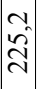 & & $\begin{array}{l}0 \\
\text { ते } \\
\text { ते }\end{array}$ & & ?n & & $\frac{n}{\frac{n}{a}}$ & & & $\begin{array}{l}0 \\
\text { bे } \\
n \\
n\end{array}$ & & $\begin{array}{c}1 \\
\text { हैं } \\
\text { bे }\end{array}$ & & $\begin{array}{l}0 \\
\hat{N} \\
\infty \\
\infty\end{array}$ & $\hat{\infty}$ & $\frac{n}{\infty}$ & & $\begin{array}{ll}n \\
\hat{c} \\
\hat{n}\end{array}$ \\
\hline & 红 & $\begin{array}{l}0 \\
0 \\
0 \\
0\end{array}$ & & $\begin{array}{l}\hat{O} \\
\hat{O} \\
0\end{array}$ & & 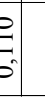 & $\hat{\bar{\theta}}$ & & $\begin{array}{l}\infty \\
0 \\
0 \\
0\end{array}$ & & $\frac{\infty}{\infty}$ & & ô & & & 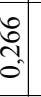 & & 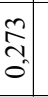 & & $\begin{array}{c}0 \\
\tilde{2} \\
0 \\
0\end{array}$ & స్ & & & \begin{tabular}{ll}
$\hat{y}$ \\
\hdashline \\
0
\end{tabular} \\
\hline & & 10 & & m & & $\infty$ & $\infty^{\circ}$ & $\sigma^{\circ}$ & $\begin{array}{l}0 \\
\mathcal{A}\end{array}$ & & $\approx$ & & in & 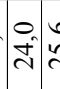 & m. & 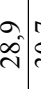 & $\begin{array}{c}m \\
\dot{n}\end{array}$ & 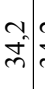 & & $\stackrel{N}{m}$ & 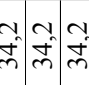 & 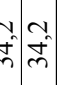 & & 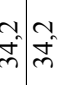 \\
\hline & & $\begin{array}{l}0 \\
0 \\
0\end{array}$ & $\begin{array}{l}\dot{m}^{\prime} \\
\dot{m}\end{array}$ & 8 & $\begin{array}{l}0 \\
i \\
i\end{array}$ & 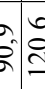 & \begin{tabular}{|l|}
0 \\
0 \\
1 \\
1
\end{tabular} & $\begin{array}{l}n \\
0 \\
0 \\
0\end{array}$ & $\vec{d}$ & & & & ते & $\begin{array}{ll}2 & 0 \\
\tilde{f} & 0 \\
f & 2\end{array}$ & & & 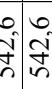 & & & 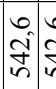 & 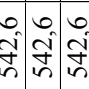 & & & 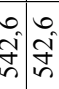 \\
\hline & $+\infty$ & $\begin{array}{c}0 \\
0 \\
\infty\end{array}$ & & $\begin{array}{c}0 \\
\infty \\
\infty\end{array}$ & क्ष: & $\begin{array}{c}0 \\
6 \\
6\end{array}$ & {$\left[\begin{array}{c}n \\
\infty \\
\infty\end{array}\right.$} & 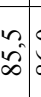 & 8 & & $f$ & & 6 & $\left.\mid \begin{array}{cc}0 & 0 \\
0 & 0\end{array}\right]$ & & $\begin{array}{l}n \\
\infty \\
\infty\end{array}$ & $\begin{array}{ll}0 \\
\dot{x} \\
\dot{x}\end{array}$ & $\begin{array}{c}n \\
\infty \\
\infty\end{array}$ & & $\begin{array}{c}0 \\
\infty \\
\infty\end{array}$ & 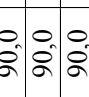 & $8: 0$ & $\begin{array}{l}n \\
\infty \\
\infty\end{array}$ & 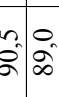 \\
\hline & 总。 & & & $\mathrm{\Omega}$ & & $b$ of & in & & $2 \otimes$ & & 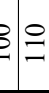 & & 9 & & & $\nsubseteq$ & & $\stackrel{\circ}{\sim}\{$ & & $\sqrt[4]{4}$ & : & & & : \\
\hline & คे & & $\vec{\Xi}$ & $\mid \begin{array}{c}3 \\
\stackrel{0}{0} \\
-1\end{array}$ & & $\begin{array}{l}+ \\
0 \\
0\end{array}$ & $\mid \begin{array}{l}\infty \\
\stackrel{\vec{N}}{\sim} \\
\end{array}$ & & is & & $\begin{array}{l}3 \\
\text { లె } \\
m\end{array}$ & & 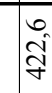 & & & 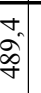 & & 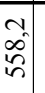 & & $\begin{array}{l}3 \\
\infty \\
\alpha \\
\sigma \\
\sigma\end{array}$ & 资 & . & & $=\vec{y}$ \\
\hline & 这 & $\mid \begin{array}{l}0 \\
0 \\
0 \\
0 \\
0\end{array}$ & ֶ̊ & $\mid \begin{array}{l}\tilde{2} \\
0 \\
0 \\
0\end{array}$ & & : & $\begin{array}{l}m \\
\cdots \\
0\end{array}$ & & $\frac{\text { I }}{O}$ & & 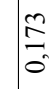 & & त̂ & & & సิ & & $\begin{array}{l}\hat{y} \\
\text { co } \\
0\end{array}$ & & के & 苦 & & & $\begin{array}{ll}4 \\
\vdots \\
0\end{array}$ \\
\hline & & & & $m^{2}$ & 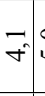 & 8 & & & I & & $\Xi$ & & $\hat{\mathrm{A}}$ & $\begin{array}{l}0 \\
\dot{i} \\
\end{array}$ & in & के & 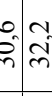 & $\begin{array}{l}\infty \\
m \\
m\end{array}$ & & $\begin{array}{ll}\infty & \alpha \\
m & \infty\end{array}$ & 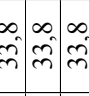 & $\begin{array}{l}\infty \\
\hat{n} \\
\hat{n} \\
\infty\end{array}$ & 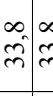 & $\begin{array}{ll}\infty & \infty \\
\tilde{n}^{n} & \infty \\
\end{array}$ \\
\hline & & $\begin{array}{c}0 \\
n^{2}\end{array}$ & 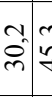 & $\begin{array}{l}\dot{1} \\
\dot{8}\end{array}$ & $\begin{array}{l}m \\
2 \\
2\end{array}$ & 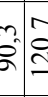 & în & 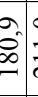 & $\vec{v}$ & & 品 & & ปิ & 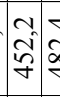 & & : & $\left.\begin{array}{ll}0 \\
n\end{array}\right]$ & 它 & & $\begin{array}{l}0 \\
i n \\
i n\end{array}$ & 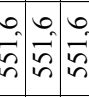 & 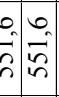 & & 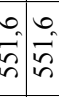 \\
\hline & & $\begin{array}{c}0 \\
0 \\
\infty\end{array}$ & \begin{tabular}{l|l}
0 \\
$\infty$ \\
$\infty$
\end{tabular} & $\mid \begin{array}{c}2 \\
\infty \\
\infty\end{array}$ & $\begin{array}{l}0 \\
+ \\
\infty \\
\infty\end{array}$ & 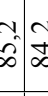 & $\infty$ & $\infty$ & $\begin{array}{l}n \\
0 \\
\infty \\
\infty\end{array}$ & $\left|\begin{array}{c}0 \\
\infty \\
\infty\end{array}\right|$ & $\begin{array}{l}n \\
\infty \\
\infty \\
\infty\end{array}$ & {$\left[\begin{array}{l}n \\
\infty \\
\infty \\
\infty\end{array}\right.$} & $\begin{array}{ll}0 & 0 \\
0 \\
0 \\
0\end{array}$ & 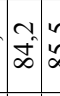 & $\left.\mid \begin{array}{l}n \\
n \\
\infty \\
\infty\end{array}\right]$ & $\begin{array}{ll}0 \\
\infty\end{array}$ & $\begin{array}{c}0 \\
0 \\
0 \\
\infty \\
\infty\end{array}$ & $\begin{array}{l}n \\
\infty \\
\infty\end{array}$ & $\begin{array}{lll}0 \\
0 \\
0\end{array}$ & $\begin{array}{ccc}2 & 0 \\
\infty & 0 & 0\end{array}$ & 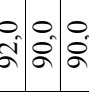 & $\dot{2}: \dot{2}$ & 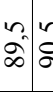 & 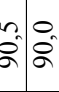 \\
\hline & & & & $\AA$ & & of & 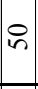 & & $2 \infty$ & \& & 8 & & bo & in & 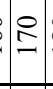 & 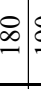 & 8 & $\stackrel{ }{\sim}$ & & $\stackrel{8}{d}$ & : & $\begin{array}{c}c \\
\sim\end{array}$ & & : \\
\hline & $\AA$ & & 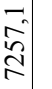 & \begin{tabular}{|}
0 \\
0 \\
0 \\
0 \\
$\sim$
\end{tabular} & & ? & 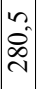 & & ma & & $\overrightarrow{\vec{g}}$ & & 현 & & & ปิ & & 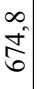 & & $\begin{array}{l}\overrightarrow{5} \\
\frac{5}{6}\end{array}$ & $\begin{array}{l}3 \\
\infty \\
\infty \\
n\end{array}$ & م. & & ठُ. \\
\hline & 象 & $\begin{array}{l}0 \\
0 \\
0 \\
0\end{array}$ & $\begin{array}{l}\text { हे. } \\
\text { - }\end{array}$ & $\begin{array}{l}\infty \\
0 \\
0 \\
0 \\
0\end{array}$ & 5 & 8 & $0^{\circ}$ & & సे & & $\overbrace{0}^{0}$ & & $0^{\circ}$ & & & ले & & $\begin{array}{c}8 \\
\text { s } \\
0 \\
\end{array}$ & & 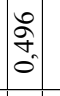 & त्र & $\begin{array}{l}0.1 \\
\vdots \\
0\end{array}$ & & 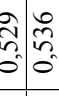 \\
\hline & & & & $\stackrel{\sim}{m}$ & & & & & $\simeq$ & & & & & & v & & 78 & & & $\tilde{m}^{\infty} d$ & 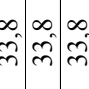 & 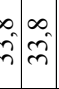 & & $\begin{array}{c}\infty \\
\text { ले } \\
\end{array}$ \\
\hline & & & & 8 & & c. & -1 & & ثُ & & & & $\therefore \sqrt{7}$ & & \begin{tabular}{|l}
7 \\
in \\
in \\
\end{tabular} & $n$ & 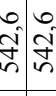 & $\begin{array}{l}0 \\
\vdots \\
\vdots \\
n\end{array}$ & & $\left.\mid \begin{array}{l}0 \\
0 \\
1 \\
y \\
n\end{array}\right]$ & 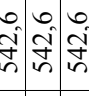 & 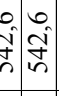 & & 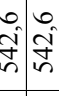 \\
\hline & & 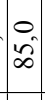 & & 0 & c & $\infty$. & & & $\stackrel{\circ}{\infty}$ & o. & $m$ & $\left\{\begin{array}{l}\infty \\
0 \\
0 \\
\infty \\
\infty\end{array}\right.$ & in & $\mid \begin{array}{lll}n & 0 \\
0 & 0 & 0\end{array}$ & $\begin{array}{l}0 \\
\infty\end{array}$ & $\begin{array}{l}\infty \\
\infty \\
\infty\end{array}$ & 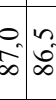 & : & $\begin{array}{ll}0 & 0 \\
0 & 0 \\
0 & \infty\end{array}$ & $\begin{array}{l}0 \\
\dot{\infty} \\
\infty\end{array}$ & 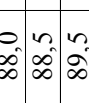 & 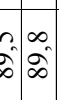 & & $\stackrel{8}{\circ}$ \\
\hline & 㫼。 & & & & & & & & & & & 1 & & & - & & $\mathrm{C}_{1}$ & & & 0 & i) & 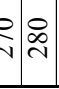 & & : \\
\hline
\end{tabular}




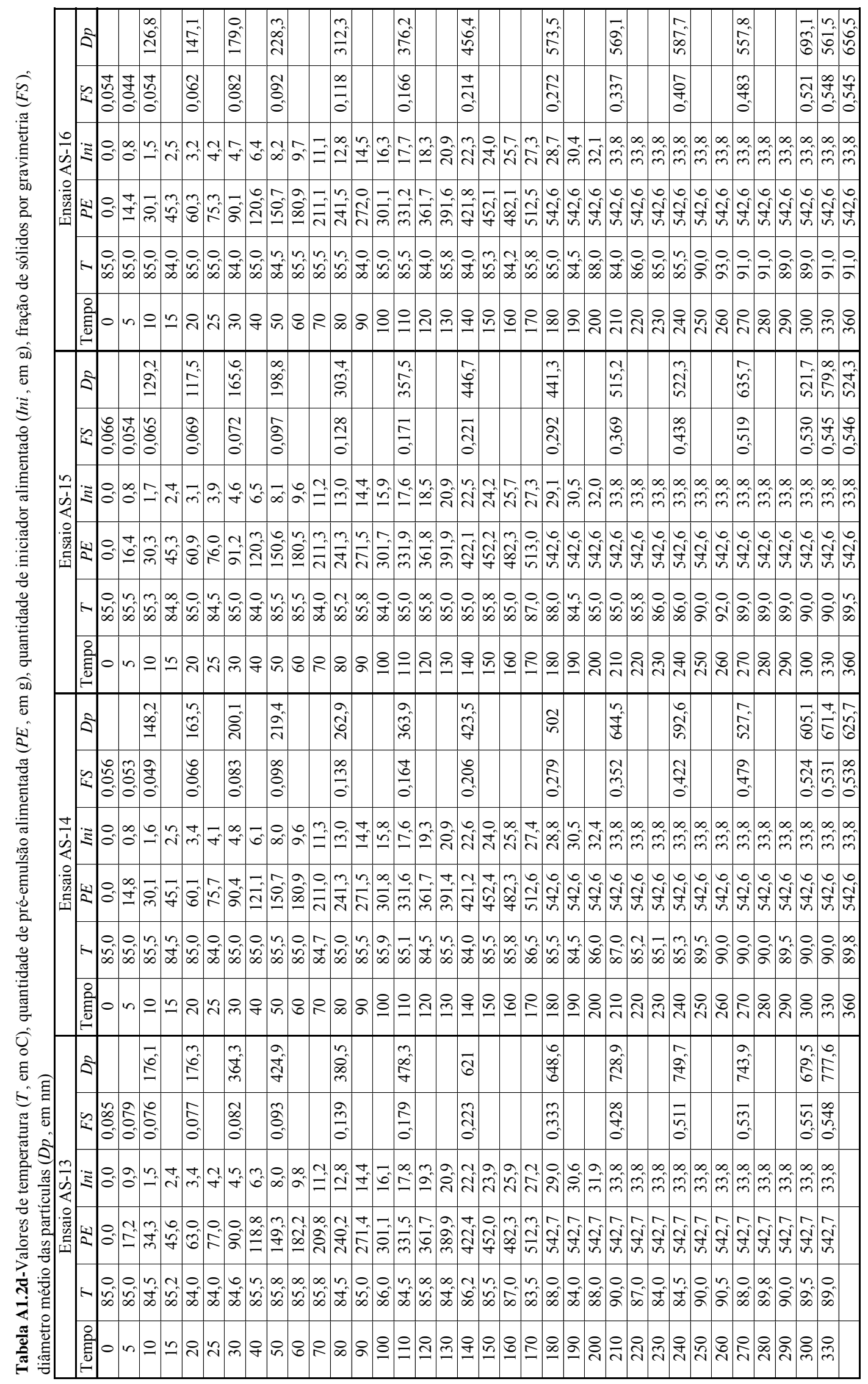




\begin{tabular}{|c|c|c|c|c|c|c|c|c|c|c|c|c|c|c|c|c|c|c|c|c|c|c|c|c|}
\hline & هิ & $\frac{O}{\bar{\tau}}$ & & ڤ్ & $\propto$ & & 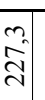 & & है & & & & 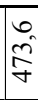 & & 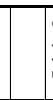 & 每 & & $\begin{array}{l}\infty \\
\vdots \\
\vdots \\
\vdots\end{array}$ & & |: & & త్ర & & 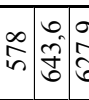 \\
\hline & 记 & 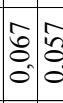 & & "ै & ई & & ह & & ?. & & $\infty$ & & $\overline{\tilde{N}}$ & & & 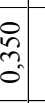 & & . & & $\begin{array}{c}0 \\
\text { ?े } \\
0 \\
0\end{array}$ & & 结 & & 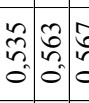 \\
\hline & $: \Xi$ & & & 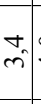 & 8 & $f$ & $\infty^{\circ}$ & in & $\stackrel{\circ}{9}$ & & 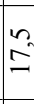 & & $\hat{\mathrm{d}}$ & $\begin{array}{l}\bar{f} \\
\dot{d}\end{array}$ & $\stackrel{\sim}{\sim}$ & & : & & & $\stackrel{\infty}{\infty} \mathrm{m}^{\infty}$ & & 文: & & 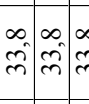 \\
\hline & $2: 0$ & $\therefore=\frac{7}{m}$ & f & छे & yे & 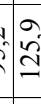 & $\begin{array}{c}a \\
\infty \\
\infty \\
\infty\end{array} \mid$ & ह. & $\begin{array}{l}\infty \\
\hat{n} \\
\end{array}$ & & $\vec{g}$ & & 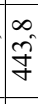 & \begin{tabular}{l|l}
$\infty$ \\
$\vdots$ \\
$\vdots$ \\
$y$
\end{tabular} & & & 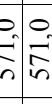 & & & id & & $\begin{array}{ll}0 & 0 \\
0 \\
i \\
i\end{array}$ & $\begin{array}{l}8 \\
\text { in } \\
\text { in }\end{array}$ & 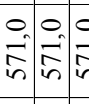 \\
\hline & & : $\begin{array}{l}0 \\
\infty \\
\infty \\
\infty\end{array}$ & & $+\infty$ & $\propto$ & 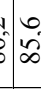 & $\begin{array}{l}0 \\
\vdots \\
\infty \\
\infty\end{array}$ & b. & ?a. & & \$ & & $\begin{array}{l}\infty \\
\dot{\infty} \\
\dot{\infty}\end{array}$ & & $\mid \begin{array}{l}\infty \\
\infty \\
\infty \\
\infty\end{array}$ & & $\begin{array}{l}0 \\
0 \\
\infty \\
\infty\end{array}$ & $\begin{array}{l}1 \\
\infty \\
\infty \\
\infty\end{array}$ & & $\begin{array}{l}0 \\
\dot{+} \\
\infty\end{array}$ & & : & & $\bar{m}^{m} \hat{\alpha} \dot{\alpha}$ \\
\hline & 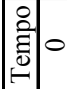 & & & & c & s. & in 5 & & $\infty$ & & - & & g & & & & & & & & & & & ৪্ল \\
\hline & $\AA$ & $\bar{\AA}$ & & $\overrightarrow{\vec{a}}$ & 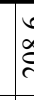 & & 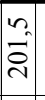 & & 守 & & ले & & ma & & & $\begin{array}{l}\text { I } \\
\text { f } \\
n \\
n\end{array}$ & & $\frac{\bar{\alpha}}{\alpha}$ & & $\begin{array}{l}\infty \\
0 \\
0 \\
0\end{array}$ & & 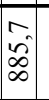 & & $\begin{array}{ll}\hat{m} \\
\stackrel{9}{9}\end{array}$ \\
\hline & 杄| & $\begin{array}{ll}\pi & \pi \\
0 & 0 \\
0 & 0 \\
0 & 0\end{array}$ & & $\begin{array}{l}\overline{0} \\
\vdots \\
0\end{array}$ & है & & वे & & $\vec{I}$ & & $0^{\circ}$ & & 0 & & & In & & c & & $\begin{array}{c}5 \\
\vdots \\
0 \\
0 \\
0\end{array}$ & & 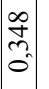 & & 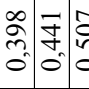 \\
\hline 它 & & & r & i & c & & $f^{\circ}$ & & \begin{tabular}{l}
$\infty$ \\
\hdashline \\
\end{tabular} & & 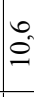 & & $\hat{\mathrm{m}}$ & & $\overrightarrow{6}$ & & & 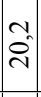 & & ¿े. & & $\left|\begin{array}{l}\infty \\
\vdots \\
i\end{array}\right|$ & & 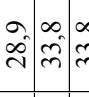 \\
\hline 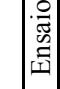 & & $\therefore$ & 8 & 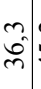 & 8 & $\stackrel{i}{i}$ & $\mid \begin{array}{l}0 \\
8 \\
8\end{array}$ & 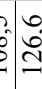 & $\begin{array}{l}0 \\
\dot{J} \\
\end{array}$ & & $\hat{\varrho}$ & & त̂ & 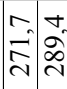 & $\mid \begin{array}{l}0 \\
0 \\
0 \\
0 \\
0\end{array}$ & 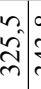 & 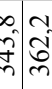 & $\left|\begin{array}{c}N \\
0 \\
0 \\
\infty \\
m\end{array}\right|$ & & $\begin{array}{l}0 \\
\dot{y} \\
\vec{y}\end{array}$ & & 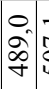 & & 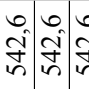 \\
\hline & & & & + & 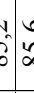 & 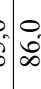 & 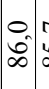 & 0 & $\begin{array}{l}\overrightarrow{1} \\
\infty \\
\infty\end{array}$ & & $\infty$ & & $\begin{array}{l}\forall \\
\infty\end{array}$ & & $\begin{array}{c}\vec{b} \\
\infty \\
\infty\end{array}$ & \begin{tabular}{l|l}
$c$ & \\
$\infty$ & $\infty$
\end{tabular} & 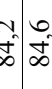 & $\begin{array}{l}+ \\
\infty \\
\infty\end{array}$ & & $\begin{array}{l}0 \\
0 \\
\infty\end{array}$ & & $\begin{array}{c}n \\
2 \\
2\end{array}$ & & $\vec{\delta}=\vec{\sigma}$ \\
\hline & :월 & & & $\bar{\varsigma}$ & $\approx$ & & ins & $R$ & $\bowtie$ & & 잉 & & g & & 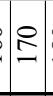 & & $\lesssim \approx$ & $\stackrel{ }{N}$ & & $\underset{\sim}{\stackrel{9}{*}}$ & & & & ¿্লm \\
\hline & $\AA$ & $\stackrel{m}{\curvearrowright}$ & & $\begin{array}{c}\sim \\
\infty \\
\infty \\
-1\end{array}$ & 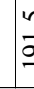 & & $\mid$ & & $\begin{array}{l}\text { m. } \\
\text { के } \\
\text { ते }\end{array}$ & & $\infty$ & & ثे & & & 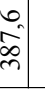 & & $\hat{m}$ & & 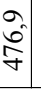 & & $\mid \begin{array}{c}2 \\
\dot{f} \\
\text { in }\end{array}$ & & 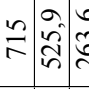 \\
\hline & 证管 & $\begin{array}{l}0 \\
0 \\
0 \\
0\end{array}$ & & $\begin{array}{l}\overrightarrow{0} \\
\stackrel{8}{\circ} \\
\stackrel{0}{0}\end{array}$ & 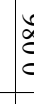 & & 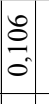 & & $\frac{7}{0}$ & & $0^{\circ}$ & & $\frac{m}{\vec{\lambda}}$ & & & $\begin{array}{l}0 \\
\text { in } \\
\text { o }\end{array}$ & & ले & & है & & $\mid \begin{array}{l}0 \\
\mathfrak{f} \\
0 \\
0\end{array}$ & & 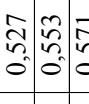 \\
\hline$\left|\begin{array}{l}\infty \\
\dot{2} \\
\dot{\alpha}\end{array}\right|$ & & $: 3$ & & 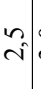 & 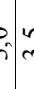 & & in & & $\stackrel{\Delta}{\circ}$ & 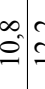 & తి & & $\stackrel{0}{=}$ & $\begin{array}{ll}0 & = \\
\infty & 0\end{array}$ & 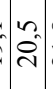 & $\begin{array}{l}\infty \\
\vec{\sim}\end{array}$ & ते ते & ঋ & 8 & 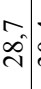 & & $\begin{array}{ll}\infty & 0 \\
m & 0\end{array}$ & 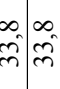 & $\begin{array}{lll}\infty & \infty \\
\tilde{m}^{\infty} & \infty & \infty\end{array}$ \\
\hline & & $=\begin{array}{l}\infty \\
\dot{A} \\
\mathbb{N}\end{array}$ & & $i^{6}$ & $\alpha$ & & $\begin{array}{c}m \\
\vdots \\
\vdots\end{array}$ & 2 & $\stackrel{\bar{\infty}}{-}$ & 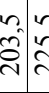 & 部 & & $\frac{6}{m}$ & $\vec{m} \bar{m}$ & 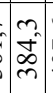 & & & $\frac{2}{2}$ & $\frac{\partial}{2}$ & 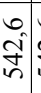 & & $\begin{array}{c}0 \\
\tilde{y} \\
\tilde{n} \\
\dot{n}\end{array}$ & & 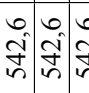 \\
\hline & & $\begin{array}{cc}-1 \\
\infty & 0 \\
\infty & \infty\end{array}$ & & $\infty$ & 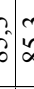 & 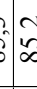 & 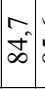 & 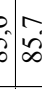 & $\infty$ & $\begin{array}{ll}\vec{b} \\
\dot{\infty}=0 \\
\infty\end{array}$ & $\infty$ & & 就 & & $\begin{array}{l}\infty \\
\dot{\infty} \\
\infty\end{array}$ & $\begin{array}{c}5 \\
\infty \\
\infty\end{array}$ & $\begin{array}{cc}+ \\
0 \\
\infty & \infty \\
\infty & \infty \\
0\end{array}$ & $\infty$ & 0 & $\begin{array}{l}\infty \\
\infty \\
\infty \\
-\infty\end{array}$ & & âd & $\dot{\infty}$ & 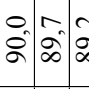 \\
\hline & & & & o & ک & & ins & $b$ & $\infty$ & & 으 & & g & & $\stackrel{2}{I}$ & $\stackrel{\infty}{ \pm}$ & 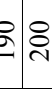 & $\bar{N}$ & जै & $\underset{q}{+}$ & & $\stackrel{R}{\sim}$ & 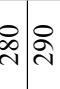 & ৪্ল \\
\hline & ฉิ & $\stackrel{\beth}{\beth}$ & & $\begin{array}{l}0 \\
\text { ì } \\
\text { ñ }\end{array}$ & ฮ & & 垈 & & 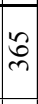 & & $\underset{f}{\stackrel{\infty}{f}}$ & & D্ল & & & $\begin{array}{l}\infty \\
\text { đi } \\
\vdots \\
\vdots\end{array}$ & & 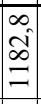 & & $\vec{s}$ & & $\begin{array}{l}0 \\
0 \\
\vdots \\
2\end{array}$ & & $\begin{array}{ll}0 \\
\vdots \\
\vdots \\
\vdots\end{array}$ \\
\hline & 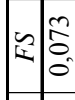 & $\begin{array}{ll}R & 0 \\
0 \\
0 \\
0 & 0 \\
0\end{array}$ & & to & 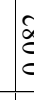 & & \begin{tabular}{|c|} 
\\
0 \\
0 \\
0 \\
\end{tabular} & & 0 & & & & $0^{3}$ & & & $\frac{5}{5}$ & & 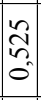 & & $\begin{array}{l}1 \\
5 \\
0 \\
0 \\
0\end{array}$ & & $\mid$ & & $\begin{array}{l}\text { foll } \\
0 \\
0\end{array}$ \\
\hline & & $\begin{array}{ll}\infty & 0 \\
0 & -1\end{array}$ & & 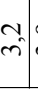 & 7 & & $\infty^{\infty}$ & & & 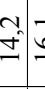 & & & & $\sqrt{4}$ & $\bar{\sim}$ & & 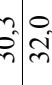 & & & m. & & $\begin{array}{c}\infty \\
m \\
m\end{array}$ & & 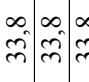 \\
\hline & & $\begin{array}{l}0 \\
n^{\infty} \\
i\end{array}$ & & 6 & & & - & & & & & & & 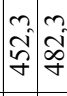 & $\frac{1}{n}$ & fis & $n$ in & & fin & 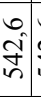 & & 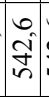 & 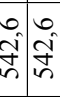 & 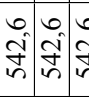 \\
\hline & & $\begin{array}{ll}+ & 0 \\
\dot{\infty} & 0 \\
\dot{\infty} & \\
\end{array}$ & & & & & 7. & & 0 & & & & & 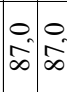 & $\begin{array}{l}+ \\
\dot{\infty}\end{array}$ & i & $\begin{array}{ll}\infty & \\
\dot{\infty} & + \\
\dot{\infty}\end{array}$ & & 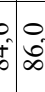 & $\begin{array}{l}+ \\
+ \\
\infty\end{array}$ & & $\frac{\pi}{a}$ & 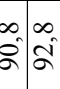 & $\vec{\sigma}$ \\
\hline & 畧。 & 1 & & & & & & & & & & & & & -1 & $\stackrel{9}{\infty}$ & 8 : & & 1 & a & & $\stackrel{R}{\pi}$ & & \& \\
\hline
\end{tabular}




\begin{tabular}{|c|c|c|c|c|c|c|c|c|c|c|c|c|c|}
\hline คి & & & & & & $\begin{array}{l}\infty \\
n \\
n \\
n \\
\end{array}$ & & & $\begin{array}{l}a \\
\frac{1}{6}\end{array}$ & & $\begin{array}{l}n \\
0 \\
8 \\
0\end{array}$ & & $r$ \\
\hline & 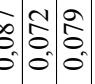 & $\begin{array}{l}\infty \\
0 \\
0 \\
0\end{array}$ & I & $\begin{array}{l}\infty \\
0 \\
0 \\
0\end{array}$ & $\begin{array}{l}n \\
m \\
0 \\
0\end{array}$ & & $\begin{array}{l}\hat{n} \\
\hat{n} \\
0\end{array}$ & $\begin{array}{l}0 \\
2 \\
2 \\
0\end{array}$ & 辛 & $\begin{array}{c}n \\
\tilde{n} \\
0 \\
0\end{array} \mid$ & $\mid \begin{array}{l}\infty \\
n \\
n \\
0 \\
0\end{array}$ & & \\
\hline
\end{tabular}

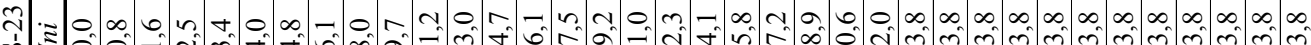

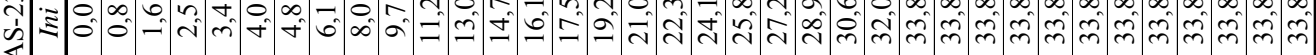

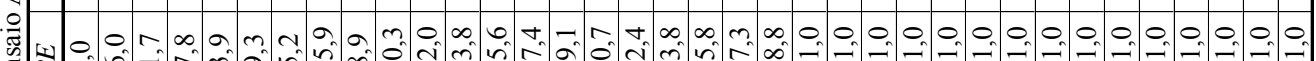
ज्ञ

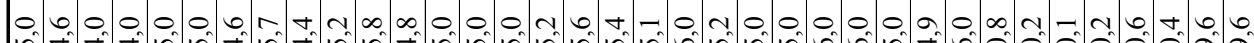

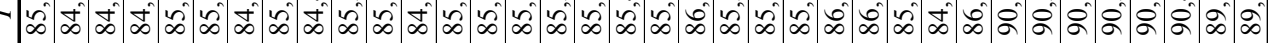

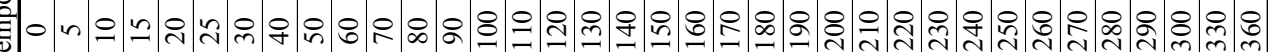

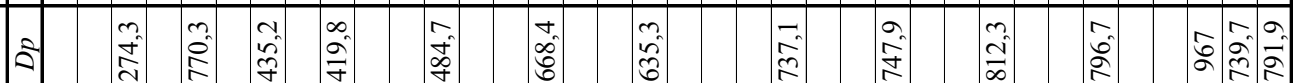

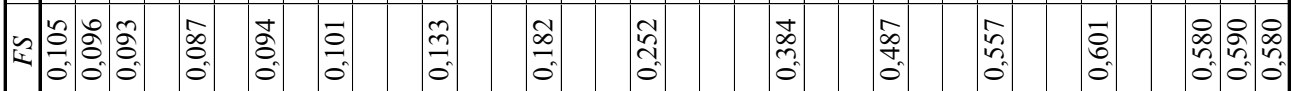

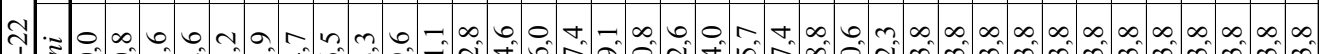

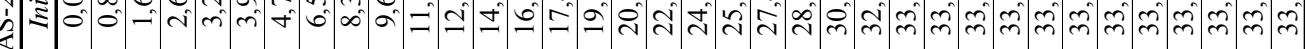

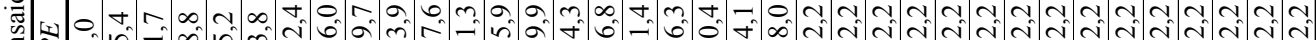

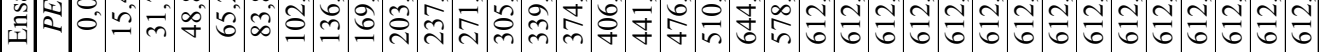

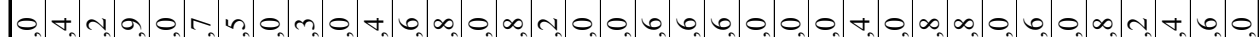
की

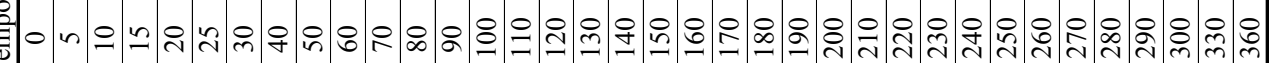
仓़

$\therefore$

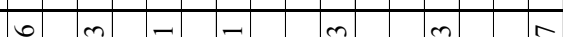

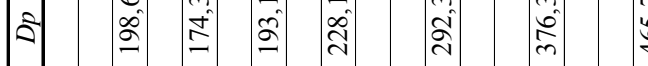

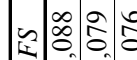

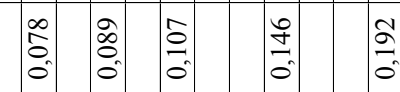

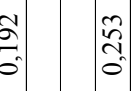

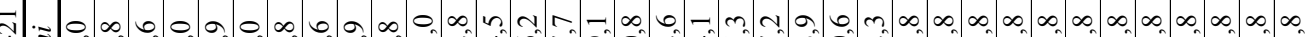

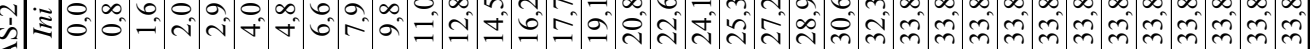

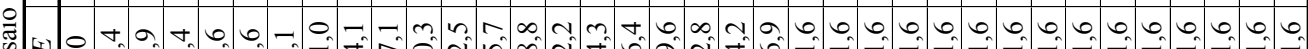

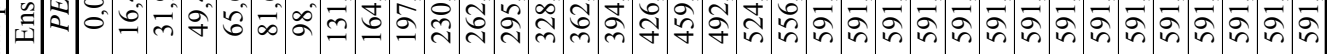

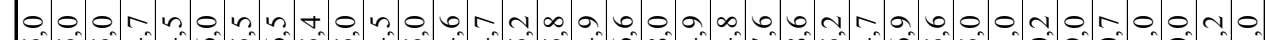

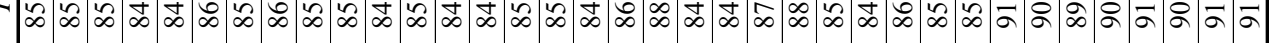

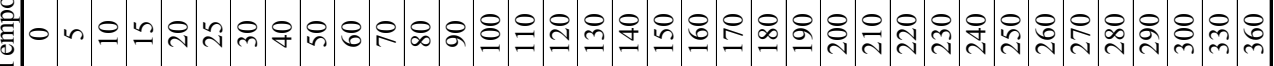




\begin{tabular}{|c|c|c|c|c|c|c|c|c|c|c|c|c|}
\hline 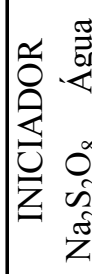 & 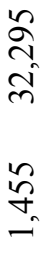 & 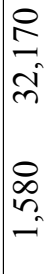 & 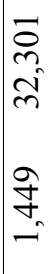 & 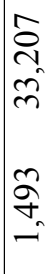 & $\begin{array}{l}\delta \\
\text { ల్ } \\
\tilde{m}\end{array}$ & $\frac{i}{n}$ & $\begin{array}{l}\text { 位 } \\
0 \\
\delta\end{array}$ & $\begin{array}{l}\text { J } \\
\hat{d}\end{array}$ & $\frac{1}{m}$ & $\begin{array}{l}\tilde{y} \\
\text { in }\end{array}$ & 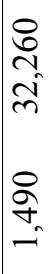 & 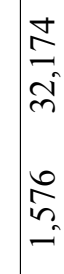 \\
\hline ڤิ & 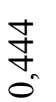 & 管 & $\begin{array}{l}\infty \\
\text { Dh } \\
\text { ? }\end{array}$ & Tे & $\begin{array}{l}0 \\
\vdots \\
0 \\
0\end{array}$ & $\mid \begin{array}{l}\stackrel{y}{9} \\
0 \\
0\end{array}$ & $\begin{array}{l}0 \\
\vdots \\
0 \\
0\end{array}$ & శ్ & (3) & 3 & 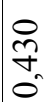 & $\begin{array}{l}\infty \\
\dot{\alpha} \\
+ \\
0\end{array}$ \\
\hline & $\begin{array}{l}\text { बे } \\
\text { के } \\
\sigma^{2}\end{array}$ & 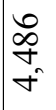 & 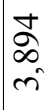 & $\begin{array}{l}\mathscr{0} \\
\dot{\sigma} \\
\dot{0}\end{array}$ & $\begin{array}{l}1 \\
0 \\
\end{array}$ & $\begin{array}{l}\mathbb{O}_{0} \\
-\end{array}$ & 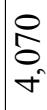 & בे & {$\left[\begin{array}{c}\bar{n} \\
n^{2}\end{array}\right.$} & 勇 & 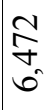 & $\frac{\pi}{\pi}$ \\
\hline 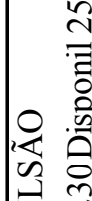 & ל్రి & lof & $\begin{array}{l}0 \\
\vdots \\
0 \\
0 \\
0\end{array}$ & $\begin{array}{l}0 \\
0 \\
0 \\
0\end{array}$ & $\begin{array}{l}n \\
0\end{array}$ & 13 & $\begin{array}{l}n \\
n \\
0\end{array}$ & $\begin{array}{l}n \\
n \\
0\end{array}$ & $\begin{array}{l}\tilde{n} \\
3 \\
0\end{array}$ & $\begin{array}{c}\tilde{n} \\
3 \\
0\end{array}$ & $\begin{array}{l}0 \\
0 \\
0 \\
0\end{array}$ & $\begin{array}{l}\hat{0} \\
0\end{array}$ \\
\hline
\end{tabular}

赑

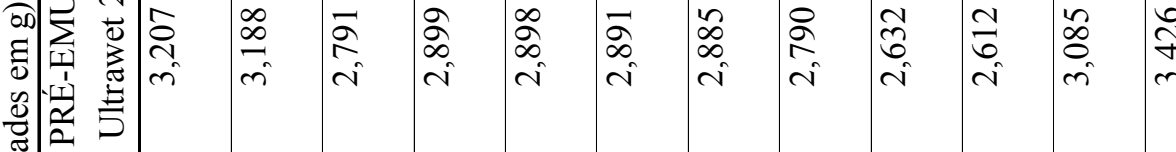

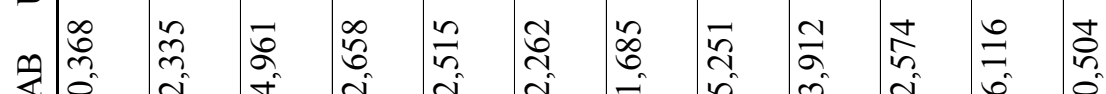

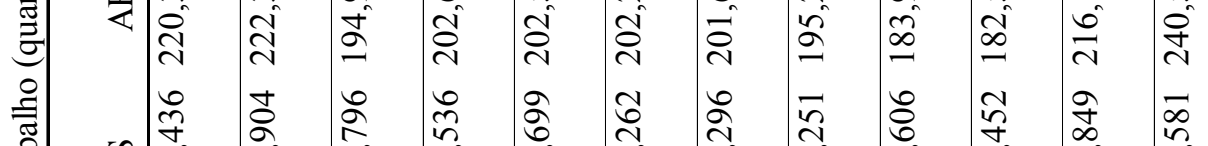

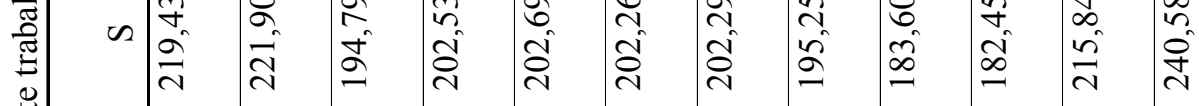

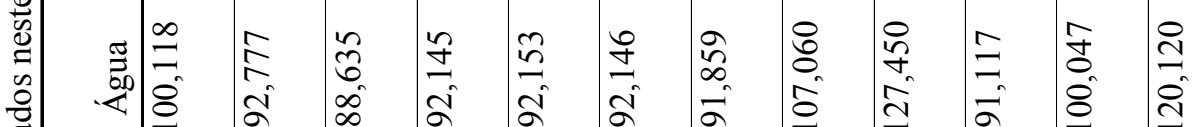

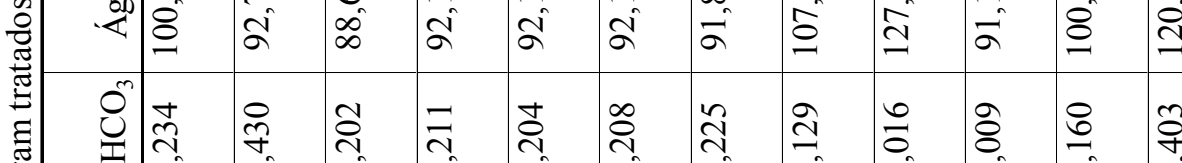

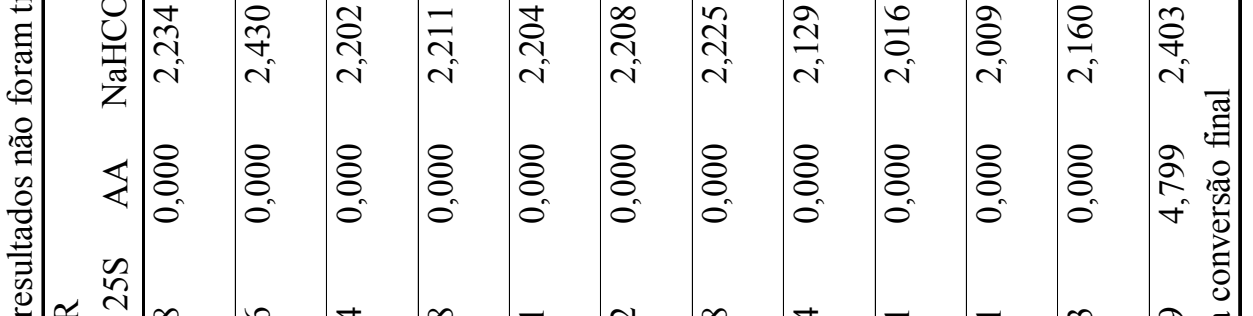

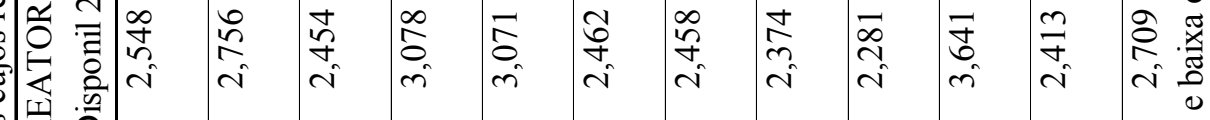
要

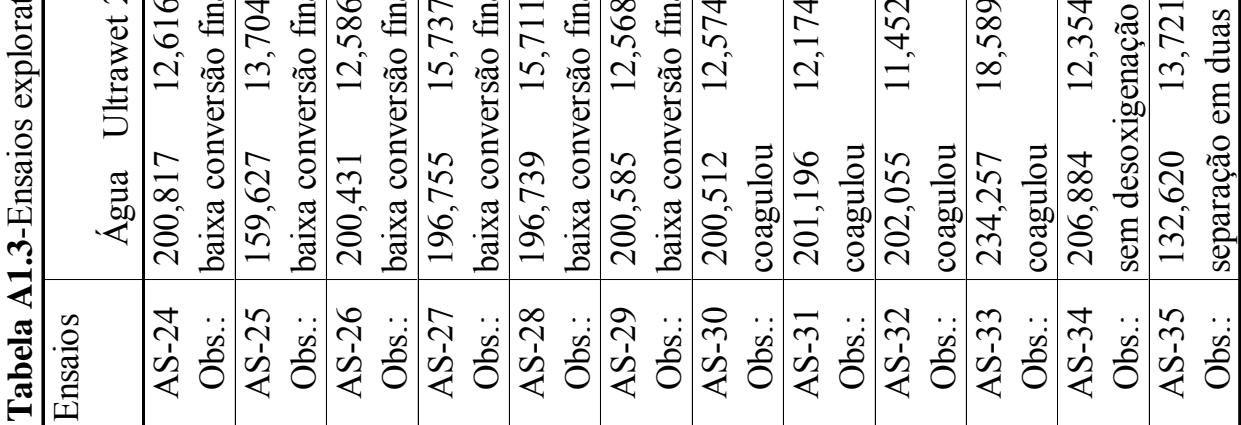

